\begin{tabular}{|c|c|c|}
\hline (ATINER) & $\begin{array}{l}\text { Athens Journal of Health } \\
\text { and Medical Sciences }\end{array}$ & (ATINARR) \\
\hline \multicolumn{3}{|c|}{ Volume 7, Issue 2, June 2020} \\
\hline \multicolumn{3}{|c|}{$\begin{array}{l}\text { IBRAHIM LAWAL ABDULLAHI \& ALI SANI } \\
\text { Effects of Metal Welding Fumes on Kidney Function Parameters in } \\
\text { Male Albino Rats }\end{array}$} \\
\hline \multicolumn{3}{|c|}{$\begin{array}{l}\text { SOMJIT BARAT } \\
\text { The Dilemma of Outsourcing Drug Trials }\end{array}$} \\
\hline \multicolumn{3}{|c|}{$\begin{array}{l}\text { YILDIZ DENAT E ZEYNEP GÜNEŞ } \\
\text { Risk of Obstructive Sleep Apnea and Risk Factors in Patıents with } \\
\text { Type } 2 \text { Diabetes in Turkey }\end{array}$} \\
\hline \multicolumn{3}{|c|}{$\begin{array}{l}\text { PETER KAISER, MARIE T. BENNER \& KAI POHLMANN } \\
\text { Prolonged Humanitarian Crises - Mental Health in a Refugee } \\
\text { Setting at the Thai-Myanmar Border }\end{array}$} \\
\hline
\end{tabular}




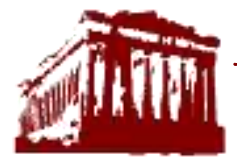

$(A T I \mathcal{N} E)$

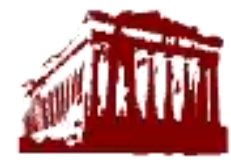

$($ ATINER)

\section{Mission}

ATINER is an Athens-based World Association of Academics and Researchers based in Athens. ATINER is an independent and non-profit Association with a Mission to become a forum where Academics and Researchers from all over the world can meet in Athens, exchange ideas on their research and discuss future developments in their disciplines, as well as engage with professionals from other fields. Athens was chosen because of its long history of academic gatherings, which go back thousands of years to Plato's Academy and Aristotle's Lyceum. Both these historic places are within walking distance from ATINER's downtown offices. Since antiquity, Athens was an open city. In the words of Pericles, Athens"... is open to the world, we never expel a foreigner from learning or seeing". ("Pericles' Funeral Oration", in Thucydides, The History of the Peloponnesian War). It is ATINER's mission to revive the glory of Ancient Athens by inviting the World Academic Community to the city, to learn from each other in an environment of freedom and respect for other people's opinions and beliefs. After all, the free expression of one's opinion formed the basis for the development of democracy, and Athens was its cradle. As it turned out, the Golden Age of Athens was in fact, the Golden Age of the Western Civilization. Education and (Re)searching for the 'truth' are the pillars of any free (democratic) society. This is the reason why Education and Research are the two core words in ATINER's name. 
The Athens Journal of Health and Medical Sciences

ISSN NUMBER: 2241-8229 - DOI: 10.30958/ajh

Volume 7, Issue 2, June 2020

Download the entire issue ( $\underline{\mathrm{PDF}})$

Front Pages $\quad i-x$

Effects of Metal Welding Fumes on Kidney Function 63

Parameters in Male Albino Rats

Ibrahim Lawal Abdullahi \& Ali Sani

The Dilemma of Outsourcing Drug Trials

75

Somjit Barat

Risk of Obstructive Sleep Apnea and Risk Factors in

95

Pat1ents with Type 2 Diabetes in Turkey

Yildz Denat \& Zeynep Güneş

Prolonged Humanitarian Crises - Mental Health in a 105 Refugee Setting at the Thai-Myanmar Border

Peter Kaiser, Marie T. Benner E Kai Pohlmann 


\section{Athens Journal of Health and Medical Sciences Editorial and Reviewers' Board}

Editors

- Dr. Zoe Boutsioli, Vice President of Publications \& Research, ATINER \& President, Athens Centre for Greek \& International Education (ACEGIE), zb5@atiner.gr.

- Dr. John Moraros, Academic Member, ATINER \& Associate Professor, University of Saskatchewan, Canada, john.moraros@usask.ca.

- Dr. Douglas E. Angus, Full Professor, Telfer School of Management, University of Ottawa, Canada, Angus@telfer.uottawa.ca.

- Dr. George Zahariadis, Academic Member, ATINER \& Associate Professor, Faculty of Medicine, Memorial University of Newfoundland, Canada, george.zahariadis@easternhealth.ca.

- Dr. Apostolos Tsiachristas, Academic Member, ATINER \& Senior Researcher, Health Economics Research Centre, Nuffield Dept. of Population Health, University of Oxford, UK, apostolos.tsiachristas@dph.ox.ac.uk.

- Dr. Paul Contoyannis, Head, Health Economics and Management Research Unit, ATINER \& Associate Professor, Faculty of Social Sciences, Department of Economics, McMaster University, Canada, contoyp@mcmaster.ca.

\section{Editorial Board}

- Dr. Steven M. Oberhelman, Associate Dean and Jr. Professor of Liberal Arts, Texas A\&M University, USA, s-oberhelman@tamu.edu.

- Dr. Sandra Bassendowski, Professor, College of Nursing, University of Saskatchewan, Canada, sandra.bassendowski@usask.ca.

- Dr. Sabine Bohnet-Joschko, Walcker Professor of Management and Innovation in Healthcare, Faculty of Management and Economics, Witten-Herdecke University, Germany, Sabine.Bohnet-Joschko@uniwh.de.

- Dr. H R Chitme, Academic Member, ATINER \& Professor, Oman Medical College, Sultanate of Oman, hrchitme@rediffmail.com.

- Dr. Mihajlo Jakovljevic, Academic Member, ATINER \& Professor, University of Kragujevac, Serbia, sidartagothama@gmail.com.

- Dr. Elizabeth Poster, Professor, College of Nursing and Health Innovation, University of Texas Arlington, USA, poster@exchange.uta.edu.

- Dr. Paolo Ricci, Professor, University of Bologna, Italy, apricci@earthlink.net.

- Dr. Iga Rudawska, Head and Professor, Chair of Health Economics, Faculty of Economics and Management, University of Szczecin, Poland, igita@wneiz.pl.

- Dr. Mary Tsouroufli, Academic Member, ATINER \& Reader in Education, University of Wolverhampton, UK, M.Tsouroufli@wlv.ac.uk.

- Dr. Yelena Bird, Academic Member, ATINER \& Associate Professor, University of Saskatchewan, Canada, yelena.bird@usask.ca.

- Dr. Donald Rob Haley, Associate Professor, Health Administration Program Department of Public Health, Brooks College of Health, University of North Florida, USA, rhaley@unf.edu.

- Dr. Jarmila Kristová, Associate Professor, Slovak Medical University in Bratislava, Slovakia, jarmila.kristova@szu.sk.

- Dr. Amardeep Thind, Academic Member, ATINER \& Professor and Director, Western University, Canada, athind2@uwo.ca.

- Dr. Reza Yousefi, Associate Professor of Biochemistry, Department of Biology, Shiraz University, Iran,ryousefi@shirazu.ac.ir.

- Dr. Yanzhong Huang, Senior Fellow for Global Health, Council on Foreign Relations, USA \& Professor and Director for Global Health Studies, School of Diplomacy and International Relations, 
Seton Hall University, USA, YHuang@cfr.org.

- Dr. David P. Keys, Associate Professor, Department of Criminal Justice, New Mexico State, USA, davekeys@nmsu.edu.

- Dr. Christiaan Lako, Academic Member, ATINER \& Associate Professor, Department of Public Administration, Radboud University Nijmegen, The Netherlands, c.lako@fm.ru.nl.

- Dr. Emmanouil Mentzakis, Academic Member, ATINER \& Associate Professor, Department of Economics, University of Southampton, UK, E.Mentzakis@soton.ac.uk.

- Dr. Laurence G. Rahme, Associate Professor, Department of Surgery, Microbiology and Immunobiology, Harvard Medical School, Boston, Massachusetts \& Director of Molecular Surgical Laboratory, Burns Unit, Department of Surgery, Massachusetts General Hospital, USA, rahme@molbio.mgh.harvard.edu.

- Dr. Peter Erwin Spronk, Internist-Intensivist, FCCP, Director of Research of Intensive Care Medicine, Medical Director Intensive Care, Gelre Hospitals, Apeldoorn, The Netherlands, pspronk@chello.nl.

- Dr. Roseane Maria Maia Santos, Academic Member, ATINER \& Associate Professor, Pharmaceutical Sciences Department, South University School of Pharmacy, USA, rsantos@southuniversity.edu.

- Dr. Fiona Timmins, Associate Professor, School of Nursing and Midwifery, Trinity College Dublin, Ireland, timminsf@tcd.ie.

- Dr. Eleni L. Tolma, Associate Professor, Department of Health Promotion Sciences, College of Public Health, University of Oklahoma Health Sciences Center, USA, eleni-tolma@ouhsc.edu.

- Dr. Amalia Tsiami, Associate Professor, London School of Hospitality and Tourism, University of West London, UK, Amalia.Tsiami@uwl.ac.uk.

- Dr. Tibebe Woldemariam, Academic Member, ATINER \& Associate Professor, College of Pharmacy, California Northstate University, USA, TWoldemariam@cnsu.edu.

- Dr. Alberto Zamora, Associate Professor, School of Medicine, University of Girona \& Internal Department, Hospital of Blanes, Girona, Spain, azamorac.zamora@gmail.com.

- Dr. Alain Touwaide, Scientific Director, Institute for the Preservation of Medical Traditions History of Sciences \& Department of Botany, National Museum of Natural History, Smithsonian Institution, USA, atouwaide@hotmail.com.

- Dr. Anita Meldrum, Assistant Head of Department, Sustainable Environments \& Communities, School of Engineering \& the Built Environment, Glasgow Caledonian University, Glasgow, Scotland, Anita.Meldrum@gcu.ac.uk.

- Dr. Jennie De Gagne, Assistant Professor, School of Nursing, Duke University, USA, jennie.degagne@duke.edu.

- Dr. Anna Hnatyszyn-Dzikowska, Academic Member, ATINER \& Assistant Professor, Department of Health Economics, Nicolaus Copernicus University in Torun, Poland, a.hnatyszyn@cm.umk.pl.

- Dr. Selini Katsaiti, Assistant Professor, Department of Economics and Finance, College of Business and Economics, United Arab Emirates University, UAE, Selini.katsaiti@uaeu.ac.ae.

- Dr. Zia-Ullah Khokhar, Assistant Professor in Chemistry, Institute of Biochemistry and Biotechnology, Punjab University, Lahore \& Govt. Islamia College, Gujranwala, Pakistan, zia2_khokhar@hotmail.com.

- Dr. Tammy Lampley, Assistant Professor, Assistant Program Director, Nurse Education Program, Sacred Heart University, USA, lampleyt@sacredheart.edu.

- Dr. Blazej Lyszczarz, Assistant Professor, Department of Public Health, Nicolaus Copernicus University, Poland, blazej@cm.umk.pl.

- Dr. Abeer Orabi, Assistant Professor, Women and Newborn Health Nursing, College of NursingJeddah, King Saud bin Abdulaziz University for Health Sciences, Kingdom of Saudi Arabia, orabiab@NGHA.MED.SA.

- Dr. Igor V. Pantic, Assistant Professor, Institute of Medical Physiology, School of Medicine, University of Belgrade, Serbia, igorpantic@gmail.com.

- Dr. Efrosini Papaconstantinou, Assistant Professor, Faculty of Health Sciences, University of Ontario Institute of Technology, Canada, Efrosini.Papaconstantinou@uoit.ca.

- Dr. Tara N. Turley-Stoulig, Instructor, Department of Biological Sciences, Southeastern Louisiana 
University, USA, tturley@selu.edu.

- Dr. Samah Anwar Mohamed Shalaby, Lecturer Critical Care and Emergency, Faculty of Nursing, Alexandria University, Egypt, samahanwar_2005@yahoo.com.

- Dr. Abraham Brown, Senior Lecturer, Division of Marketing, Nottingham Business School, Nottingham Trent University, UK, abraham.brown@ntu.ac.uk.

- Dr. Graeme Lockwood, Senior Lecturer in Law and Management, Department of Management, King's College London, UK, Graeme.lockwood@kcl.ac.uk.

- Dr. Nditsheni Jeanette Ramakuela, Academic Member, ATINER \& Senior Lecturer, University of Venda, South Africa, Nditsheni.Ramakuela@univen.ac.za.

- Dr. Melina Dritsaki, Academic Member, ATINER \& Senior Health Economist, Oxford Clinical Trials Unit, Nuffield Department of Orthopaedics, Rheumatology and Musculoskeletal Sciences , University of Oxford, UK, melina.dritsaki@ndorms.ox.ac.uk.

- Dr. Camelia Diaconu, Lecturer, University of Medicine and Pharmacy (UMF) Carol Davila, Faculty of General Medicine, Internal Medicine Clinic \& Internal medicine physician, Floreasca Clinical Emergency Hospital of Bucharest, Romania, camiluciemi@yahoo.com.

- Dr. Janet Dzator, Academic Member, ATINER \& Senior Lecturer, The University of Newcastle, NSW, Australia, janet.dzator@newcastle.edu.au.

- Dr. Efi Mantzourani, Academic Member, ATINER \& Lecturer in Pharmacy Practice, Leader of Undergraduate Placement-Based Learning, School of Pharmacy and Pharmaceutical Sciences, Cardiff University, UK, MantzouraniE1@cardiff.ac.uk.

- Dr. Helena Martins, Lecturer, Polytechnic of Porto \& University of Port, Portugal, helenagmartins@gmail.com.

- Dr. Catherine Wright, Academic Member, ATINER \& Lecturer and Principal Investigator, Glasgow Calcedonian University, UK, Catherine.Wright@gcu.ac.uk.

- Mr. Themba T. Sigudu, Lecturer of Environmental Health, Faculty of Health Sciences, University of Johannesburg, South Africa, thembas@uj.ac.za.

- Dr. Junhong Zhu, Academic Member, ATINER \& Postdoctoral Associate, Arthur Labatt Family School of Nursing, Western University, Canada, JUNHONGZHU66@hotmail.com.

- Dr. Noha El-Baz, Emergency and Critical Care Nursing Department, Faculty of Nursing, Alexandria University, Egypt, noha.elbaz@gmail.com.

- Dr. Audrey Marie Callum, Learning and Development Manager, SweetTree Home Care Services, London, UK, apeart.callum@gmail.com.

- Dr. Christos Andreou, Academic Member, ATINER \& Special Educational Officer, Nursing Department, Faculty of Health Sciences, Cyprus University of Technology, Cyprus, christos.andreou@cut.ac.cy.

- Dr. Peter Vermeir, Academic Member, ATINER \& Head ATP/Researcher, Ghent University Hospital/Ghent University, Belgium, Peter.Vermeir@uzgent.be.

- Dr. Kisalaya Basu, Academic Member, ATINER \& Senior Economic Advisor, Applied Research and Analysis Directorate, Canada, kisalaya.basu@canada.ca.

- Abdosaleh Jafari, PhD Student in Health Economics, Iran University of Medical Sciences, Tehran, Iran, abdosaleh.jafari@gmail.com.

- General Managing Editor of all ATINER's Publications: Ms. Afrodete Papanikou

- ICT Managing Editor of all ATINER's Publications: Mr. Kostas Spyropoulos

- Managing Editor of this Journal: Ms. Effie Stamoulara ( $\underline{\text { bio })}$

\section{Reviewers' Board}

Click Here 


\section{President's Message}

All ATINER's publications including its e-journals are open access without any costs (submission, processing, publishing, open access paid by authors, open access paid by readers etc.) and is independent of presentations at any of the many small events (conferences, symposiums, forums, colloquiums, courses, roundtable discussions) organized by ATINER throughout the year and entail significant costs of participating. The intellectual property rights of the submitting papers remain with the author. Before you submit, please make sure your paper meets the basic academic standards, which includes proper English. Some articles will be selected from the numerous papers that have been presented at the various annual international academic conferences organized by the different divisions and units of the Athens Institute for Education and Research. The plethora of papers presented every year will enable the editorial board of each journal to select the best, and in so doing produce a top-quality academic journal. In addition to papers presented, ATINER will encourage the independent submission of papers to be evaluated for publication.

The current issue is the second of the seventh volume of the Athens Journal of Health and Medical Sciences (AJHMS), published by the published by the Health \& Medical Sciences Division of ATINER 


\section{Athens Institute for Education and Research}

\section{A World Association of Academics and Researchers}

19th Annual International Conference on Health Economics, Management \& Policy, 22-25 June 2020, Athens, Greece

The Health Economics \& Management Unit of ATINER will hold its 19 $^{\text {th }}$ Annual International

Conference on Health Economics, Management \& Policy, 22-25 June 2020, Athens,

Greece sponsored by the Athens Journal of Health and Medical Sciences. The aim of the conference is to bring together academics, researchers and professionals in health economics, management and policy. You may participate as stream leader, presenter of one paper, chair of a session or observer. Please submit a proposal using the form available (https://www.atiner.gr/2020/FORM-HEA.doc).

\section{Academic Members Responsible for the Conference}

- Dr. Paul Contoyannis, Head, Health Economics \& Management Unit, ATINER \& Associate Professor, McMaster University, Canada.

- Dr. Vickie Hughes, Director, Health \& Medical Sciences Division, ATINER \& Assistant Professor, School of Nursing, Johns Hopkins University, USA.

- Abstract Submission: 8 June 2019

- Acceptance of Abstract: 4 Weeks after Submission

- Submission of Paper: 25 Mav 2020

\section{Social and Educational Program}

The Social Program Emphasizes the Educational Aspect of the Academic Meetings of Atiner.

- Greek Night Entertainment (This is the official dinner of the conference)

- Athens Sightseeing: Old and New-An Educational Urban Walk

- Social Dinner

- Mycenae Visit

- Exploration of the Aegean Islands

- Delphi Visit

- Ancient Corinth and Cape Sounion

- More information can be found here: https://www.atiner.gr/social-program

\section{Conference Fees}

Conference fees vary from $400 €$ to $2000 €$

Details can be found at: https://www.atiner.gr/2019fees 


\section{Athens Institute for Education and Research}

A World Association of Academics and Researchers

\section{$9^{\text {th }}$ Annual International Conference on Health \& Medical Sciences 3-6 May 2021, Athens, Greece}

The Medicine Unit of ATINER is organizing its $9^{\text {th }}$ Annual International Conference on Health \& Medical Sciences, 3-6 May 2021, Athens, Greece sponsored by the Athens Journal of Health and Medical Sciences. The aim of the conference is to bring together academics and researchers from all areas of health sciences, medical sciences and related disciplines. You may participate as stream leader, presenter of one paper, chair a session or observer. Please submit a proposal using the form available (https://www.atiner.gr/2021/FORM-HSC.doc).

\section{Important Dates}

- Abstract Submission: 5 October 2020

- Acceptance of Abstract: 4 Weeks after Submission

- Submission of Paper: 5 April 2021

\section{Academic Member Responsible for the Conference}

- Dr. Vickie Hughes, Director, Health \& Medical Sciences Research Division, ATINER \& Assistant Professor, School of Nursing, Johns Hopkins University, USA.

- Dr. Carol Anne Chamley, Head, Nursing Research Unit \& Associate Professor, School of Health and Social Care, London South Bank University UK.

- Dr. Andriana Margariti, Head, Medicine Research Unit, ATINER \& Lecturer, Centre for Experimental Medicine, Queen's University Belfast, U.K.

\section{Social and Educational Program}

The Social Program Emphasizes the Educational Aspect of the Academic Meetings of Atiner.

- Greek Night Entertainment (This is the official dinner of the conference)

- Athens Sightseeing: Old and New-An Educational Urban Walk

- Social Dinner

- Mycenae Visit

- Exploration of the Aegean Islands

- Delphi Visit

- Ancient Corinth and Cape Sounion

More information can be found here: https://www.atiner.gr/social-program

\section{Conference Fees}

Conference fees vary from $400 €$ to $2000 €$

Details can be found at: https://www.atiner.gr/2019fees 



\title{
Effects of Metal Welding Fumes on Kidney Function Parameters in Male Albino Rats
}

\author{
By Ibrahim Lawal Abdullahi ${ }^{*} \&$ Ali Sani ${ }^{ \pm}$
}

\begin{abstract}
Welding is described as one of the most hazardous occupations. The study aims to determine the influence of metal welding fumes on kidney function parameters in blood of the exposed animals. The fumes were collected from welding sites during the activity by a skilled welder. One hundred thirty experimental animals were used and made into 13 groups. Twelve groups were given dosages calculated to correspond to real life workers exposure regimes and 1 group served as control. The dosages were administered intratracheally after been anesthetized weekly for 12 weeks. The animals were sacrificed and whole blood samples were taken. Serum was used to determine urea, chloride $(\mathrm{Cl})$, Sodium ( $\mathrm{Na}$ ), Potassium $(\mathrm{K})$ and the activity of creatinkinase $(\mathrm{CK})$. The values of Urea and Creatinine in the treatment groups have exceeded the control values and slightly significant. Values of electrolytes $\mathrm{Cl}, \mathrm{K}$ and $\mathrm{Na}$ in all the treatment groups have exceeded the control. Thus, it shows impairment of the kidney by elevated serum levels of the metabolites and probable damage in the kidney function. Benchmark dose and standard limits should be proposed for such occupations in Kano.
\end{abstract}

Keywords: Effects, Evaluation, Kidney function, Metal welding fumes

\section{Introduction}

Welding is an industrial process which is common, and use excessively high temperatures to join metals. Importantly, the process produces metallic fumes and gases that are potentially hazardous (Gordon 2004, Antonini et al. 2004). Tierney (1977) described welding as one of the most hazardous occupations. There are several reasons why welding is regarded as dangerous occupation: workers suffer excessive heat, burns, radiation, noise, fumes, gases, electrocution, and even the uncomfortable postures involved in the work; the different chemical composition of welding fumes, work piece, method employed, and surrounding environment; and lastly the routes of entry or surface exposed to these harmful agents access the body (Zakhari and Anderson 1981). There is some suggestion that Manual Metal Arc welding may result in acute decreased lung function compared to other processes (Leonard et al. 2004). Generation of Reactive Oxygen Species (ROS) is theorized as one mechanism for welding fume acute adverse health effects, (Taylor et al. 2003) with stainless steels containing chrome and nickel producing more reactive oxygen species (ROS) than mild steel (Leonard et al. 2004). Health authorities in Kano focus more attention on communicable diseases such as malaria, typhoid, etc. caused by vectors or water borne as environmental health problems. However, many deaths in the metropolis could be as a result of ailments from hazardous compounds/substances that destroy tissues and organs which

${ }^{*}$ Lecturer, Department of Biological Sciences, Bayero University, Nigeria.

${ }^{ \pm}$Lecturer, Department of Biological Sciences, Bayero University, Nigeria. 
existing laboratory practices and techniques cannot diagnose correctly and efficiently. Are the metal fumes toxic? What organ(s) are the most susceptible to the metal fumes? What concentration of the metal fumes can cause damage to human tissue/organ? Answers to these questions are not only important but necessary in order to broaden the scope of environmental health issues in urban Kano. Thus, the present study was aimed at determining the kidney function parameters (Chloride, Sodium, Potassium, urea, creatinine) of the experimental animal groups.

\section{Materials and Methods}

\section{Collection of Welding Fumes}

The metal fumes were generated in a cubical open front fume chamber (volume $=1 \mathrm{~m}^{3}$ ) by a skilled welder performing manual metal welding (shielded manual metal arc welding) process using a stainless-steel hard surfacing electrode (Hyundai Welding electrode low hydrogen E 7018 3.2mm) and collected on $0.2 \mu \mathrm{m}$ nuclepore filters. They were collected in significant amount just before the start of the study. The particle size of the collected fume sample was determined using scanning electron microscopy (SEM) and found to be within the respirable size range with a mean diameter of $<1 \mu \mathrm{m}$ (Popstojanov et al. 2014).

\section{Experimental Design}

Experimental activity requires the use of appropriate lab animals. Albino rats were chosen for this study. The rats were obtained and housed at the Animal house, Department of Pharmacology, Aminu Kano Teaching Hospital, Kano, Nigeria. Randomized block design was adopted for this study. A total of 130 laboratory rats (Rattus norvegicus) were utilized for the study. The animals were maintained in the animal room and were allowed to acclimatize for two weeks before treatment. The animals weigh between 210-250g. The animals were divided into 13 experimental groups with each group composing of 10 albino rats.

\section{Housing and Feeding Conditions for Experimental Animals}

The animal house has restricted access, free from pathogens and other extraneous factors. They were placed in cages with each cage housing 5 animals. The animals were marked on their tails for identification. The temperature in the experimental animal room was maintained at about $22^{\circ} \mathrm{C}\left( \pm 3^{\circ} \mathrm{C}\right)$ and the relative humidity was at least 30\%. For lighting, the sequence was 12 hours light and 12 hours dark. They were given a conventional laboratory diet for rats bought from Vital Feeds Kano with water ad libitum. Existing protocols for the use of lab animals were adhered to strictly and ethical approval for the study was obtained 
from College of Health Sciences Research Ethics Committee (CHS-REC), Bayero University, Kano (OECD 2018).

\section{Preparation of the Test Substance}

The dosing paradigm employed in this study was related to workplace exposures of metal workers. A mathematical calculation was utilized to determine the daily lung burden of a metal worker on a specified number of hours work schedule (Antonini et al. 2010, Sriram et al. 2010). Below are the factors that were taken into consideration during the calculation:

Fume concentration ( $5 \mathrm{mg} \mathrm{m}^{-3}$, threshold limit value for welding fumes).

Human minute ventilation volume $\left(20,000 \mathrm{mlmin}^{-1} \times 10^{-6} \mathrm{~m}^{3} \mathrm{ml}^{-1}\right)$.

Exposure duration (no. of hr day ${ }^{-1} \times 60 \mathrm{~min} \mathrm{~h}^{-1}$ ).

Deposition efficiency (15\%) (ICRP 1994, Antonini et al. 2006).

With reference to the above factors, metal workers daily burden for various hours per day.

1. Metal worker daily burden $(2 \mathrm{hrs} /$ day $)=$ Fume concentration $\left(5 \mathrm{mg} / \mathrm{m}^{3}\right) \times$ Human minute ventilation volume $\left(20,000 \mathrm{ml} / \mathrm{min} \times 10-6 \mathrm{~m}^{3} / \mathrm{ml}\right) \times$ Exposure duration $(2 \mathrm{hr} /$ day $\times 60 \mathrm{~min} / \mathrm{hr}) \times$ Deposition efficiency $(15 \%)=1.8 \mathrm{mg}$.

Using surface area of alveolar epithelium ( $\mathrm{rat}=0.4 \mathrm{~m}^{2}$; human $=102 \mathrm{~m}^{2}$ ) as dose metric (Stone et al. 1992). Rat daily burden of exposure was taken as $0.0070 \mathrm{mg}$.

Then, similar exposure in rats for 3 years, 5 years, 10 years and 20 years will be $7.66 \mathrm{mg}, 12.77 \mathrm{mg}, 25.55 \mathrm{mg}$ and $51.10 \mathrm{mg}$, respectively at 365 days per year. Each of these concentrations was then divided into 12 which was administered weekly for the period of the study (12 weeks).

2. Metal worker daily burden $(4 \mathrm{hrs} /$ day $)=$ Fume concentration $\left(5 \mathrm{mg} / \mathrm{m}^{3}\right) \times$ Human minute ventilation volume $\left(20,000 \mathrm{ml} / \mathrm{min} \times 10-6 \mathrm{~m}^{3} / \mathrm{ml}\right) \times$ Exposure duration $(4 \mathrm{hr} /$ day $\times 60 \mathrm{~min} / \mathrm{hr}) \times$ Deposition efficiency $(15 \%)=3.6 \mathrm{mg}$.

Using surface area of alveolar epithelium ( $\mathrm{rat}=0.4 \mathrm{~m}^{2}$; human $=102 \mathrm{~m}^{2}$ ) as dose metric (Stone et al. 1992). Rat daily burden of exposure was taken as $0.0141 \mathrm{mg}$.

Then, similar exposure in rats for 3 years, 5 years, 10 years and 20 years will be $15.44 \mathrm{mg}, 25.73 \mathrm{mg}, 51.46 \mathrm{mg}$ and $102.93 \mathrm{mg}$, respectively at 365 days per year. Each of these concentrations was then divided into 12 which were administered weekly for the period of the study (12 weeks).

3. Metal worker daily burden $(8 \mathrm{hrs} /$ day $)=$ Fume concentration $\left(5 \mathrm{mg} / \mathrm{m}^{3}\right) \times$ Human minute ventilation volume $\left(20,0000 \mathrm{ml} / \mathrm{min} \times 10-6 \mathrm{~m}^{3} / \mathrm{ml}\right) \times$ Exposure duration $(8 \mathrm{hr} /$ day $\times 60 \mathrm{~min} / \mathrm{hr}) \times$ Deposition efficiency $(15 \%)=7.2 \mathrm{mg}$. 
Using surface area of alveolar epithelium ( $r a t=0.4 \mathrm{~m}^{2}$; human $=102 \mathrm{~m}^{2}$ ) as dose metric (Stone et al. 1992). Rat daily burden of exposure was taken as $0.0282 \mathrm{mg}$.

Then, similar exposure in rat for 3 years, 5 years, 10 years and 20 years will be $30.88 \mathrm{mg}, 51.46 \mathrm{mg}, 102.93 \mathrm{mg}$ and $205.86 \mathrm{mg}$, respectively at 365 days per year. Each of these concentrations was then divided into 12 which was administered weekly for the period of the study (12 weeks).

Table 1 describes the working concentrations (dosage) of metal fumes administered to test animals for 12 weeks. Each concentration was given per animal per week.

Table 1. Working Concentration for Test Substances Administered to Groups of Animals used for the Study

\begin{tabular}{|c|c|c|}
\hline \multicolumn{3}{|c|}{ Groups } \\
\hline I & II & III \\
\hline Group IA (0.64 & Group IIA (1.29 & Group IIIA (2.57 \\
mg/animal/week) & mg/animal/week) & mg/animal/week) \\
\hline Group IB (1.06 & Group IIB (2.14 & Group IIIB (4.27 \\
mg/animal/week) & mg/animal/week) & mg/animal/week) \\
\hline Group IC (2.13 & Group IIC (4.29 & Group IIIC (8.56 \\
mg/animal/week) & mg/animal/week) & mg/animal/week) \\
\hline Group ID (4.26 & Group IID (8.58 & Group IIID (17.16 \\
mg/animal/week) & mg/animal/week) & mg/animal/week) \\
\hline
\end{tabular}

The metal fumes sample was prepared in sterile saline and sonicated for $1 \mathrm{~min}$ to disperse the particulates. Rats were anaesthesized with ketamine $(0.1 \mathrm{ml} / 100 \mathrm{~g}$ b.w IP) and after passing out, immediately followed by intratracheal instillation of the respective dose per animal once a week for 12 weeks. Control animals were given $200 \mu$ l of sterile saline via intratracheal route after been anaesthesized.

\section{Administration and Dosage of Test Substances}

The study involved chronic toxicity testing of the metal fumes in albino rats which lasted for 12 weeks and treatment was administered weekly by intratracheal instillation (Antonini et al. 2013).

\section{Collection of Blood Samples of Treated Animals}

Animals were euthanized 1 week after the 12 weekly treatments. Blood samples were collected from jugular vein into an EDTA container for biochemical analysis. However, the blood sample was centrifuged at 3000rpm to obtain the serum for subsequent analysis (Hoff and Rlagt 2000, Antonini et al. 2013).

\section{Kidney Function Tests}

Biochemical parameters were determined in serum photometrically. Concentrations of urea, chloride $(\mathrm{Cl})$, Sodium $(\mathrm{Na})$, Potassium $(\mathrm{K})$ and the activity 
of creatinkinase (CK) were determined using Pliva Lachema test kits (Czech Republic).

\section{Data Analysis}

Sigmastat v.3.5 statistical tool was employed to analyze data or results obtained from the study. Means of various parameters were analyzed statistically to test for statistical difference by one-way analysis of variance (ANOVA) and level of significance was taken at $\mathrm{p}<0.05$ indicating significance.

\section{Results}

Tables 2-4 show the kidney function parameters in blood of experimental animals in groups I (A, B, C, D), II (A, B, C, D) \& III (A, B, C, D). The parameters include Urea, creatinine and electrolytes which are potassium, chloride and sodium.

Table 2. Mean Values of Kidney Function Parameters of Blood Samples of Animals Exposed to lower Metal Welding Fumes for 12 Weeks

\begin{tabular}{|l|c|c|c|c|c|}
\hline $\begin{array}{l}\text { Test animal } \\
\text { groups }\end{array}$ & Urea (mg/dl) & $\begin{array}{c}\text { Creatinine } \\
(\boldsymbol{\mu m o l} / \mathbf{l})\end{array}$ & $\begin{array}{c}\text { Potassiu } \\
\mathbf{m} \\
(\mathbf{m m o l} / \mathbf{l})\end{array}$ & $\begin{array}{c}\text { Chloride } \\
(\mathbf{m E q} / \mathbf{l})\end{array}$ & $\begin{array}{c}\text { Sodium } \\
(\mathbf{m E q} / \mathbf{l})\end{array}$ \\
\hline IA & $222.5 \pm 12.58$ & $31.37 \pm 4.25^{\mathrm{a}}$ & $4.16 \pm 0.33$ & $93.92 \pm 5.51$ & $50.95 \pm 3.91^{\mathrm{a}}$ \\
\hline IB & $268.35 \pm 11.21$ & $30.94 \pm 3.91^{\mathrm{b}}$ & $4.25 \pm 0.41$ & $99.6 \pm 5.84$ & $58.15 \pm 5.03^{\mathrm{bc}}$ \\
\hline IC & $313.35 \pm 15.27$ & $34.85 \pm 4.53^{\mathrm{c}}$ & $4.41 \pm 0.52$ & $102.77 \pm 6.36$ & $60 \pm 4.62^{\text {abd }}$ \\
\hline ID & $327.77 \pm 14.04$ & $45.73 \pm 4.33^{\text {abc }}$ & $4.47 \pm 0.43$ & $116.98 \pm 6.76$ & $90.3 \pm 4.88^{\text {cd }}$ \\
\hline $\begin{array}{l}\text { Control } \\
\text { P value }\end{array}$ & $183.35 \pm 10.37$ & $28.02 \pm 2.40$ & $4.1 \pm 0.42$ & $97.2 \pm 5.44$ & $49.6 \pm 4.73$ \\
\hline
\end{tabular}

$\mathrm{p}<0.05$ : there is significant difference.

p $>0.05$ : there is no significant difference.

Means \pm SD values with same letters as superscript indicate significance.

Table 3. Mean Values of Kidney Function Parameters Blood Samples of Animals Exposed to moderate Metal Welding Fumes for 12 Weeks

\begin{tabular}{|l|c|c|c|c|c|}
\hline $\begin{array}{l}\text { Test animal } \\
\text { groups }\end{array}$ & Urea $(\mathbf{m g} / \mathbf{d l})$ & $\begin{array}{c}\text { Creatinine } \\
(\boldsymbol{\mu m o l} / \mathbf{l})\end{array}$ & $\begin{array}{c}\text { Potassium } \\
(\mathbf{m m o l} / \mathbf{l})\end{array}$ & $\begin{array}{c}\text { Chloride } \\
(\mathbf{m E q} / \mathbf{l})\end{array}$ & $\begin{array}{c}\text { Sodium } \\
(\mathbf{m E q} / \mathbf{l})\end{array}$ \\
\hline IIA & $295 \pm 11.02$ & $34.35 \pm 2.88$ & $4.84 \pm 0.31$ & $107.31 \pm 8.04$ & $59.56 \pm 3.47^{\text {ab }}$ \\
\hline IIB & $320.85 \pm 14.75$ & $36.1 \pm 3.55$ & $4.79 \pm 0.24$ & $121.77 \pm 7.22$ & $76.45 \pm 4.24^{\mathrm{a}}$ \\
\hline IIC & $361.1 \pm 13.33$ & $39.73 \pm 4.01$ & $4.51 \pm 0.30$ & $122.98 \pm 7.64$ & $80.85 \pm 4.53$ \\
\hline IID & $386.65 \pm 18.21$ & $46.1125 \pm 4.44$ & $4.56 \pm 0.26$ & $132.99 \pm 7.08$ & $98.1 \pm 4.71^{\mathrm{d}}$ \\
\hline $\begin{array}{l}\text { Control } \\
\text { P value }\end{array}$ & $\begin{array}{c}183.35 \pm 10.37 \\
>\mathbf{0 . 0 5}\end{array}$ & $\begin{array}{c}28.02 \pm 2.40 \\
>\mathbf{0 . 0 5}\end{array}$ & $\begin{array}{c}4.1 \pm 0.42 \\
\mathbf{> 0 . 0 5}\end{array}$ & $\begin{array}{c}97.2 \pm 5.44 \\
\mathbf{> 0 . 0 5}\end{array}$ & $\begin{array}{c}49.6 \pm 4.73 \\
<\mathbf{0 . 0 5}\end{array}$ \\
\hline
\end{tabular}

$\mathrm{p}<0.05$ : there is significant difference.

$\mathrm{p}>0.05$ : there is no significant difference.

Means \pm SD values with same letters as superscript indicate significance. 
Vol. 7, No. 2 Abdullahi \& Sani: Effects of Metal Welding Fumes on Kidney Function...

Table 4. Mean Values of Kidney Function Parameters of Blood Samples of Animals Exposed to High Metal Welding Fumes for 12 Weeks

\begin{tabular}{|l|c|c|c|c|c|}
\hline $\begin{array}{l}\text { Test animal } \\
\text { groups }\end{array}$ & Urea $(\mathbf{m g} / \mathbf{d l})$ & $\begin{array}{c}\text { Creatinine } \\
(\boldsymbol{\mu m o l} / \mathbf{l})\end{array}$ & $\begin{array}{c}\text { Potassium } \\
(\mathbf{m m o} / \mathbf{l})\end{array}$ & $\begin{array}{c}\text { Chloride } \\
(\mathbf{m E q} / \mathbf{l})\end{array}$ & $\begin{array}{c}\text { Sodium } \\
(\mathbf{m E q} / \mathbf{l})\end{array}$ \\
\hline IIIA & $339.35 \pm 13.30^{\mathrm{a}}$ & $36.56 \pm 3.61^{\mathrm{ab}}$ & $5.52 \pm 0.31$ & $117.43 \pm 4.41$ & $68.23 \pm 4.54^{\mathrm{ac}}$ \\
\hline IIIB & $361.1 \pm 11.10^{\mathrm{b}}$ & $39.73 \pm 2.15^{\mathrm{c}}$ & $4.61 \pm 0.22$ & $142.98 \pm 4.55$ & $84.3 \pm 4.88^{\text {abd }}$ \\
\hline IIIC & $392.65 \pm 12.36$ & $48.61 \pm 3.41^{\mathrm{ad}}$ & $4.56 \pm 0.19$ & $152.99 \pm 3.99$ & $101.5 \pm 5.05^{\mathrm{bc}}$ \\
\hline IIID & $430.83 \pm 15.27^{\mathrm{ab}}$ & $57.36 \pm 3.68^{\mathrm{bcd}}$ & $5.07 \pm 0.34$ & $199.09 \pm 6.71$ & $112.43 \pm 5.04^{\mathrm{d}}$ \\
\hline $\begin{array}{l}\text { Control } \\
\text { P value }\end{array}$ & $\begin{array}{c}283.35 \pm 10.37 \\
<\mathbf{0 . 0 5}\end{array}$ & $\begin{array}{c}28.02 \pm 2.40 \\
<\mathbf{0 . 0 5}\end{array}$ & $\begin{array}{c}4.10 \pm 0.42 \\
>\mathbf{0 . 0 5}\end{array}$ & $\begin{array}{c}97.20 \pm 5.44 \\
>\mathbf{0 . 0 5}\end{array}$ & $\begin{array}{c}49.60 \pm 4.73 \\
<\mathbf{0 . 0 5}\end{array}$ \\
\hline
\end{tabular}

$\mathrm{p}<0.05$ : there is significant difference.

$\mathrm{p}>0.05$ : there is no significant difference.

Means \pm SD values with same letters as superscript indicate significance.

\section{Discussion}

The mean values of Urea for groups IA, IB, IC \& ID range from 222.5 to $327.77 \mathrm{mg} / \mathrm{dl}$ as shown in Table 2. Group IA has the least mean value of $222.5 \mathrm{mg} / \mathrm{dl}$ while Group ID has the highest mean value of $327.77 \mathrm{mg} / \mathrm{dl}$. The mean values are increasing across the groups. The values of all the groups have exceeded the control mean value of $183.35 \mathrm{mg} / \mathrm{dl}$. There is no significant difference statistically between the groups $(\mathrm{p}>0.05)$.

The mean values of Urea for groups IIA, IIB, IIC \& IID range from 295 to $386.65 \mathrm{mg} / \mathrm{dl}$ as shown in Table 3. Group IIA has the least mean value of $295 \mathrm{mg} / \mathrm{dl}$ while Group IID has the highest mean value of $386.65 \mathrm{mg} / \mathrm{dl}$. The mean values are increasing across the groups. The values of all the groups have exceeded the control mean value of $183.35 \mathrm{mg} / \mathrm{dl}$. There is no significant difference statistically between the groups $(\mathrm{p}>0.05)$.

The mean values of Urea for groups IIIA, IIIB, IIIC \& IID range from 339.35 to $430.83 \mathrm{mg} / \mathrm{dl}$ as shown in Table 4 . Group IIIA has the least mean value of $339.35 \mathrm{mg} / \mathrm{dl}$ while Group IIID has the highest mean value of $430.83 \mathrm{mg} / \mathrm{dl}$. The mean values are increasing across the groups. The values of all the groups have exceeded the control mean value of $183.35 \mathrm{mg} / \mathrm{dl}$. There is a significant difference statistically between the groups $(\mathrm{p}<0.05)$. Similarly, in another study, treatment with the mixture of metals arsenic (As), cadmium $(\mathrm{Cd})$ or lead $(\mathrm{Pb})$ in rats has resulted in a significant increase in urea and a significant decrease in protein and albumin levels, indicating a systemic toxic effect of the treatment (Choudhuri et al. 2016).

The mean values of Creatinine for groups IA, IB, IC \& ID range from 30.94 to $45.73 \mu \mathrm{mol} / \mathrm{l}$ as shown in Table 2 . Group IA has the least mean value of $30.94 \mu \mathrm{mol} / 1$ while Group ID has the highest mean value of $45.73 \mu \mathrm{mol} / 1$. The mean values are increasing across IB, IC \& ID. The values of all the groups have exceeded the control mean value of $28.02 \mu \mathrm{mol} / \mathrm{l}$. There is significant difference statistically between the groups $(\mathrm{p}<0.05)$. 
The mean values of Creatinine for groups IIA, IIB, IIC \& IID range from 34.35 to $46.11 \mu \mathrm{mol} / \mathrm{l}$ as shown in Table 3 . Group IIA has the least mean value of $34.35 \mu \mathrm{mol} / 1$ while Group IID has the highest mean value of $46.11 \mu \mathrm{mol} / 1$. The mean values are increasing across the groups. The values of all the groups have exceeded the control mean value of $28.02 \mu \mathrm{mol} / \mathrm{l}$. There is no significant difference statistically between the groups ( $p>0.05$ ).

The mean values of Creatinine for groups IIIA, IIIB, IIIC \& IIID range from 36.56 to $57.36 \mu \mathrm{mol} / 1$ as shown in Table 4 . Group IIIA has the least mean value of $36.56 \mu \mathrm{mol} / 1$ while Group IIID has the highest mean value of $57.36 \mu \mathrm{mol} / 1$. The mean values are increasing across the groups. The values of all the groups have exceeded the control mean value of $28.02 \mu \mathrm{mol} / \mathrm{l}$. There is a significant difference statistically between the groups $(\mathrm{p}<0.05)$. Similarly, treatment with the mixture of metals arsenic $(\mathrm{As})$, cadmium $(\mathrm{Cd})$ or lead $(\mathrm{Pb})$ in rats has resulted in a significant increase in serum cholesterol and creatinine levels (Choudhuri et al. 2016).

The values of Urea and Creatinine in the treatment groups have exceeded the control values thus it shows impairment of the kidney by elevated serum levels of these metabolites. Similarly, Afify et al. (2007) found a statistically significant correlation between the level of blood chromium and renal insult represented by the affection of urinary beta- 2 microglobulin, urea, and creatinine. An increase in serum urea and creatinine level in the animals, treated with mixture of heavy metals (As, $\mathrm{Cd}$ and $\mathrm{Pb}$ ), relative to control animal and animal treated with individual metal $\mathrm{As}, \mathrm{Cd}$ or $\mathrm{Pb}$ indicated nephrotoxic effect of metals treatment. In addition, Samir et al. (2015) revealed also an increase in serum creatinine concentration in cadmium group and no changes was signalized in the others treated groups, while serum urea concentration was increased in cadmium and combined treated rats and no change was observed in mercury treated rats.

Kareem et al. (2015) showed that renal parameters in terms of serum creatinine level and proteinuria were deranged evident on biochemical analysis. When group B and C were compared to group A (Control), a statistically significant difference $(\mathrm{p}<0.05)$ was noticed in terms of renal parameters.

Serum levels of creatinine increased as a result of copper exposure in comparison to the control group. These observed changes are in accordance with other authors' results (Wang et al. 2014, Onwuka 2005). Both urea and creatinine are excreted through kidney. In fact, urea is the first acute renal marker which increases during any kind of kidney injury. But, creatinine is the most trustable renal marker which increases only due to loss of major renal function (Peres et al. 2013).

The mean values of Potassium (K) for groups IA, IB, IC \& ID range from 4.16 to $4.47 \mathrm{mmol} / \mathrm{l}$ as shown in Table 2 . Group IA has the least mean value of $4.16 \mathrm{mmol} / 1$ while Group ID has the highest mean value of $4.47 \mathrm{mmol} / \mathrm{l}$. The mean values are increasing across the groups. The values of all the groups have exceeded the control mean value of $4.1 \mathrm{mmol} / \mathrm{l}$. There is no significant difference statistically between the groups ( $\mathrm{p}>0.05$ ).

The mean values of Potassium (K) for groups IIA, IIB, IIC \& IID range from 4.51 to $4.84 \mathrm{mmol} / \mathrm{l}$ as shown in Table 3 . Group IIA has the least mean value of $4.51 \mathrm{mmol} / 1$ while Group IID has the highest mean value of $4.84 \mathrm{mmol} / \mathrm{l}$. The mean 
values are decreasing across the groups. The values of all the groups have exceeded the control mean value of $4.1 \mathrm{mmol} / \mathrm{l}$. There is no significant difference statistically between the groups $(\mathrm{p}>0.05)$.

The mean values of Potassium (K) for groups IIIA, IIIB, IIIC \& IIID range from 4.56 to $5.52 \mathrm{mmol} / \mathrm{l}$ as shown in Table 4 . Group IIIC has the least mean value of $4.56 \mathrm{mmol} / 1$ while Group IIIA has the highest mean value of $5.52 \mathrm{mmol} / 1$. The mean values have decreased from IIIA, IIIB, IIIC. The values of all the groups have exceeded the control mean value of $4.1 \mathrm{mmol} / \mathrm{l}$. There is no significant difference statistically between the groups $(\mathrm{p}>0.05)$. Similarly, the results of De Jong et al. (2019) have shown that levels of potassium increased as a result of $\mathrm{Cu}$ exposure in comparison to the control group.

The mean values of Chloride $(\mathrm{Cl})$ for groups IA, IB, IC \& ID range from 93.92 to $116.98 \mathrm{mEq} / \mathrm{l}$ as shown in Table 2. Group IA has the least mean value of $93.92 \mathrm{mEq} / \mathrm{l}$ while Group ID has the highest mean value of $116.98 \mathrm{mEq} / \mathrm{l}$. The mean values are increasing across the groups. The values of all the groups have exceeded the control mean value of $97.2 \mathrm{mEq} / \mathrm{l}$. There is no significant difference statistically between the groups ( $p>0.05$ ).

The mean values of Chloride $(\mathrm{Cl})$ for groups IIA, IIB, IIC \& IID range from 107.31 to $132.99 \mathrm{mEq} / \mathrm{l}$ as shown in Table 3. Group IIA has the least mean value of $107.31 \mathrm{mEq} / 1$ while Group IID has the highest mean value of $132.99 \mathrm{mEq} / 1$. The mean values are increasing across the groups. The values of all the groups have exceeded the control mean value of $97.2 \mathrm{mEq} / \mathrm{l}$. There is no significant difference statistically between the groups ( $\mathrm{p}>0.05)$.

The mean values of Chloride $(\mathrm{Cl})$ for groups IIIA, IIIB, IIIC \& IIID range from 117.43 to $199.09 \mathrm{mEq} / \mathrm{l}$ as shown in Table 4. Group IIIA has the least mean value of $117.43 \mathrm{mEq} / \mathrm{l}$ while Group IIID has the highest mean value of $199.09 \mathrm{mEq} / \mathrm{l}$. The mean values are increasing across the groups. The values of all the groups have exceeded the control mean value of $97.2 \mathrm{mEq} / \mathrm{l}$. There is no significant difference statistically between the groups ( $p>0.05)$.

The mean values of Sodium $(\mathrm{Na})$ for groups IA, IB, IC \& ID range from 50.95 to $90.30 \mathrm{mEq} / 1$ as shown in Table 2 . Group IA has the least mean value of $50.95 \mathrm{mEq} / \mathrm{l}$ while Group ID has the highest mean value of $90.30 \mathrm{mEq} / 1$. The mean values are increasing across the groups. The values of all the groups have exceeded the control mean value of $49.6 \mathrm{mEq} / \mathrm{l}$. There is significant difference statistically between the groups $(\mathrm{p}<0.05)$.

The mean values of Sodium (Na) for groups IIA, IIB, IIC \& IID range from 59.56 to $98.1 \mathrm{mEq} / \mathrm{l}$ as shown in Table 3. Group IIA has the least mean value of $59.56 \mathrm{mEq} / \mathrm{l}$ while Group IID has the highest mean value of $98.1 \mathrm{mEq} / 1$. The mean values are increasing across the groups. The values of all the groups have exceeded the control mean value of $49.6 \mathrm{mEq} / \mathrm{l}$. There is significant difference statistically between the groups $(\mathrm{p}<0.05)$.

The mean values of Sodium $(\mathrm{Na})$ for groups IIIA, IIIB, IIIC \& IIID range from 68.23 to $112.43 \mathrm{mEq} / \mathrm{l}$ as shown in Table 4. Group IIIA has the least mean value of $68.23 \mathrm{mEq} / \mathrm{l}$ while Group IIID has the highest mean value of $112.43 \mathrm{mEq} / \mathrm{l}$. The mean values are increasing across the groups. The values of all the groups have exceeded the control mean value of $49.6 \mathrm{mEq} / \mathrm{l}$. There is 
significant difference statistically between the groups $(\mathrm{p}<0.05)$. However, the results have shown that levels of urea, sodium and protein decreased as a result of $\mathrm{Cu}$ exposure in comparison to the control group. Significant effects were seen already at a dose and $\mathrm{Cu}$ toxicity on serum parameters related to renal function (Babaknejad et al. 2015).

The values of these electrolytes $(\mathrm{Cl}, \mathrm{K}, \mathrm{Na})$ in all the treatment groups have exceeded the control which indicates probable damage in the kidney function. In another study, predominant renal injury among welders is tubular, and this injury is correlated with the blood chromium level (Afify et al. 2007). Powers et al. (1986) said that glomerular injury has been noted in chromium workers, the predominant renal injury is tubular, with low doses acting specifically on the proximal convoluted tubules and this injury is correlated with the blood chromium level as low-dose, chronic chromium exposure typically results only in transient renal effects. They also reported that elevated urinary B2-microglobulin levels (an indicator of renal tubular damage) have been found in chrome platters, and higher levels have generally been observed in younger persons exposed to higher $\mathrm{Cr}$ (VI) concentrations. As the kidneys are highly sophisticated transport organs, they excrete metabolic waste. Such a function is optimised by a special circulatory structure in the kidney, which has a remarkable ability to adjust the haemodynamic inputs in order to maintain renal circulation (Burkitt et al. 2000).

Some studies have shown that recurrent exposure to metal fumes could result in the urinary excretion of low molecular weight proteins (Wedeen and Qian, 1991, Petersen et al. 1994, Ding et al. 2011) although this state might be reversible at the onset unless there is already established renal impairment as evident by decreasing glomerular filtration rate. Chronic exposure to heavy metals like lead, chromium and cadmium may produce insidious, yet progressive tubulointerstitial nephropathy often leading to renal failure (Petersen et al. 1994, Garcon et al. 2007). In contrast to tubular proteinuria in which low molecular weight proteins are seen, glomerular proteinuria is readily detected by testing for urinary albumin using albustix (Wedeen and Qian 1991).

Among possible target organs of heavy metals liver, kidney and neural systems appear to be the most sensitive one (Flora and Pachauri 2010). Chronic exposure to $\mathrm{Pb}$ showed nephropathy, including nephromegaly and dysfunction of proximal tubules in animal studies (Liu et al. 2012).

\section{Conclusions}

The values of Urea and Creatinine in the treatment groups have exceeded the control values thus it shows impairment of the kidney by elevated serum levels of these metabolites. The values of the electrolytes $\mathrm{Cl}, \mathrm{K}$ and $\mathrm{Na}$ in all the treatment groups have exceeded the control which indicates probable damage in the kidney function. Benchmark dose and standard limits should be proposed for such occupations in Kano. 
Vol. 7, No. 2 Abdullahi \& Sani: Effects of Metal Welding Fumes on Kidney Function...

\section{References}

Afify M, Helal SF, Arafaa AM (2007) Assessment of respiratory and renal functions among gas metal arc welders and their relations with chromium exposure. In Defence against the Effects of Chemical Hazards: Toxicology, Diagnosis and Medical Countermeasures, 22-1-22-12. Meeting Proceedings RTO-MP-HFM-149, Paper 22. Neuilly-sur-Seine, France: RTO.

Antonini JM, Taylor MD, Zimmer AT, Roberts JR (2004) Pulmonary responses to welding fumes: role of metal constituents. Journal of Toxicology and Environmental Health Part A 67(3): 233-249.

Antonini JM, Afshari AA, Stone S, Chen B, Schwegler-Berry D, Fletcher WG et al. (2006) Design, construction, and characterization of a novel robotic welding fume generator and inhalation exposure system for laboratory animals. Journal of Occupational and Environmetal Hygiene 3(4): 194-203.

Antonini JM, Roberts JR, Chapman RS, Soukup JM, Ghio AJ, Sriram K (2010) Pulmonary toxicity and extra pulmonary tissue distribution of metals after repeated exposure to different welding fumes. Inhalation Toxicology 22(10): 805-816.

Antonini JM, Roberts JR, Schwegler-Berry D, Mercer RR (2013) Comparative microscopic study of human and rat lungs after overexposure to welding fume. Annals of Occupational Hygiene 57(9): 1167-1179.

Babaknejad N, Moshtaghie AA, Shahanipour K (2015) The toxicity of copper on serum parameters related to renal functions in male Wistar rats. Zahedan Journal of Research in Medicine and Science 15(3): 29-31.

Burkitt HG, Young B, Health JW (2000) Wheater's Functional Histology. London: Churchill Livingstone.

Choudhuri D, Bhattacharjee T, Bhattacharjee S (2016) Hepatotoxic and nephrotoxic effects of chronic low dose exposure to a mixture of heavy metals-lead, cadmium and arsenic. International Journal of Pharmaceutical, Chemical and Biological Sciences 6(1): 39-47.

De Jong WH, De Rijk E, Bonetto A, Wohlleben W, Stone V, Brunelli A, Badetti E, Marcomini A, Gosens I, Cassee FR (2019) Toxicity of copper oxide and basic copper carbonate nanoparticles after short-term oral exposure in rats. Nanotoxicology 13(1): $50-72$.

Ding X, Zhang Q, Wei H, Zhang Z (2011) Cadmium-induced renal tubular dysfunction in a group of welders. Occupational Medicine 61(4): 277-279.

Flora SJ, Pachauri V (2010) Chelation in Metal Intoxication. International Journal of Environmental Research and Public Health 7(7): 2745-2788.

Garcon G, Leleu B, Marez T, Zerimech F, Haguenoer J, Furon D et al. (2007) Biomonitoring of the adverse effects induced by the chronic exposure to lead and cadmium on kidney function: usefulness of alpha-glutathione S-transferase. Science of the Total Environment 377(2/3): 165-172.

Gordon T (2004) Metalworking fluid-the toxicity of a complex mixture. Journal of Toxicology and Environmental Health Part A 67(3): 209-219.

Hoff J, Rlagt LV (2000) Methods of blood collection in the mouse. Lab Animal 29(10): 47-53.

ICRP-International Commission on Radiological Protection (1994) Human respiratory tract model for radiological protection. A report of a task group of the international commission on radiological protection. Annals of the ICRP 24(1/3): 1-482. 
Kareem H, Naseem N, Nagi AH, Romman U (2015) Deranged levels of renal parameters after using heavy metal kushta of copper in diet of albino rats. Pakistan Journal of Medical and Health Sciences 9(3): 807-810.

Leonard SS, Chen BT, Stone SG, Schwegler-Berry D, Kenyon AJ, Frazer D et al. (2004) Occupational exposure to welding fume among welders: alterations of manganese, iron, zinc, copper, and lead in body fluids and the oxidative stress status. Journal of Occupational and Environmental Medicine 46(3): 241-248.

Liu CM, Ma JQ, Sun YZ (2012) Puerarin protects rats kidney from lead-induced apoptosis by modulating the P13K/AKt/eNOS pathway. Toxicology and Applied Pharmacology 258(3): 330-342.

OECD (2018) Guidelines for the testing of chemicals. Chronic Toxicity Studies. Retrieved from https://bit.ly/3a8Dj55.

Onwuka GI (2005) Food analysis and instrumentation: theory and practice. Lagos: Napthali Print.

Peres LAB, Júnior ADDC, Schäfer AJ, Silva ALD, Gaspar AD, Scarpari DF et al. (2013) Biomarkers of acute kidney injury. Brazilian Journal of Nephrology 35(3): 229-236.

Petersen R, Mikkelsen S, Thomsen OF (1994) Chronic interstitial nephropathy after plasma cutting in stainless steel. Occupational and Environmental Medicine 51(4): 259-261.

Popstojanov R, Antonini JM, Rebecca S, Morgan Y, Zheng W, Castranova V et al. (2014) Alterations in cardiomyocyte function after pulmonary treatment with stainless steel welding fume in rats. Journal of Toxicology and Environmental Health Part A 77(12): 705-715.

Powers WJ, Gad SC, Siino KM, Pechman JC (1986) Effects of therapeutic agents on chromiuminduced acute nephrotoxicity. In DM Serrone (Ed.), Chromium Symposium: An Update, 79-86. Pittsburgh (PA): Industrial Health Foundation, Inc.

Samir H, Mohamed FN, Abdelhamid E (2015) Simultaneous effect of cadmium and mercury on some biochemical parameters of kidney function in male rats. Journal of Current Chemical \& Pharmaceutical Sciences 5(1): 26-30.

Sriram K, Lin GX, Jefferson AM, Roberts JR, Wirth O, Hayashi Y et al. (2010) Mitochondrial dysfunction and loss of Parkinson's disease linked proteins contribute to neurotoxicity of manganese-containing welding fumes. Federation of American Society of Experimental Biology - FASEB Journal 24(12): 4989-5002.

Stone KC, Mercer RR, Gehr P (1992) Allometric relationships of cell numbers and size in the mammalian lung. American Journal of Respiratory Cell Molecular Biology 6(2): 235-243.

Taylor MD, Roberts JR, Leonard SS, Shi X, Antonini JM (2003) Effects of welding fumes of differing composition and solubility on free radical production and acute lung injury and inflammation in rats. Toxicological Sciences 75(1): 181-191.

Tierney MP (1977) Analysis of mine injuries associated with maintenance \& repair in metal \& non-metal mines. US Department of the Interior, Mining Enforcement \& Safety Administration.

Wang Y, Katzmarzyk PT, Horswell R, Zhao W, Johnson J, Hu G (2014) Kidney function and the risk of cardiovascular disease in patients with type 2 diabetes. Kidney International 85(5): 1192-1199.

Wedeen RP, Qian L (1991) Chromium- induced kidney disease. Environmental Health Perspectives 92: 71-74.

Zakhari S, Anderson RS (1981) Effects of Welding on Health II. Miami, FL: American Welding Society. 



\title{
The Dilemma of Outsourcing Drug Trials
}

\begin{abstract}
By Somjit Barat*
As ubiquitous as drug trails are becoming, more and more marketing companies in the western world are looking beyond their own borders to recruit participants and conduct such experiments. While this has led to faster turnaround times and higher number of potential drugs being pushed into the market pipeline, such practices often raise questions about procedural thoroughness, propriety and marketing ethics. Are participants being provided the full and unbiased information? Are the recruits educated enough to comprehend the risks? Do the drugs being tested have any relevance at all in the host country? Are the same standards of rigor and oversight being followed in the host country as in their western counterparts? Consequently, the study achieves the following objectives: 1. Helps us better understand the extent of the loopholes that pharma companies exploit while marketing the 'benefits' of such drug trials to the intended participants and 2. Encourages more researchers to innovate better marketing strategies, so that future drug trials can be conducted in a systematic, ethical and yet rigorous manner.
\end{abstract}

Keywords: Emerging economies, ethics, drug trials, theory of reasoned action

\section{Introduction}

The importance of conducting thorough trials before a drug can be officially approved for the market is beyond dispute. However, research companies often push the envelope when it comes to best practices for conducting such trials, especially in non-Western countries. Faced with a domestic shrinking market and increasing oversight from their own regulatory agencies, western countries are increasingly 'outsourcing' such trials to other countries.

Concurrently, a sizeable segment of low-income, under-educated population resides in developing countries, who are often promised a cure for their disease under study or their future medical expenses to be borne by the drug company conducting the research. Given the ubiquity of drug use, it may, therefore, be no surprise that the rate of drug trials for commercialization purposes has assumed astronomical proportions. Consequently, the current study explores different dimensions of ethical marketing issues, which have made some developing countries the 'guinea-pigs' of the Western labs.

Basing the research on the Theory of Reasoned Action (Ajzen and Fishbein 1980), the author argues that the individual's beliefs about the outcomes and consequences of conducting drug trials influence his/her attitude towards conducting such trials. The study will achieve the following objectives: 1 . Help us better understand the extent of the loopholes that pharma companies exploit while marketing the 'benefits' of such drug trials to the intended participants and 2.

\footnotetext{
*Associate Professor, Penn State University, USA.
} 
Encourage more researchers to innovate better marketing strategies, so that future drug trials can be conducted in a systematic, ethical and rigorous manner.

The paper is organized as follows: The author introduces the concept of and concern about marketing ethics in outsourcing drug trials, using hard data. In the next section, the author reviews extant literature focusing on the topic of discussion and identifies gaps in literature. This section is followed by a discussion of the major perspectives on 'ethics', given that this article relies heavily on the role and interpretation of ethics. Next the author introduces the theoretical framework, while the next section focuses on how and why such marketing practices raise serious marketing ethics concerns. The penultimate section titled marketing drug trials in an ethical manner talks about how we can market such trials in a more ethical manner and yet, maintain the rigors of the testing procedures. The concluding section briefly discusses the limitations of the research, and provides ideas for future studies on this highly relevant topic.

Western countries frequently outsource their drug trials to Third World countries. According to one Duke University survey (2007), more than two-thirds of US clinical trials were conducted outside the US (see Glickman et al. 2009). The Office of Inspector General (OIG) noted in a 2010 report about the increasing use of locations outside the western world for clinical trials, and highlighted FDA statistics pertaining to the same (Levinson 2010):

- Over half of all clinical trial sites are outside the U.S.

- $35 \%$ of non-U.S. clinical investigators were conducting trials under independent agencies.

- $80 \%$ of applications for drugs and biologics contain data from ex-U.S. studies.

- $78 \%$ of all subjects were enrolled outside the U.S.

- $87 \%$ of all subjects in recent biologics trials were enrolled outside the U.S.

Trial-participants also indicated that drugs and supplies were shipped throughout the world, with North America topping the chart at $78 \%$, followed by Western Europe (66\%), Eastern Europe (63\%), Latin America (29\%), Asia-Pacific (22\%), and Rest of World (18\%). In order to make the movement of equipment and supplies more efficient, companies often set up regional hubs such as in a wheel-and-spoke system (for example, Western Europe tops the list at 38\%, followed by Asia-Pacific (31\%), and Rest of World (13\%). Similarly, top local depot locations are located in Latin America (49\%), North America (41\%), and Asia-Pacific (36\%) regions.

The statistics in Table 1 proves, beyond reasonable doubt, that even though the numbers of sites in most western countries is considerably higher compared to their non-Western counterparts, the trend is exactly the opposite in terms of average relative annual growth rates (ARAGR) percent. For example, Canada hosted 3032 testing sites while the UK had 1753 sites. Compared to those, China (which is only the fourth largest country) has only 533 sites, while Peru and Malaysia had only 125 and 161 sites respectively. In contrast, the ARAGR for Switzerland, Sweden, Belgium and the UK were all in the negative territory (with 
the exception of Canada, which had a 12\% ARAGR). In contrast, China, Estonia, Russia, Peru and Malaysia exhibited ARAGR of 47\%, 35\%, 33\%, 33\% and 32\% respectively.

Table 1. Sample of Countries Ranked by Average Relative Annual Growth Rates of \# Sites (2007)

\begin{tabular}{|l|c|c|c|}
\hline \multicolumn{1}{|c|}{ Ranking } & Country & \# Sites & \% ARAGR \\
\hline 1 & China & 533 & 47 \\
\hline 2 & Estonia & 83 & 34.6 \\
\hline 3 & Russia & 1084 & 33 \\
\hline 4 & Peru & 125 & 32.5 \\
\hline 5 & Malaysia & 161 & 32.1 \\
\hline 45 & Switzerland & 309 & -7.6 \\
\hline 46 & Sweden & 739 & -8.6 \\
\hline 47 & Belgium & 986 & -9.4 \\
\hline 48 & UK & 1753 & -9.9 \\
\hline 49 & Canada & 3032 & 12.0 \\
\hline 50 & Norway & 290 & -14.7 \\
\hline
\end{tabular}

Adapted from Table S4: Thiers at al. (2008).

While the reasons for such trend are beyond the scope of the current review, it can be surmised that most Western countries had either reached their capacity or found economically and logistically infeasible to set up more testing sites (again, with the exception of Canada, which has significant vacant landscape). On the other hand, several non-Western countries (India and Thailand being the topmost) quickly developed the infrastructure to host medical testing sites and as such, found a ready market among Western research labs and drug testing agencies eager to outsource their work.

An identical trend, especially in phase 1 and phase 3 of the trial process, is corroborated further by Jeong et al. (2017). For example, the author notes that phase 3 trials were more popular in India, whereas phase 1 trials were predominant in other countries compared to the US. Interestingly, as well, a larger number of 'child' age group trials were conducted during the same time period (2011-2013) in Poland, Israel, and South Africa compared to the US.

As indicated in another study by Lexchin et al. (2003), there is also an increasing role of industry sponsors of such trials, sometimes making it all the more difficult to adhere to ethical standards; consider the following findings that buttress what the author surmises: all 16 studies showed favorable outcomes for company-sponsored trials compared to only 10 for non-sponsored trails and industry-sponsored trials were more likely to report favorable qualitative conclusions compared to their non-sponsored counterparts (for further details, see Table 2 in Lexchin et al. 2003).

Paradoxically, scant literature has been devoted to this issue from a marketing perspective, which will be evident from the review in the next section. Therefore, the author's contribution fills a considerable void, and bridges the gap between the medical and ethical marketing worlds. 


\section{Literature Review}

Researchers in the medical community, have long bemoaned the lack of oversight in conducting drug trials. On the other hand, discussions focus on a range of issues starting with the history of drug trials going all the way to some of the most recent developments in this field. Consequently, for the reader's convenience, this review has been segmented under two headings: antecedents and consequences of medical trials.

Antecedents: As indicated earlier, drug trials on human subjects have been a prerogative of western countries for multiple reasons, such as higher testing standards and requirements, more extensive use of drugs by patients and prescriptions written by doctors (Bachman et al. 2016, Grigoryan et al. 2006, Birke et al. 2016). A stark indicator of this chasm between the two worlds is reflected in Figure 1, which shows the preponderance of antidepressant medication use in western countries compared to their non-Western counterparts.

Figure 1. Use of Antidepressant in Select Countries

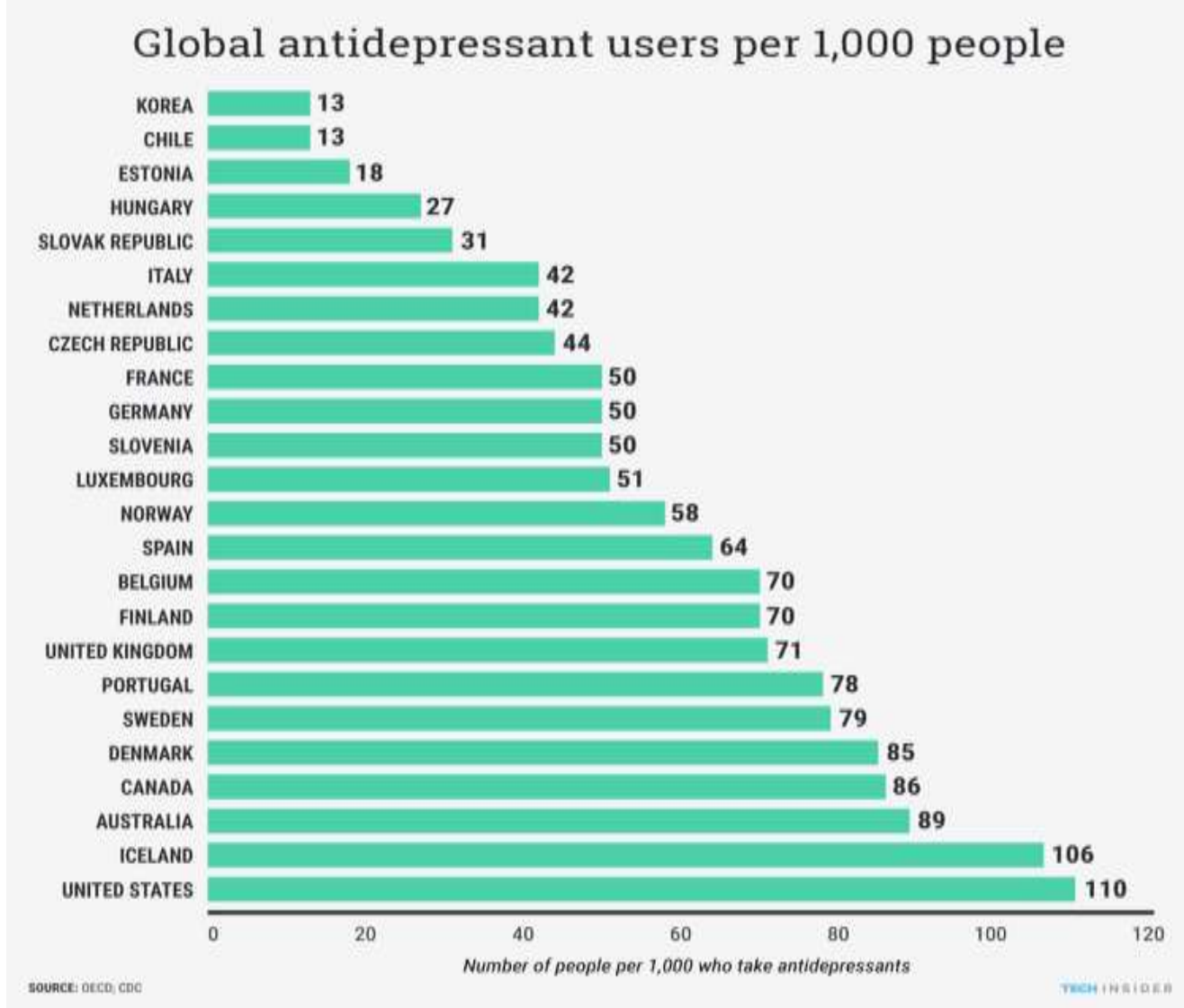

Adapted from Gould and Friedman, 2016.

Given that per capita consumption of medications is significantly higher in western than in other countries, western countries pioneer pharmaceutical research and drug trials at an unprecedented rate, saturating their domestic population for such purposes. 
At the same time, the standards and rigors of pharmaceutical trials have become more stringent, with regulatory bodies requiring pharma companies to employ higher a sample sizes for testing purposes. Getting such a higher sample size and conducting the trials within the time frame in-country was simply getting economically infeasible. Consequently, Western pharma companies were left with no choice but to look outside of their geographical boundaries.

This is where many of the non-Western countries, with a vast population, and lagging in healthcare infrastructure, proved to be a goldmine for Western nations. Pharmaceutical companies and research institutes hired marketing agencies with knowledge of and presence in non-Western countries to tout the benefits of drug trials to a hotbed of potential participants. And the marketing agencies haven not looked back since then. In addition, the following factors appeared to have played a significant role in globalization of such trials: 1) lower operational costs, 2) ready availability of subjects and in vast numbers, 3) mushrooming of marketing agencies specializing in pharmaceutical trials, and 4) standardization of clinical guidelines and research methodology, including in non-western countries (Thiers et al. 2008, Rettig 2000, Zarin et al. 2007, Jia 2005).

In addition, higher requirements (such as larger sample, more testing before commercialization), expansion of high-incidence drug introductions (such as hypertension) and the pressure to bring new drugs to the market even faster, have all contributed to the globalization of drug trials (Petryna 2005, 2007).

Finally, many researchers have highlighted the role of 'treatment naivete' in popularizing drug trials in Asian, Eastern European or African countries. Treatment naivete refers to the incidence of patients who have not been exposed to any drugs yet. Such patients are highly sought-after by pharma companies because there is none to very little drug interaction. Naturally, given the preponderance of drug use in Western countries, finding 'virgin' patients in Western countries for drug trials became increasingly challenging. Consequently, pharma companies marketed their trials to non-Western countries (Good 2001, Das 1996, Biehl 2001).

\section{Discussion}

The author's research also revealed significant literature about the consequences of this trend. Once again, for the reader's convenience, the author has classified the literature under two sub-headings: benefits and disadvantages

- Benefits: As indicated at the very onset, the main objective of conducting drug trials is to establish the efficacy of treatment, patient reaction and possible side-effects of a medication or procedure. This is especially critical for regions that are economically poorer and/or have a weaker medical infrastructure (Petryna 2005, 2007). The diffusion of medical knowledge and information has long-term implications that might impact the entire evolution of certain populations in terms of physical, emotional 
and psycho-social development (de Zulueta 2001, Crouch et al. 1998, Bothwell et al. 2016, Darrow et al. 2015).

There is no question that different drugs should be tested on subjects, barring which, their effects cannot be compared, nor will it be possible to prescribe the most effective cure for serious diseases. Gupta et al. (2015) opine that drug trials on pregnant and post-partum women are critical, especially for epidemics such as HIV, because it affects not just the patients but future generations as well. From a marketing perspective, therefore, the benefits of such trials far outweigh the costs and risks.

Finally, Davis et al. (2017) put forth the argument that drugs may not necessarily cure all chronic diseases such as cancer, but can potentially improve the quality of life of the patients. In other words, the benefits of drug trials may not always be obvious to 'healthy' people but can potentially be a game changer for chronically ill patients.

- Disadvantages: Marketing companies (aka Contract Research Organizations or CRO-s) often resort to increased pressure and suppression tactics, which lead to bypassing due process (such as Institutional Review Board or IRB review) in such trials. One study, for example, found that only $69 \%$ of the trial studies had IRB approval (Samuel et al. 2016).

A second factor is the lure of money and/or quick 'cure' that CRO-s sometimes use as an added incentive to recruit subjects. Such incentives cloud the participant's ability to make a medically informed decision regarding participation. Often a patient who is desperate for a cure, fails to realize that a 'trial' is not a cure, but only a possible path towards a cure, and is, therefore, prone to making hasty decisions. In other words, irrespective of the outcome of the trial, the process of conducting the trial does not necessarily seem to in the best interests of the patient (Ahmed et al. 2014, Jacob 2018, Limbu et al. 2018, Heneghan et al. 2017).

A yet third criticism arises from the perspective of lack of follow through after the conclusion of the trial. Once again, this can most likely be traced back to insufficient information for the participants, who either fail to adhere to the proper protocol, precautions, best practices or to continue follow-up procedures. This leads to tainted or biased results, thereby nullifying the entire trial procedure, sometimes without the lack of knowledge of the pharma company. The subject suffers from financial, physical and emotional distress (Goyal et al. 2014).

Many researchers are concerned that the absence of strong legal infrastructure in non-Western countries makes them a hotbed for drug trials by research companies. This is important, because citizens of those countries (especially the economically disadvantaged) have little to no legal recourse, should something go wrong during or after the trials (Petryna 2007, Angell 1988, 1997, 2000, 2005).

There also exists considerable literature about controversial use of 'placebo' in drug trials. Pharma companies have failed to provide the same level of care for subjects who were administered the placebo during a trial in Africa in 1994 for example, even though providing similar level of care was the norm in the US at that time. Researchers have lamented that dual standards are practiced by pharma 
companies. For more on the disadvantages of drug trials, the reader can consult Bayer (1998), Botbol-Baum (2000), Crouch and Arras (1998), and Rothman (2000).

Critics argue that pharma companies conduct trials in countries where the drugs being tested are least likely to find a large market, such as India, China, Eastern European and South American nations. The reason is that, very few of these trials involved diseases prominent in third world countries. Many doctors also raise questions whether participants were volunteers or coerced into such studies, not to mention that many of the drugs in question are too expensive for the local people to afford.

While a lot can be gleaned about the multiple research perspectives from the previous section, there is seldom any doubt that little attention has been paid to the topic from a marketing-ethics perspective; while reference to ethics in drug trials is copious, the role that marketing agencies (CRO-s) play in popularizing this phenomenon has been consistently overlooked.

'Marketing' according to the American Marketing Association's definition, is basically creating, communicating, delivering and exchanging offerings that have value for consumers for members of the society at large. ${ }^{1}$ In the current context, while the potential benefit of drug trials may be significant, the shortcomings and questionable marketing tactics described above raise the questions whether 'even exchange' and 'value creation' are taking place at all! For example, one of the fundamental requirements for 'exchange' to take place is that it should not be conducted under duress. However, as indicated earlier, the lure of money and a false promise of cure influence the potential subject's ability to make an informed decision regarding participation in the study; clearly, such participants are subject to psychological duress. Consequently, the behavior of pharma companies is subject to ethical scrutiny to say the least -- an issue that is further discussed in the following section.

\section{Ethics and Proposition Development}

'Ethics' is often identified with jello: the more one tries to nail it to the wall, the messier it gets. It is no surprise, therefore, that the topic of ethics has been discussed and interpreted from multifarious perspectives. Given that an exhaustive discussion is neither possible nor necessary in the present context, the author presents a limited view of only those perspectives that are the most relevant for the medical field. It must be noted that ethics is an even bigger concern when it comes to the healthcare field, especially for issues such as, patient recruitment, drug testing, administering a test, side effects of administering a drug etc. The reason for such complexities arises from (but not necessarily limited to) technical language, methodology involved, rules about proper disclosure of possible risks and side effects and ability of potential subjects to comprehend the instructions

\footnotetext{
${ }^{1}$ American Marketing Association: https://www.ama.org/AboutAMA/Pages/Definition-ofMarketing.aspx.
} 
and technical language. As such, major bodies such as Food and Drug Administration (FDA), European Federation of Pharmaceutical Industries and Associations (EFPIA) and Good Clinical Practice (GCP) have very strict ethical guidelines to deal with such issues.

Figure 2. A Simplified Model of Ethics

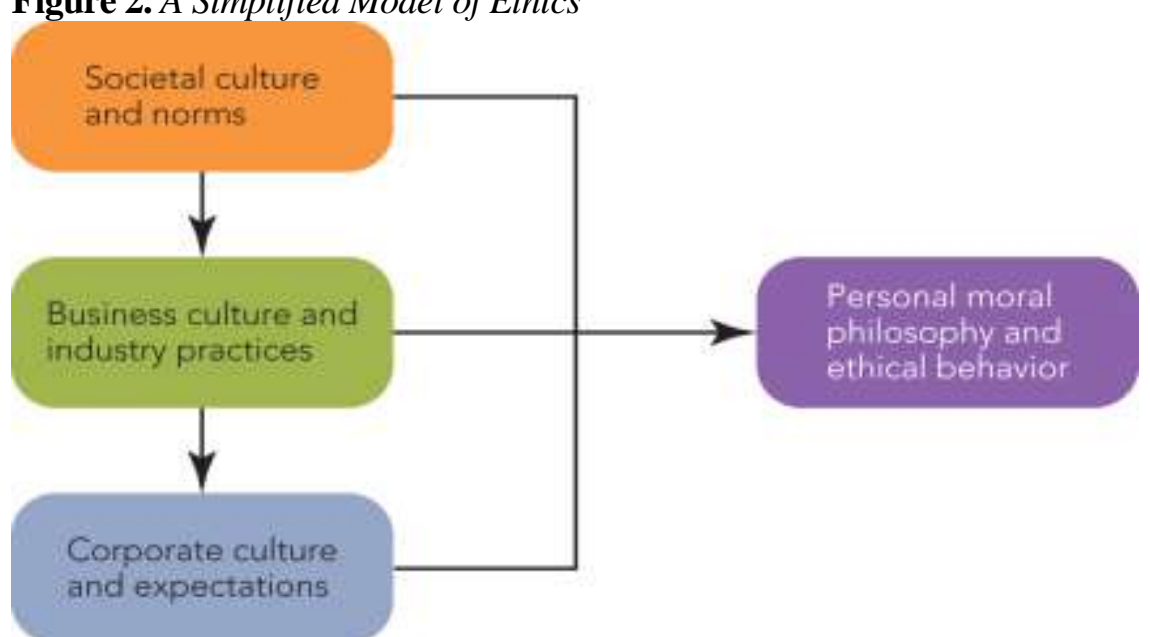

Adapted from Kerin, Roger A. and Hartley, Steven W. (2018). Marketing: The Core; McGraw Hill Education, page 81, Figure 3-2.

Ethics are the moral principles and values that individuals imbibe throughout their lifecycle, and influence their everyday behavior, whether alone or in a group (Murphy et al. 2005). From a very rudimentary standpoint, 'ethics' is the distinction between what is right and what is wrong. However, everyone's assessment of what constitutes right or wrong may be potentially different from another. Consequently, it is important that the individual lay out certain guidelines in making critical decisions. From a personal standpoint, ethics are as much the result of individual judgement as they are the products of the societal norms and practices that we have grown up with and what we have seen our parents, friends and relatives practice. This ethical perspective, as such, is more inclined towards the deontological school (morals and principles) compared to the teleological school. From the teleological prism of ethical viewpoint, the distinction between what is right and what is wrong is governed more by the consequences of the individual's action and less by what the individual's moral standpoint is. Thus, for example, even though someone personally believes that stealing is unethical, the person will nonetheless steal money from rich people and distribute it to the poor. From a utilitarian standpoint, more poor people will benefit compared to the handful of rich people who will be harmed because of the person's action. For drug testing conducted on people on non-Western countries, the author proposes that researchers and recruiters look at the long-term profits of the pharma companies, even if it means going against their personal ethical standards, which leads to: P1: Drug trial subjects recruiters are guided by profit-based utilitarian objectives rather than personal ethical principles.

From a business standpoint, likewise, it is important that the company design a 'code of ethics', which will help its employees make responsible business 
decisions. At the same time, it is important to distinguish between societal norms/ethics, business ethics and corporate ethics. Societal norms are governed principally by what is 'socially acceptable' and therefore, may vary from culture to culture. In many countries where social norms and structures may not be as rigid as in Western countries, cutting in line may not be a big deal but in other cultures, that perpetrator will most likely be scoffed at and called out by others whom he cut in front of. In many traditional cultures, subjects may refuse to participate in drug trial studies because of fear of social ostracization, which leads us to: P2: Potential subjects in non-Western countries may be hesitant to participate in drug trials due to social and normative concerns.

Business ethics, on the others hand, are guided principally by and subservient to, the profit motive. Businesses exist to make profits. Typically, a business will stretch the limits of ethics in order to make profits, but largely stay shy of breaking the law. In other words, personal ethics are different from business ethics, a dichotomy that has existed for ages (Crane and Matten 2016). While industrial psychologists argue that it is possible to make profits even while following the standards of business ethics (Taylor 2013), it actually depends on two factors: 1 . How seriously the business executives themselves follow ethical principles and 2. How well the company can convince its employees to do the same. As reflected by the data in Table 2, industry and 'other' industry sponsors seem to play an increasing role in conducting drug trials on a global basis. Consequently, lack of strong business ethics at the top often drives pharma companies to drive their employees to act in an unethical manner, which motivates: P3: Unethical practices in drug trials frequently result from greed for profit by pharma companies and external industries that often lack a strong business ethic

This brings us to the third component of our ethics model, which is corporate culture and expectations. Charity begins at home. When a business displays strong ethical practices at the helm, it also expects that such spirit will percolate to the bottom ranks. In contrast, if the top corporate culture itself is fraught with unethical practices, the employees will consider it their prerogative to indulge in similar behavior, as is exemplified by Wells Fargo (Verschoor 2016) in its recent acts of multiple gross violations. Thus, even though we might blame the field practitioners for misrepresenting and/or suppressing information from the poor and gullible people into participating in drug trials, the trail of evidence might point the finger of suspicion towards the company executives, thereby resulting in: P4: Unethical practices by top executives at pharma companies can encourage field level recruiters to engage in unethical practices while conducting drug trials in non-Western countries.

Data suggest that close to $60 \%$ of Fortune 500 companies surveyed in 2000 had a 'code of ethics' but only a fraction of those (41\%) implemented them (Smith 2012). Having a code of ethics in place but not implementing the same defeats the whole purpose of abiding by corporate ethics standards. Nonetheless, according to the following graphics, empirical data reveal that employees are more likely to indulge in unethical acts when such code is non-existent as compared to when such code exists on paper. For example, only $32 \%$ reported misconduct of those who observed wrongdoing in large companies without and effective ethics 
program, whereas the corresponding percentage was 87 in companies with an effective ethics program in place.

Figure 3. Ethical Practices at Large Organizations

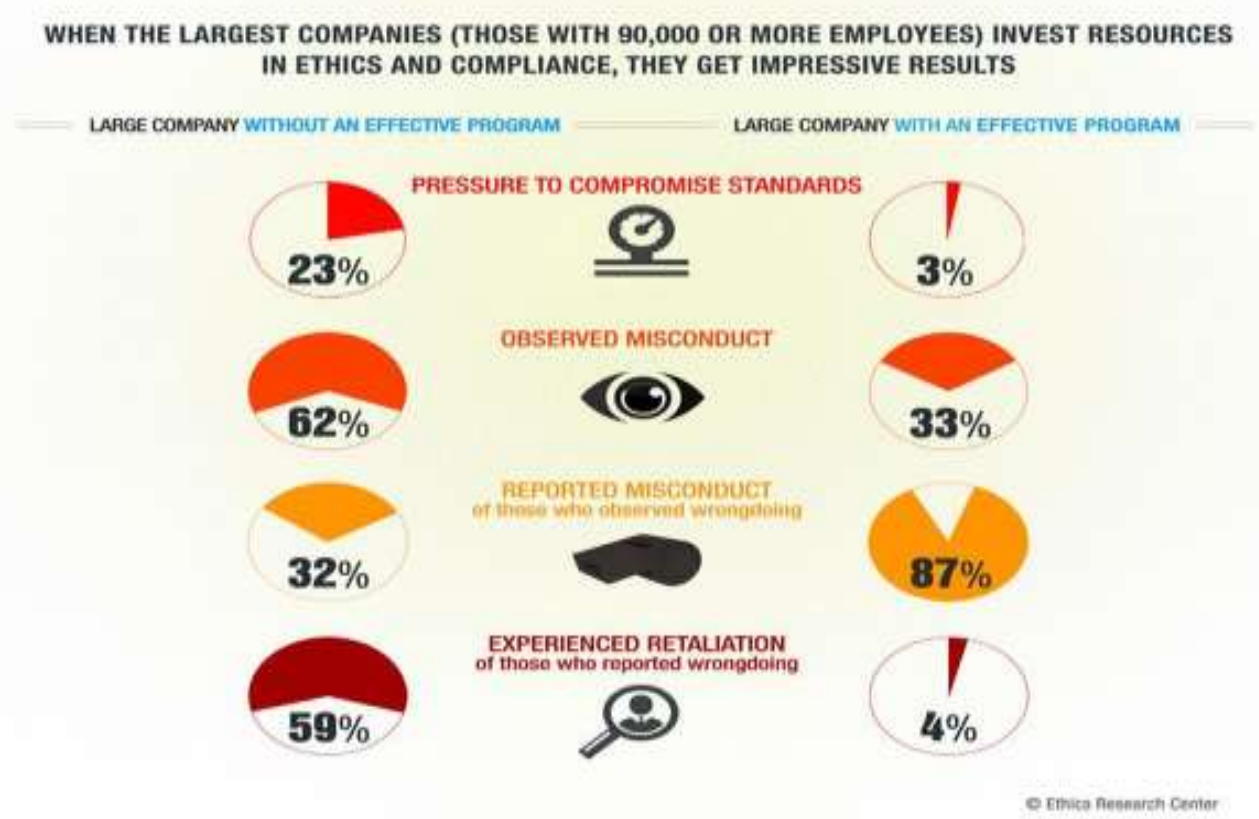

Adapted from State of Ethics in Large Companies: A Research Report from the National Business Ethics Survey® (NBES®) Accessed October 24, 2018.

One such school of thought suggests that certain individuals act under the pretext of 'pre-conventional morality', which refers to the notion that an individual will do whatever it takes to fulfil that individual's self-interests without breaking the law or getting punished; others follow 'conventional morality', where the individual conforms to what is socially acceptable rather than the individual's selfinterests. Finally, 'post-conventional morality' offers more importance to social expectations and norms, where the individual in questions makes well-informed decisions only after examining all perspectives of the given scenario (Kohlberg 1976, D'Souza and Gurin 2016, Northouse 2018).

Another school of ethics principles centers around virtue ethics, consequentialism and deontological strains of what is right or what is wrong, collectively referred to as 'normative ethics'. Normative ethics basically refers to what is most acceptable under the given circumstances, and involves actions taken by 'moral agents', who are considered to possess the mental capability to decide right from wrong and act accordingly. As indicated before, a terminally or several ill patient cannot, by any stretch of imagination, be considered a moral agent, because his/her desperation to live overpowers his/her sense of judgment (Taylor 2013). In many cases such as this, researchers and drug companies take advantage of the patients' helpless situation to conduct tests and trials, thereby making such actions unethical. 
Our spotlight on the role and perspectives of ethics, therefore, helps us understand and appreciate how conducting drug trials in countries where ethical guidelines are either not clear or not implemented rigorously may lead to questionable practices by pharma companies and marketing firms. The next section discusses the theoretical framework of our article.

\section{Theoretical Framework}

The Theory of Reasoned Action (TRA) provides an appropriate framework within which the current research can be anchored. Extrapolating this theory to the current context, the author argues that the individual's beliefs about the outcomes and consequences of conducting drug trials influence his/her attitude towards conducting such trials. His/her attitude, in turn, influences the individual's intention to conduct drug trials (Ajzen and Fishbein 1980, Fishbein and Ajzen 1975, Fishbein and Jaccard 1973). On one hand, if the researchers foresee significant potential, they will conduct such trials; participants will volunteer to be a part of such trials if they expect the potential gains and remuneration from such participation to outweigh the associated risks.

Moreover, the individual's normative beliefs about the feelings of his/her close friends and relatives towards participating in drug trials also affect the individual's subjective norms (refer to Figure 4). For example, the individual might believe that participating in drug trials is a "smart" thing to do, leading to a positive attitude towards study participation. If, on the other hand, the individual or any of his/her acquaintances has had a bad experience with clinical trials in the past, then the individual will most likely have a negative attitude towards participation.

Figure 4. The Theory of Reasoned Action as Applied to Outsourcing Drug Trials

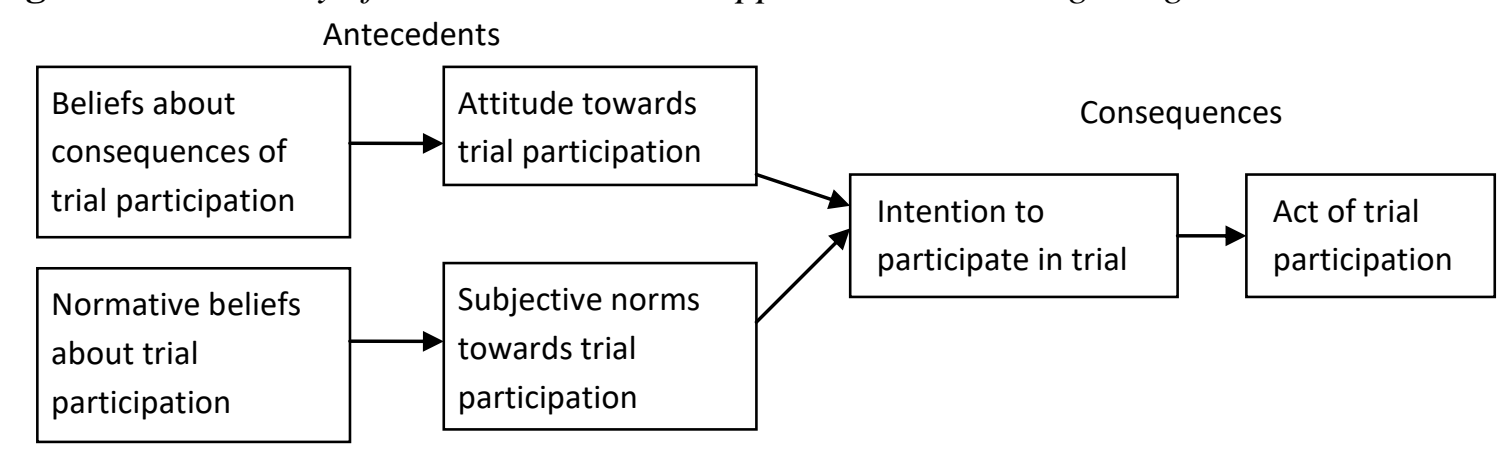

Adapted from Ajzen and Fishbein, 1980, 8.

There exist several disconcerting issues why random outsourcing of drug trials may be detrimental not just for the participants but also for the entire medical community, some of which are discussed below in accordance with the theoretical framework of Figure 3.

1) Based on trial-participants' input gleaned from multi-country studies, it appears that prohibitive costs of conducting such trials in western countries on one 
hand, and unfettered access to a huge pool of patients eager to earn a 'fast buck' on the other hand are the primary motivators that lead pharmaceutical companies and researchers to conduct trials outside western countries (Ali et al. 2018).

2) Given that the easy availability of and access to such vulnerable population in many of the African, Asian, East European and South American regions, it is of utmost importance that such targets of drug trials be protected from, and adequately informed about the potential risks associated with drug trials if proper protocols are not followed (Rajadhyaksha 2010).

3) There remain serious concerns as to whether external marketing agencies fully reveal the rigors and risks of participation while promoting trials in foreign countries and 4) From a global marketing perspective, cultural issues such as diet and popular herbal remedies etc. can considerably skew the results of such trials. However, such factors are rarely addressed while selecting participants, thereby leading to a system that can potentially skew the results.

What medical researchers and authors often have failed to take into account is the role that normative beliefs and subjective norms play a role in the potential subject's decision whether or not to participate in a trial. From a marketing perspective, the author believes that this is one of the most significant contributions of the current paper. Many Asian, South American and African cultures have deep-seated taboos about drugs and their effects on humans. For example, friends and relatives who consider the participant to be 'greedy' and 'needy' might socially ostracized the participant. Nonetheless, given the economic struggles that these people must go through, they participate in drug trials even if doing so is against their will and morals. In other words, economic conditions, normative beliefs and subjective norms often moderate the influence of beliefs about participation in drug trials on the intention to participate in drug trials. Clearly, this cannot be considered 'ethical' by any standards. Once again, the literature on this dimension is almost non-existent, hence the current paper is an attempt by the author to stimulate thinking in that direction (Piantadosi 2017, Anglada et al. 2015, Leon et al. 2015, Chow et al. 2015).

\section{Concerns about Marketing Ethics and Laws}

Ethics can be defined as the moral principles or values that generally govern the conduct of an individual or a group (Lamb et al. 2018). Arguably, different people have different standards and interpretations of what is 'ethical' and what is 'unethical'. On the other hand, some ethical rules and guidelines are often codified into laws. Laws are typically created by governments and are then enforced by governmental authority. By definition, therefore, ethical guidelines are more prone to misinterpretation and distortion compared to laws. Such behavior often leads to self-regulation, which involves the voluntary acceptance of standards established by nongovernmental entities.

The tenets of Utilitarian ethical theory are founded on the ability to predict the consequences of an action. Unfortunately, many of the participant subjects have relatively low levels of education, which severely limits their ability to foresee the 
consequences of their participation in such clinical trials. To be sure, the author argues that the marketing and research agencies operate with calculating, selfserving and selfish motives, where they look for every opportunity to evade the long arm of the law by resorting to notions of pre-conventional morality (Lamb et al. 2018).

The author also notes that in certain circumstances, as per the code of deontological ethics (Paquette 2015) the morality of an action or decision should be based on whether the action itself is right or wrong in the eyes of a series of rules, rather than on the consequences of the action. Regrettably, whether we look at the issue from a deontological perspective or the theory of Reasoned Action perspective described under our theoretical framework, many of the actions perpetrated by pharma companies can be considered unethical in both categories.

The author's main concern, therefore, in the current research is how marketing companies and pharma organizations take advantage of such moral bankruptcy. They stretch the boundaries of ethical behavior in their recruiting of subjects, in providing the subjects the right and accurate information, gathering their consent for participation through full disclosure, in conducting the clinical trials, and finally, in presenting and interpreting the results of the study.

In an open, democratic society, the media plays a key role in informing the public about the actions of individuals and organizations - both good and bad. At the same time, an active civil society works as an informed and engaged entity that can help mold individual and corporate behavior. Ironically, none of these two characteristics exist in many non-Western countries, where drug trials are rampant.

Consequently, the marketing agencies conducting such trials do seldom get caught, and much less prosecuted, because of lax legal loopholes in non-Western countries. According to a report published in Applied Clinical Trials about resource-limited sites, the author raises serious concerns about the following (Garg 2017): 1) Dearth of trained personnel; 2) Training materials (either face-to-face or online webinars conducted right before the commencement of the trials) focus more on the human subject requirements and protections thereof but lack the rigors of operational procedures and the consequences of failure to adhere to the protocols; 3) Training courses include case-studies, but seldom relate to the specific trials that will be conducted on site. Site personnel often take shortcuts in daily procedures because they fail to appreciate the impact of their (in)action on the studies' outcomes.

In another recent survey, regional experts and study participants raised the following concerns, which raise ethical red flags about the conduct of such drug trials. $22 \%$ of the respondents were concerned about the process of 'informed consent', which remains questionable for many reasons. The participants are either not provided full disclosure or do not fully understand the complexities of such trials. For others, the promised monetary or non-monetary rewards from participation cloud the individual's ability to make an unbiased decision (Bentley et al. 2004, Russell et al. 2000, Bigorra et al. 1990).

$22 \%$ of respondents also lamented the lack of health literacy. This is a concern because it influences the ability of the participant to comprehend 
directions, requirements, warnings, precautions and to-do lists and other such obstacles (Tanner et al. 2015, Bonevski et al. 2014, Alemayehu et al. 2018).

Another concern among the respondents was lack of qualified translators or regions that are capable of accurately creating materials for participants in native language $(25 \%)$. This concern is graver than what appears on the surface, because medical terminology and specifications often do not lend themselves to easy 'translation'. Some terminologies and names simply do not have a local language synonym (McNeish et al. 2015, Daley et al. 2001, Ford and Norrie 2016).

Finally, the ability to predict the utility of such trials in a Western setting is a critical factor that can help drug companies justify their experiments. For example, the food habits, lifestyle, family history and gene structure of Western people are significantly different from those of their Asian and South American counterparts. Consequently, the validity of trials pertaining to a specific disease such as cancer or diabetes, for example, may be irrelevant to the Western population (Kordes et al. 2015, Green et al. 2015, Lewis et al. 2011). And yet, these trials appear to be the most widely conducted ones that Western countries outsource to other countries, simply because those diseases are among the most prevalent in Western countries. In other words, as has been pointed out by oversight and regulatory agencies, the responsibility lies with the drug companies or the research institutes to make their case that the results of the drug trials in offshore locations are valid, reliable, complete, unbiased and most importantly-relevant to the Western patients and Western clinical system.

\section{Marketing Drug Trials in an Ethical Manner}

Given that health literacy and informed consent are two critical factors, experts suggest that marketing materials must be made available in the native language. Consequently, availability of and ability to generate translators from English to the native language will alleviate many concerns. Another solution is choosing a country/region that already has an existing supply chain (including cold chain) infrastructure. According to a study conducted by the Tufts Center for the Study of Drug Development (CSDD) in 2016, the economics of supply chain management and distribution have become exponentially complex. Therefore, the marketing agencies need to enforce proper coordination, collaboration and professional training of vertical and horizontal members of the supply chain network. Such measures will help market drug trials in a more ethical manner by providing a more realistic view of the challenges that the host country might face.

The silver lining is that some non-Western countries have recently woken up to this very serious issue and begun to take positive steps. India, which is among the largest host of drug trials outside the western world, has instituted a requirement of video recording of the subject's consent (Kulkarni et al. 2014). In addition, the government has instituted more stringent compensation guidelines in case of physical harm or death of trial subjects. This has significantly reduced the number of trials conducted in India since 2010-2013-time period. 
The case of China, on the other hand, is that of extremes. In 2016, the Chinese Food and Drug Administration found out that as many as $80 \%$ of drug trials results were fabricated following which, the regulatory authority came down heavily on such practices (MacDonald 2016). It reduced the approval times from 12-18 months to a period of 60 days, not to mention the imposition of hefty fines and penalties for violation. Nonetheless, as of June 2016, China ranked $13^{\text {th }}$ in world in terms of drug trial hotbeds.

\section{Implications for Business Marketing Practice}

In a clinical trial conducted in Guatemala in 1946-48 and supported by the US Public Health Service, patients and inmates were intentionally infected (Wechsler 2011). While such blatant misuse and lack of protocol was not very uncommon in the past, it remains to be seen how far the situation has improved in non-Western countries. Recent trends in outsourcing of drug trials suggest that India, Russia/Eastern Europe and China top the charts. While this is a positive trend from the perspective of global marketing, as academics, we must weigh such 'advancements' against increasing scrutiny whether desired participants are being provided complete information regarding the rigors and potential risks of participation.

This is where the author believes the current research fills a notable void. Citing glaring examples and statistics on marketing ethics violation and basing his research on the Theory of Reasoned Action, the author draws the readers' attention towards the role that marketing ethics and communication loopholes play in the medical field.

Future researchers can also learn from current study and devise better marketing strategies where the interests of both parties can be preserved. An interesting aside of the study is that it encourages new debate about the benefits of global marketing. Thanks to the mobility of expertise and of intellectual capital, scientific research can have a lasting impact on remote locations. This trend has been further boosted by availability of speedy and cheap Internet connectivity.

One obvious limitation of the study, on the other hand, is gathering current data from regions where drug trials are most popular. Given the reluctance of study participants to either share their concerns with researchers or simply failure to recognize the potential harm that can be caused to themselves are reasons for serious consideration.

\section{Conclusion}

As long as humankind exists, there will be diseases, and as long as there are diseases, there will be a need to test drugs to the bring out a cure for the disease. We are skilled at formulating smart alternatives whenever we face challenges. That is how the practice of outsourcing drug trials came into being. We reviewed its history, the advantages and its shortcomings. But an unbiased review leads is to 
conclude that the advantages easily outweigh the challenges, especially because the challenges can be overcome with prudent measures that drug testing companies can undertake. As such, the author believes that one major contribution of this discussion is the ability to bring awareness of this issue within the medical and patient communities.

\section{References}

Ahmed RR, Saeed A (2014) Pharmaceutical drug promotion practices in Pakistan: Issues in ethical and non-ethical pharmaceutical practices. Middle-East Journal of Scientific Research 20(11): 1630-1640.

Ajzen I, Fishbein M (1980) Understanding attitudes and predicting social behavior. $1^{\text {st }}$ Edition. Pearson.

Alemayehu C, Mitchell G, Nikles J (2018) Barriers for conducting clinical trials in developing countries - a systematic review. International Journal for Equity in Health 17(1): 37.

Ali S, Egunsola O, Babar ZUD, Hasan SS (2018) Challenges of conducting clinical trials in Asia. International Journal of Clinical Trials 5(4): 194-199.

Angell, M. (1988). Ethical imperialism? Ethics in international collaborative clinical research. The New England Journal of Medicine 319(16): 1081-1083.

Angell M (1997) The ethics of clinical research in the Third World. The New England Journal of Medicine 337(12): 847-849.

Angell M (2000) Investigators' responsibilities for human subjects in developing countries. The New England Journal of Medicine 342(13): 967-969.

Angell M (2005) The truth about the drug companies: how they deceive us and what to do about it. Random House Incorporated.

Anglada-Martinez H, Riu-Viladoms G, Martin-Conde M, Rovira-Illamola M, Sotoca-Momblona JM, Codina-Jane C (2015) Does mHealth increase adherence to medication? Results of a systematic review. International Journal of Clinical Practice 69(1): 9-32.

Bachmann CJ, Aagaard L, Burcu M, Glaeske G, Kalverdijk LJ, Petersen I et al. (2016). Trends and patterns of antidepressant use in children and adolescents from five western countries, 2005-2012. European Neuropsychopharmacology 26(3): 411419.

Bayer R (1998) The debate over maternal-fetal HIV transmission prevention trials in Africa, Asia, and the Caribbean: racist exploitation or exploitation of racism? American Journal of Public Health 88(4): 567-570.

Bentley JP, Thacker PG (2004) The influence of risk and monetary payment on the research participation decision making process. Journal of Medical Ethics 30(3): 293-298.

Biehl J, Coutinho D, Outeiro AL (2001) Technology and affect: HIV/AIDS testing in Brazil. Culture, Medicine and Psychiatry 25(1): 87-129.

Bigorra J, Banos JE (1990) Weight of financial reward in the decision by medical students and experienced healthy volunteers to participate in clinical trials. European Journal of Clinical Pharmacology 38(5): 443-446.

Birke H, Kurita GP, Sjøgren P, Højsted J, Simonsen MK, Juel K et al. (2016) Chronic non-cancer pain and the epidemic prescription of opioids in the Danish population: trends from 2000 to 2013. Acta Anaesthesiologica Scandinavica 60(5): 623-633. 
Bonevski B, Randell M, Paul C, Chapman K, Twyman L, Bryant J et al. (2014) Reaching the hard-to-reach: a systematic review of strategies for improving health and medical research with socially disadvantaged groups. BMC Medical Research Methodology 14(1): 42.

Botbol-Baum M (2000) The shrinking of human rights: the controversial revision of the Helsinki Declaration. HIV Medicine 1(4): 238-245.

Bothwell LE, Greene JA, Podolsky SH, Jones DS (2016) Assessing the gold standard lessons from the history of RCTs. The New England Journal of Medicine 374(Jun): 2175-2181.

Chow CK, Redfern J, Hillis GS, Thakkar J, Santo K, Hackett ML et al. (2015) Effect of lifestyle-focused text messaging on risk factor modification in patients with coronary heart disease: a randomized clinical trial. Jama 314(12): 1255-1263.

Crane A, Matten D (2016) Business ethics: Managing corporate citizenship and sustainability in the age of globalization. Oxford University Press.

Crouch RA, Arras JD (1998) AZT trials and tribulations. Hastings Center Report 28(6): 26-34.

Daley GQ, Hyun I, Apperley JF, Barker RA, Benvenisty N, Bredenoord AL et al. (2001) Randomised Placebo-controlled trials and HIV-infected Pregnant Women in Developing Countries. Ethical Imperialism or Unethical Exploitation. Bioethics 15(4): 289-311.

Darrow JJ, Sarpatwari A, Avorn J, Kesselheim AS (2015) Practical, legal, and ethical issues in expanded access to investigational drugs. The New England Journal of Medicine 372(Jan): 279-286.

D'Souza J, Gurin M (2016) The universal significance of Maslow's concept of selfactualization. The Humanistic Psychologist 44(2): 210-214.

Das V (1996) Critical events: an anthropological perspective on contemporary India. USA: Oxford University Press.

Davis C, Naci H, Gurpinar E, Poplavska E, Pinto A, Aggarwal A (2017) Availability of evidence of benefits on overall survival and quality of life of cancer drugs approved by European Medicines Agency: retrospective cohort study of drug approvals 200913. BMJ 359(Oct): j4530.

De Zulueta P (2001) Randomised placebo-controlled trials and HIV-infected pregnant women in developing countries. Ethical imperialism or unethical exploitation. Bioethics 15(4): 289-311.

Fishbein M, Jaccard JJ (1973) Theoretical and methodological considerations in the prediction of family planning intentions and behavior. Representative Research in Social Psychology 4(1): 37-51.

Fishbein M, Ajzen I (1975) Belief, attitude, intention, and behavior: An introduction to theory and research. Reading, MA: Addison-Wesley Publishing Co.

Ford I, Norrie J (2016) Pragmatic trials. The New England Journal of Medicine 375(5): 454-463.

Garg S (2017) An auditor's view of compliance challenges in resource-limited clinical trial sites. Applied Clinical Trials 26(2/3).

Glickman SW, McHutchison JG, Peterson ED, Cairns CB, Harrington RA, Califf RM et al. (2009) Ethical and scientific implications of the globalization of clinical research. The New England Journal of Medicine 360(8): 816-823.

Good MJD (2001) The biotechnical embrace. Culture, Medicine and Psychiatry 25(4): 395-410.

Gould S, Friedman LF (2016) Something startling is going on with antidepressant use around the world. Tech News. 
Goyal M, Singh S, Sibinga EM, Gould NF, Rowland-Seymour A, Sharma R et al. (2014) Meditation programs for psychological stress and well-being: a systematic review and meta-analysis. JAMA Internal Medicine 174(3): 357-368.

Green JB, Bethel MA, Armstrong PW, Buse JB, Engel SS, Garg J et al. (2015) Effect of sitagliptin on cardiovascular outcomes in type 2 diabetes. The New England Journal of Medicine 373(3): 232-242.

Grigoryan L, Haaijer-Ruskamp FM, Burgerhof JG, Mechtler R, Deschepper R, TambicAndrasevic A et al. (2006) Self-medication with antimicrobial drugs in Europe. Emerging Infectious Diseases 12(3): 452-459.

Gupta A, Jamal S, Goyal S, Jain R, Wahi D, Grover A (2015) Structural studies on molecular mechanisms of Nelfinavir resistance caused by non-active site mutation V77I in HIV-1 protease. BMC Bioinformatics 16(19): S10.

Heneghan C, Goldacre B, Mahtani KR (2017) Why clinical trial outcomes fail to translate into benefits for patients. Trials 18(1): 122.

Jacob NT (2018) Drug promotion practices: a review. British Journal of Clinical Pharmacology 84(8): 1659-1667.

Jeong S, Sohn M, Kim JH, Ko M, Seo HW, Song YK et al. (2017) Current globalization of drug interventional clinical trials: characteristics and associated factors, 20112013. Trials 18(1): 288.

Jia H (2005) China beckons to clinical trial sponsors. Nature Biotechnology 23(768).

Kerin RA, Hartley SW (2018) Marketing: The Core. McGraw Hill Education.

Kohlberg L (1976) Moral stages and moralization: the cognitive developmental approach. In moral development and behavior: theory, research and social issues (Ed.), T. Lickona. New York, NY: Holt, Rinehart and Winston, 31-53.

Kordes S, Pollak MN, Zwinderman AH, Mathôt RA, Weterman MJ, Beeker A et al. (2015) Metformin in patients with advanced pancreatic cancer: a double-blind, randomised, placebo-controlled phase 2 trial. The Lancet Oncology 16(7): 839-847.

Kulkarni NG, Dalal JJ, Kulkarni TN (2014) Audio-video recording of informed consent process: boon or bane. Perspectives in Clinical Research 5(1): 6-10.

Lamb CW, Hair JF, McDaniel C (2018) MKTG. 12 ${ }^{\text {th }}$ Edition. New York: Cengage Learning.

Leon N, Surender R, Bobrow K, Muller J, Farmer A (2015) Improving treatment adherence for blood pressure lowering via mobile phone SMS-messages in South Africa: a qualitative evaluation of the SMS-text Adherence SuppoRt (StAR) trial. BMC Family Practice 16(1): 80.

Levinson DR, General I (2010) Challenges to FDA's ability to monitor and inspect foreign clinical trials. Washington, DC: Department of Health and Human Services Office of Inspector General.

Lewis JD, Habel LA, Quesenberry CP, Strom BL, Peng T, Hedderson MM et al. (2011) Clinical research ethics, oversight draw scrutiny. Applied Clinical Trials 20(4).

Lexchin J, Bero LA, Djulbegovic B, Clark O (2003) Pharmaceutical industry sponsorship and research outcome and quality: systematic review. BMJ 326(7400): 1167-1170.

Limbu YB, McKinley C, Temperini V (2018) A longitudinal examination of FDA warning and untitled letters issued to pharmaceutical companies for violations in drug promotion standards. Journal of Consumer Affairs 53(1): 3-23.

MacDonald F (2016) 80\% of data in Chinese clinical trials have been fabricated. Science Alert. Retrieved from https://www.sciencealert.com/80-of-the-data-in-chineseclinical-trial-is-fabricated.

McNeish J, Gardner JP, Wainger BJ, Woolf CJ, Eggan K (2015) From dish to bedside: lessons learned while translating findings from a stem cell model of disease to a clinical trial. Cell Stem Cell 17(1): 8-10. 
Murphy PE, Laezniak GR, Bowie NE, Klein TA (2005) Ethical marketing: basic ethics in action. Upper Saddle River, NJ: Prentice Hall.

Northouse PG (2018) Leadership: theory and practice. Sage Publications.

Paquette M, Sommerfeldt EJ, Kent ML (2015) Do the ends justify the means? Dialogue, development communication, and deontological ethics. Public Relations Review 41(1): 30-39.

Petryna A (2005) Ethical variability: drug development and globalizing clinical trials. American Ethnologist 32(2): 183-197.

Petryna A (2007) Clinical trials offshored: on private sector science and public health. BioSocieties 2(1): 21-40.

Piantadosi S (2017) Clinical trials: a methodologic perspective. John Wiley \& Sons.

Rajadhyaksha V (2010) Conducting feasibilities in clinical trials: an investment to ensure a good study. Perspectives in Clinical Research 1(3): 106-109.

Rettig RA (2000) The industrialization of clinical research. Health Affairs 19(2): 129-146.

Rothman DJ (2000) The shame of medical research. The New York Review of Books 47(19), 60-64.

Russell ML, Moralejo DG, Burgess ED (2000) Paying research subjects: participants' perspectives. Journal of Medical Ethics 26(2): 126-130.

Samuel JP, Burgart A, Wootton SH, Magnus D, Lantos JD, Tyson JE (2016) Randomized n-of-1 trials: quality improvement, research, or both? Pediatrics 138(2): e20161103.

Smith R (2012) Fortune 500 firms face unique pressures leading to ethical lapses, report reveals. The National Business Ethics Survey of Fortune 500 Employees. Retrieved from: http://ethics.org/nbes/. [Accessed 24 October 2018].

Tanner A, Kim SH, Friedman DB, Foster C, Bergeron CD (2015) Barriers to medical research participation as perceived by clinical trial investigators: communicating with rural and African American communities. Journal of Health Communication 20(1): 88-96.

Taylor RM (2013) Ethical principles and concepts in medicine. In Handbook of Clinical Neurology (Eds.), JL Bernat, R Beresford. $3^{\text {rd }}$ Series. Ethical and Legal Issues in Neurology.

Thiers FA, Sinskey AJ, Berndt ER (2008) Trends in the globalization of clinical trials. Nature Reviews Drug Discovery 7(Jan): 13-14.

Verschoor CC (2016) Lessons from the Wells Fargo scandal. Strategic Finance 98(5): 1920.

Zarin DA, Ide NC, Tse T, Harlan, WR, West JC, Lindberg DA (2007) Issues in the registration of clinical trials. JAMA 297(19): 2112-2120. 



\title{
Risk of Obstructive Sleep Apnea and Risk Factors in Patıents with Type 2 Diabetes in Turkey
}

\author{
By Ylldı Denat* \& Zeynep Güneş ${ }^{ \pm}$
}

\begin{abstract}
The study was conducted to unveil the relation between the risk of sleep apnea and risk factors for type 2 diabetes in adult patients. The sample consisted of 228 patients with type 2 diabetes. It was found out that the patients had diabetes for $10.93 \pm 7.30$ years on average, $47.4 \%$ received insulin treatment and $89.5 \%$ had no history of sleep apnea in their family. Results revealed that $58.8 \%$ of the patients had a high risk for sleep apnea, those belonging to the male gender increased the obstructive sleep apnea risk by 4-fold compared to the female gender, and a unit increase in the body mass index increased the obstructive sleep apnea risk by 1.1-fold. It was also found that having hypertension increased the risk of obstructive sleep apnea by 5-fold and the patients who experienced excessive daytime sleepiness had 11.2 times higher risk of obstructive sleep apnea.
\end{abstract}

Keywords: Diabetes, Nursing care, Obstructive sleep apnea, Sleep apnea

\section{Introduction}

Obstructive sleep apnea (OSA) is a really common disorder that is identified by recurrent episodes of upper airway obstruction developing during sleep (Garvey et al. 2015). In the studies conducted the incidence of OSA was found to be between $14 \%$ and $49 \%$ in male patients, and 9\% in females (Young et al. 1993, Garvey et al. 2015, Qie et al. 2020). In many other studies, similar prevalence rates were reported, with higher rates in males (Barve et al. 2018, Heinzer et al. 2015, Pamidi and Tasali 2012, Senaratna et al. 2017). It has been found out that there have been different risk factors in the process of OSA, but undeniably the biggest risk factor is obesity (Barve et al. 2018, Qie et al. 2020, Tishler et al. 2003, Newman et al. 2005; Senaratna et al. 2017). Obesity is also a risk factor for type 2 diabetes. Patients with type 2 diabetes have an increased risk of OSA, unfortunately, many are undiagnosed (Jehan et al. 2018). Besides, OSA is also associated with sleep-disordered breathing (SDB), insulin resistance, and glucose intolerance. It is estimated that $83 \%$ of patients with type 2 diabetes have complained of OSA (Pamadi and Tasali 2012; Barve et al. 2018, Qie et al. 2020). Cass et al. (2013) emphasized in their study that almost half of adults with type 2 diabetes may have high risk for OSA which may not have been diagnosed.

In this regard, there are a limited number of studies in Turkey. In a study, it is recommended to investigate the presence of diabetes in all patients diagnosed with OSA and to evaluate it in terms of OSA in patients diagnosed with diabetes (Binici et al. 2016).

\footnotetext{
*Associate Professor, Aydın Adnan Menderes University, Turkey.

${ }^{ \pm}$Professor, Aydın Adnan Menderes University, Turkey.
} 
It is known that the presence of OSA is not assessed routinely in individuals with diabetes. It was emphasized in an article that to prevent respiratory sleep disorder and type 2 diabetes, health professionals must pay attention to the association of these two cases in their current practice. There is a need for more data from extensive longitudinal studies in which diabetes and OSA are evaluated meticulously (Cass et al. 2013, Pamidi and Tasali 2012, Hamilton and Naughton 2013).

For this reason, this study was planned to determine the risk and risk factors of sleep apnea in the patients with type 2 diabetes.

\section{Methodology}

Study Design

The study is a cross-sectional analytical study. The study was conducted between 01/03/2016 and 15/07/2016. The population of the study consisted of the adult patients with type 2 diabetes who applied to the diabetes polyclinic of a Public Hospital located in the west of Turkey between 01/03/2016 and 15/07/2016.

\section{Participants and Setting}

The sample of the study consisted of 228 patients who accepted to participate in the study, and who were 18 years or older, cognitively competent, able to speak Turkish, and were being monitored for diagnosis of type 2 diabetes in the Diabetes Policlinic of Public Hospital between 01/03/2016 and 15/07/2016. Since there is no study that examines the relationship of patients with type-2 diabetes with OSA markers as excessive sleepiness, snoring, witnessed apnea, the effect size calculation could not be carried out in the study.

The data of study was gathered by the researchers through face-to-face interview with the patients diagnosed with type 2 diabetes in Diabetes Polyclinic of a Public Hospital located in the west of Turkey between 01/03/2016 and15/07/2016. The research data was collected by an independent researcher.

\section{Ethics Approval}

Approval was received from Adnan Menderes University Faculty of Medicine Non-Interventional Clinical Research Ethics Committee (approval no. 53043469/050.04-108). The informed consent forms were signed earlier to include the research participants.

\section{Measurement Tools}

In this study, the data were gathered by using the "Patient Information Form" and the "Berlin Questionnaire" in which the risk of sleep apnea was evaluated. 
Patient Information Form: This form was comprised of two parts. The first part collected information about the diabetes mellitus of the patients and their socio-demographic characteristics. The second part contained questions about smoking-alcohol consumption and body mass index, neck and waist circumference, hypertension, snoring and excessive daytime sleeping that are considered among the risk factors of Obstructive Sleep Apnea Syndrome (OSAS), and about other diseases which the patients have.

Berlin Questionnaire: It is a questionnaire created to screen the community for OSAS by a consensus gathered in the "First Stage Sleep Conference" held in Berlin-Germany in 1996. The validity and reliability of the "Berlin Questionnaire" in the Turkish population was carried out by Acar et al. (2013). The sensitivity of the "Berlin Questionnaire" was found as $87.9 \%$ in the study which analyzed the sensitivity of the "Berlin Form" as a screening test in OSA. The "Berlin Questionnaire" contains 10 items in three categories. The first category contains questions on snoring and witnessed apnea (5 items), the second category questions daytime sleepiness ( 4 items), while the third category asks questions on blood pressure/obesity (1 item). If the response to at least two items in the first two categories is answered as "yes," that category is considered positive (+). The third category is considered positive if the blood pressure level is answered as "yes" or if the body mass index (BMI) is $\geq 30$. If two or three categories are positive, the patient is at high risk for OSAS, and if only one category is positive, the patient is at low risk for OSAS (Acar et al. 2013, Demir et al. 2012).

\section{Data Analysis}

The data of study were examined through the Statistical Package for Social Sciences (SPSS) for Windows 11.5 package program. The results were revealed as sample number $(\mathrm{N})$, percentage $(\%)$, and significant $p$ values. Binary logistic regression analysis that it was determined which variables predicted high risk for OSA and type 2 diabetes with enter methods. Variables such as excessive sleepiness, smoking, gender, alcohol consumption, snoring were evaluated in two categories. The cut off point for excessive daytime sleepiness is considered to be equalor greater than 10 (Andrechuk and Ceolim 2015). The findings were assessed at $95 \%$ confidence interval and significance level $p<0.05$.

\section{Results}

It was found that the average age of the patients participating in the study was $54.45 \pm 11.46$ and $63.2 \%(n=144)$ of the patients were female. Most of the patients were married $(\mathrm{n}=202 ; 88.6 \%), 78.5 \%(\mathrm{n}=179)$ were primary and secondary school graduates and $80.7 \%(\mathrm{n}=184)$ did not work. A larger percentage of the patients $(n=144 ; 63.2 \%)$ had an illness other than diabetes and of this group, 38.2\% $(n=87)$ had hypertension. Nearly all the patients $(\mathrm{n}=206 ; 90.4 \%)$ did not drink alcohol, $82 \%(n=187)$ were non-smokers and 91.2\% $(n=208)$ had BMIs greater than 30. It was found that the patients had diabetes for $10.93 \pm 7.30$ years on average, $47.4 \%$ 
$(n=108)$ received insulin treatment and $89.5 \%(n=204)$ had no history of sleep apnea in their family. When the risks of OSA of the patients in this study was examined according to the Berlin Questionnaire, it was found out that $58.8 \%$ $(n=134)$ of the patients had a high risk and $41.2 \%$ (94) of the patients had no risk (Table 1).

Table 1. Risk Levels of OSA of Patients ( $n=228)$

\begin{tabular}{|l|c|c|}
\hline Risk Evaluation & N & \% \\
\hline Risk Levels According to Berlin Questionnaire & \multicolumn{2}{|l|}{} \\
\hline No Risk & 94 & 41.2 \\
\hline High Risk & 134 & 58.8 \\
\hline
\end{tabular}

Table 2. Evaluation of OSA Risk Factors through Logistic Regression Analysis $(n=228)$

\begin{tabular}{|l|c|c|}
\hline Risk Factors & Sig. & OR $(\mathbf{9 5 \%}$ CI $)$ \\
\hline Age & 0.81 & $1.005(0.966-1.045)$ \\
\hline Gender & $\mathbf{0 . 0 5}$ & $\mathbf{4 . 0 2 9}(\mathbf{0 . 9 8 5}-\mathbf{1 6 . 4 8 6})$ \\
\hline Body Mass Index & $\mathbf{0 . 0 5}$ & $\mathbf{1 . 1 1 0}(\mathbf{0 . 0 9 9 9}-\mathbf{1 . 2 3 4})$ \\
\hline Waist & 0.88 & $1.002(0.975-1.030)$ \\
\hline Neck & $\mathbf{0 . 0 0}$ & $\mathbf{1 . 3 4 4}(\mathbf{1 . 1 0 2}-\mathbf{1 . 6 4 0})$ \\
\hline Alcohol & 0.81 & $0.795(0.122-5.171)$ \\
\hline Smoking & 0.77 & $0.809(0.192-3.410)$ \\
\hline Hypertension & $\mathbf{0 . 0 0}$ & $\mathbf{5 . 7 6 0}(\mathbf{1 . 7 7 9}-\mathbf{1 8 . 6 4 4})$ \\
\hline Snoring & 0.28 & $1.764(0.619-5.028)$ \\
\hline Excessive Daytime Sleepiness & $\mathbf{0 . 0 1}$ & $\mathbf{1 . 1 3 9}(\mathbf{1 . 0 2 4}-\mathbf{1 . 2 6 7})$ \\
\hline Sleep Apnea & 0.06 & $8.418(0.846-83.752)$ \\
\hline
\end{tabular}

Table 2 shows the findings of logistic regression analysis in which the independent variables, which have significance in univariate analysis, are involved in the model. In the logistic regression analysis performed by the Enter method, the male gender has 4 times higher OSA risk than the female gender $(\mathrm{OR}=12.351$; $\mathrm{CI}=3.450-44.218 ; p=0.000)$. One unit increase in BMI increases the OSA risk by 1.1-fold (OR=1.194; $\mathrm{CI}=1.079-1.322 ; p=0.001)$. Hypertension increases the OSA risk by 5 -fold $(\mathrm{OR}=5.962 ; \mathrm{CI}=1.887-18.839 ; p=0.002)$. The risk of OSA is 11.2 times higher in the patients with excessive daytime sleepiness than in those without it $(\mathrm{OR}=11.232 ; \mathrm{CI}=1.092-115.535 ; p=0.042)$.

\section{Discussion}

OSA is a disease that is very common in patients with type 2 diabetes (Tahrani and Ali 2013). It is estimated that $83 \%$ of the patients with type 2 diabetes have laid an unspecified OSA complaint (Pamidi and Tasalini 2012). In the study carried out by Einhorn et al. (2007) it was found that in a population of 279 people enrolled in a diabetes clinic, $48 \%$ of the adults with type 2 diabetes had OSA. Vale et al. (2015) found in their study conducted using polysomnography that $63 \%$ of the patients with type 1 and type 2 diabetes had OSA. It was also 
reported that as the severity of OSA increased, glycemic control worsened. A systematic meta-analysis revealed that OSA increased the risk of developing type 2 diabetes by 2.02 -fold $(95 \%$ CI, 1.57, 2.61) (Anothaisintawee et al. 2016). In this study, the aim was to evaluate adult patients with type 2 diabetes for the risk of sleep apnea as well as its risk factors. We found that $58.8 \%$ of the patients had high OSA risk. This was similar to the results by Cass et al. (2013) where $12.5 \%$ of the patients with type 2 diabetes had been formerly diagnosed with OSA and $48.6 \%$ of the remaining patients had a high risk for OSA. It was found in many studies that OSA was connected with insulin resistance (IR) (Hermans et al. 2013) in the patients with type 2 diabetes (Rudrappa et al. 2012, Shiba et al. 2010, Altaf et al. 2013). Similar results were also detected in weak individuals supporting that the relation between IR and OSA was independent of obesity (Lin et al. 2012, Pamidi and Tasali 2012). Several studies showed that OSA and OSA severity were connected with poorer glycemic control (HbA1c and/or fasting plasma glucose) although confounders were regulated in some studies (Aronsohn et al. 2010, Barve et al. 2018, Qie et al. 2020, Drager et al. 2009, Kosseifi et al. 2010, Papanas et al. 2009, Pillai et al. 2011). OSA is thought to have a significant part in the development and growth of diabetic microvascular complications since OSA is connected with most of the pathophysiological deficits existing in diabetes (Qie et al. 2020, Altaf et al. 2013, Tahrani and Ali 2014, Tahrani et al. 2012). It is well known that the incidence of OSA in male patients is higher than in women. Most of the population-based studies show that men have 2-3 times higher prevalence of OSA (Punjabi 2008). In our study, it was also found that men had 4 times higher OSA risk than women (Table 2). In the study conducted by West et al. (2006) using the Berlin Questionnaire, 57\% of the men with type 2 diabetes were found to have high OSA risk. In the study carried out by Young et al. (1993), it was found the incidence of OSA was 24\% in males between 30-60 years and only $9 \%$ in females. Garvey et al. (2015) found the incidence of OSA in males to be between $14 \%$ and $49 \%$ while Punjabi found OSA prevalence in females to be 25\% (Punjabi 2008). In many other studies, similar prevalence rates were observed, with higher rates in males (Lee et al. 2008, Senaratna et al. 2017; Heinzer et al. 2015, Jennum and Riha 2009, Sharma et al. 2006). It seems in the studies that this gender gap narrows after menopause (Bixler et al. 2001, Sharma et al. 2006). Indeed, it is stated in the literature that sex hormones may play a critical part in the pathogenesis of OSA, that OSA is more common in postmenopausal women than in premenopausal women, and that hormone replacement therapy in postmenopausal women may be protective against the disorder (Wesström et al. 2005). Also, it is more likely that male patients are referred for clinical assessment for OSA, perhaps as physicians seem to possess a higher index of suspicion for considering the disorder in male patients.

Obesity is typically accepted as one of the biggest risk factors of OSA (Garvey et al. 2015, Newman et al. 2005, Punjabi 2008, Tishler et al. 2003, Young et al. 2005). OSA is a sleep disorder that can be treatable and is common among overweight and obese adults representing nearly two-thirds of the US population today (Young et al. 2005). In the study conducted by Vgontzas et al. (1994), 50\% of obese patients were found to have OSA, and Young et al. (2005) confirmed that 
the incidence of OSA increased by 30-60\% in obese patients. Forty-one percent of patients with a BMI more than 28 have OSA and the incidence can be as high as $78 \%$ in the patients referred for bariatric surgery (Lopez et al. 2008; Schwartz et al. 2010). It was determined in the systematic review conducted by Senaratna et al. (2017) to find out the incidence of OSA in the general population that the incidence of OSA was higher in obese male and female patients. The estimated incidence of OSA in obese adults (30-69 years) is $11-46 \%$ in female patients and $33-77 \%$ in male patients (Young et al. 2005). Furthermore, weight gain predicts the severity of increased OSA incidence (Newman et al. 2005, Peppard et al. 2000). A $10 \%$ weight gain in the individuals who initially had no OSA or moderate OSA (apnea-hypopnea index, AHI $<15$ ) increased the likelihood of developing moderate or severe OSA (AHI $\geq 15$ ) by 6-fold (95\% CI, 2-17) (Peppard et al. 2000). In the Wisconsin Sleep Cohort study, weight gain over a 4-year period was a significant predictor of OSA development; a $10 \%$ rise in body weight conferred a $32 \%$ rise in AHI and a 6-fold rise in the risk for developing moderatesevere OSA (Peppard et al. 2000). In the Sleep Heart Health Study, a multi-centre epidemiologic cohort study of cardiovascular correlates of OSA in middle-aged and older Americans, weight gain of 10 kilograms over a 5-year period conferred a 5.2- and 2.5-fold rise on the possibility of increasing the AHI by 15 events per hour in male and female patients, respectively (Newman et al. 2005). It was found in our study that one unit rise in the BMI of the patients with type 2 diabetes increased the OSA risk by 1.1 -fold (Table 2). In the study by Cass et al. (2013) BMI of the type 2 diabetes patients with high-risk of OSA was found to be greater than 30. Various studies showed a rise in OSA incidence as well as a rise in body habitus measurements (Bixler et al. 2001, Young et al. 2002). For each unit rise in the BMI, the OSA development odds ratio is 1.14 (95\% CI, 1.10-1.19). However, the impact of the BMI on OSA becomes less significant after 60 years of age (Tishler et al. 2003). The systematic compilation of general proof certifies that advancing age, male gender, and higher body mass index increase the OSA prevalence (Senaratna et al. 2017). Given the obesity pandemic in Western society, it is likely that the incidence of OSA increases further.

Population-based cross-sectional and prospective longitudinal studies have shown a firm and independent correlation in the separate measurements of OSA severity (measurements of AHI and oxygenation) in individuals with hypertension. In a cross-sectional study based on two large populations, the participants with moderate or severe OSA $(\mathrm{AHI} \geq 15)$ were found to have an odds ratio of 1.42 to 1.72 for hypertension, when compared to those without any OSA (AHI $<1.5)$, after BMI and other known variables were established (Bixler et al. 2000, Nieto et al. 2000, Qie et al. 2020). Our study also found that hypertension increased OSA risk by 5 -fold (Table 2). Cass et al. (2013) found that $96.2 \%$ of type 2 diabetes patients with high risk of OSA had hypertension. After controlling for varied known confounders (age, body habitus, baseline hypertension, alcohol, and smoking), it was determined that in comparison with the subjects without OSA, the adjusted odds ratio for hypertension was 2.03 for mild OSA (95\% CI, 1.29-3.17) and 2.89 for moderate or severe OSA (95\% CI, 1.46-5.64) (Peppard et al. 2000). Hamilton and Naughton (2013) noted in their articles evaluating OSA impact on diabetes 
and cardiovascular diseases that people with diabetes, stroke, cardiovascular disease, and uncontrolled hypertension were at high risk for OSA and stressed that OSA symptoms, need be questioned in these patients.

Snoring, excessive daytime sleepiness and witnessed apnea are three prevalent symptoms of OSA (Gupta and Wang 2016, Lee et al. 2017). In our study, OSA was found to be 11.2 times higher in the patients who experienced excessive daytime sleepiness than in those who did not (Table 2). The study by Cass et al. (2013) revealed that $64.5 \%$ of type 2 diabetes patients with high risk of OSA had excessive daytime sleepiness. A prospective cohort study of type 2 diabetes patients found the prevalence of excessive daytime sleepiness to be $35 \%$ (Vasconcelos et al. 2016), while in another study conducted on patients with type 1 and type 2 diabetes, the prevalence of excessive daytime sleepiness was $20.7 \%$ in the group with OSA (Vale et al. 2015).

\section{Study Limitations}

This study had some limitations. Firstly, the results of this study were limited to the patients participating in the study and cannot be generalised. Secondly, Berlin Questionnaire was used in this study. For this reason, the findings were based on the individuals' own statements. Furthermore, the absence of a control group caused limitations in the discussion of the results. The confounding factor of this study is the fact that the people, who apply to the hospital, do not have a specific universe, and the sample consists of those who apply to the hospital. Therefore, confounding factors may be higher than expected in our study.

\section{Conclusions}

The results in this study are helpful for clinical practice. They revealed that the adult patients with type 2 diabetes had high risk for OSA and those belonging to the male gender; increase in BMI, hypertension and excessive daytime sleepiness were important factors for OSA risk.

\section{References}

Acar V, Kaya, Yücel F, Erdem, M, Günal SE, Özgen F et al. (2013) Validation of the stop-bang questionnaire: an obstructive sleep apnoea screening tool in Turkish population. Turkish Journal of the Anaesthesiology and Reanimation 41(4): 115-120.

Altaf Q, Dodson PM, Ali A, Raymond NT, Fellows H, Hampshire M et al. (2013) Obstructive sleep apnoea is associated with sight threatening retinopathy and predicts the development of pre proliferative and retinopathy in patients with type 2 diabetes: a longitudinal analysis. Diabetic Medicine 30: E5-E5.

Andrechuk CRS, Ceolim MF (2015) Sleep quality and adverse outcomes for patients with acute myocardial infarction. Journal of Clinical Nursing 25(1-2): 223-230. 
Anothaisintawee T, Reutrakul S, Cauter EV, Thakkinstian A (2016) Sleep disturbances compared to traditional risk factors for diabetes development; systematic review and meta-analysis. Sleep Medicine Reviews 30(Dec): 11-24.

Aronsohn RS, Whitmore H, Van Cauter E, Tasali E (2010) Impact to fun treated obstructive sleep apnea on glucose controlin type 2 diabetes. American Journal of Respiratory and Critical Care Medicine 181(5): 507-513.

Barve K, Desai U, Jashi JM (2018) Obstructive sleep apnea and diabetes mellitus: a bitter combo. Indian Sleep Medicine 13(3): 48-52.

Binici DN, Kayabekir M, Timur Ö, Taşar PT, Kaygın MA, Arslan Z et al. (2016). Type 2 diabetes mellitus rate in patients diagnosed with obstructive sleep apnea syndrome. Turkiye Klinikleri Journal of Internal Medicine 1(2): 71-75.

Bixler EO, Vgontzas AN, Lin HM, Ten Have T, Leiby BE, Vela-Bueno A et al. (2000) Association of hypertension and sleep-disordered breathing. Archives of Internal Medicine 160(15): 2289-2295.

Bixler EO, Vgontzas AN, Lin HM, Ten Have T, Rein J, Vela-Bueno A et al. (2001) Prevalence of sleep-disordered breathing in women: effects of gender. American Journal of Respiratory and Critical Care Medicine 163(3): 608-613.

Cass AR, Alanson WJ, Islam J, Weller SC (2013) Risk of obstructive sleep apnea in patients with type 2 diabetes mellitus. Family Medicine 45(7): 492-500.

Demir A, Ursavaş A, Aslan AT, Gülbay B, Çiftçi B, Çuhadaroğlu Ç et al. (2012) Türk toraks derneği obstrüktif uyku apne sendromu tanı ve tedavi uzlaşı raporu (Turkish thoracic society obstructive sleep apnea syndrome diagnosis and treatment consensus report). Turkish Thoracic Journal 13(1): 1-73.

Drager LF, Queiroz EL, Lopes HF, Genta PR, Krieger EM, Lorenzi-Filho G (2009) Obstructive sleep apnea is highly prevalent and correlates with impaired glycemic control in consecutive patients with the metabolic syndrome. Journal of the Cardiometabolic Syndrome 4(2): 89-95.

Einhorn D, Stewart D, Erman M, Gordon N, Philis-Tsimikas A, Casal E (2007) Prevalence of sleep apnea in a population of adults with type 2 diabetes mellitus. Endocrine Practice 13(4): 355-362. DOI: 10.4158/EP.13.4.355.

Garvey JF, Pengo MF, Drakatos P, Kent BD (2015) Epidemiological aspects of obstructive sleep apnea. Journal of Thoracic Disease 7(5): 920-929.

Gupta S, Wang Z (2016) Predictors of sleep disorders among patients with type 2 diabetes mellitus. Diabetes Metabolic Syndrome 10(4): 213-220.

Hamilton GS, Naughton MT (2013) Impact of obstructive sleep apnoea on diabetes and cardiovascular disease. Medical Journal of Australia 199(8): 27-30.

Heinzer R, Vat S, Marques-Vidal P, Marti-Soler H, Andries D, Tobback N et al. (2015) Prevalence of sleep-disordered breathing in the general population: the hypnolaus study. Lancet Respiratory Medicine 3(4): 310-318.

Hermans MP, Ahn SA, Mahadeb YP, Rousseau MF (2013) Sleep apnoea syndrome and 10 -year cardiovascular risk in females with type 2 diabetes: relationship with insulin secretion and insulin resistance. Diabetes/Matabolism Research and Reviews 29(3): 227-234.

Jehan S, Myers AK, Zizi F, Pondi-Perumal SR, Jean-Louis G, McFarlane DI (2018) Obesity, obstructive sleep apnea and type 2 diabetes mellitus: epidemiology and pathophysiologic insights. Sleep Medicine and Disorders: International Journal 2(3): 54-60.

Jennum P, Riha RL (2009) Epidemiology of sleep apnoea/hyponoea syndrome and sleepdisordered breathing. European Respiratory Society 33(4): 907-914. 
Kosseifi S, Bailey B, Price R, Roy TM, Byrd RP, Peiris ANJ (2010) The Association between obstructive sleep apnea syndrome and microvascular complications in wellcontrolled diabetic patients. Military Medicine 175(11): 913-916.

Lee W, Nagubadi S, Kryger MH, Mokhlesi B (2008) Epidemiology of obstructive sleep apnea: a population-based perspective. Expert Review of Respiratory Medicine 2(3): 349-364.

Lee YH, Kweon SS, Choi JS, Nam HS, Park KS, Choi SW et al. (2017) Genderspecific association between self-reported snoring and hemoglobin Alc levels in a general population without type 2 diabetes mellitus. Yonsei Medical Journal 58(6): 1152-1159.

Lin QC, Zhang XB, Chen GP, Huang DY, Din HB, Tang AZ (2012) Obstructive sleep apnea syndrome is associated with some components of metabolic syndrome in nonobese adults. Sleep \& Breathing 16(2): 571-578.

Lopez PP, Stefan B, Schulman CI, Byers PM (2008) Prevalence of sleep apnea in morbidly obese patients who presented for weight loss surgery evaluation: more evidence for routine screening for obstructive sleep apnea before weight loss surgery. The American Journal of Surgery 74(9): 834-838.

Newman AB, Foster G, Givelber R, Nieto FJ, Redline S, Young T (2005) Progression and regression of sleep-disordered breathing with changes in weight: the sleep heart health study. Archives of Internal Medicine 165(20): 2408-2413.

Nieto FJ, Young TB, Lind BK, Shahar E, Samet JM, Redline S et al. (2000) Association of sleep-disordered breathing, sleep apnea, and hypertension in a large communitybased study sleep heart health study. JAMA 283(14): 1829-1836.

Pamidi S, Tasali E (2012) Obstructive sleep apnea and type 2 diabetes: is there a link? Frontiers in Neurology 13(3): 126.

Papanas N, Steiropoulos P, Nena E, Tzouvelekis A, Maltezos E, Trakada G et al. (2009) HbA1c is associated with severity of obstructive sleep apnea hypopnea syndrome in nondiabetic men. Journal of Vascular Health and Risk Management 5(Sep): 751-756.

Peppard PE, Young T, Palta M, Dempsey J, Skatrud J (2000) Longitudinal study of moderate weight change and sleep-disordered breathing. JAMA 284(23): 3015-3021.

Pillai A, Warren G, Gunathilake W, Idris I (2011) Effects of sleep apnea severity on glycemic control in patients with type 2 diabetes prior to continuous positive airway pressure treatment. Diabetes Technology and Therapeutics 13(9): 945-949.

Punjabi NM (2008) The epidemiology of adult obstructive sleep apnea. Proceeding of the American Thoracic Society 5(2): 136-143.

Qie R, Zhang D, Liu L, Yongcheng R, Zhao Y, Liu D et al. (2020) Obstructive sleep apnea and risk of type 2 diabetes mellitus: a systematic review and dose-response meta-analysis of cohort studies. Journal of Diabetes (Dec): 1-10.

Rudrappa S, Warren G, Idris I (2012) Obstructive sleep apnoea is associated with the development and progression of diabetic retinopathy, independent of conventional risk factors and novel biomarkers for diabetic retinopathy. British Journal of Ophthalmology 96(12): 1535.

Schwartz AR, Patil SP, Squier S, Schneider H, Kirkness JP, Smith PL (2010) Obesity and upper airway control during sleep. Journal of Applied Physiology 108(2): 430-435.

Senaratna CV, Perret J, Lodge CJ, Lowe AJ, Campbell BE, Matheson MC et al. (2017) Prevalence of obstructive sleep apnea in the general population: a systematic review. Sleep Medicine Reviews 34(Jul): 70-81.

Sharma SK, Kumpawat S, Banga A, Goel A (2006) Prevalence and risk factors of obstructive sleep apnea syndrome in a population of Delhi, India. Chest 130(1): 149-156. 
Shiba T, Maeno T, Saishin Y, Hori Y, Takahashi M (2010) Nocturnal intermittent serious hypoxia and reoxygenation in proliferative diabetic retinopathy cases. American Journal of Ophthalmology 149(6): 959-963.

Tahrani AA, Ali A (2013) Obstructive sleep apnea and diabetes: an update. Current Opinion in Pulmonary Medicine 19(6): 631-638.

Tahrani AA, Ali A (2014) Oxidative stress, inflammation and endothelial dysfunction: the link between obstructive sleep apnoea and vascular disease in type 2 diabetes. In I Obrosova, MJ Stevens, A Yörek (ed.), Studies in Diabetes, 149-171. New York: Springer.

Tahrani AA, Ali A, Raymond NT, Begüm S, Dubb K, Mughol S et al. (2012) Obstructive sleep apnea and diabetic neuropathy: a novel association in patients with type 2 diabetes. American Journal of Respiratory and Critical Care Medicine 186(5): 434 441.

Tishler PV, Larkin EK, Schluchter MD, Redline S (2003) Incidence of sleep-disordered breathing in an urban adult population: the relative importance of risk factors in the development of sleep disordered breathing. JAMA 289(17): 2230-2237.

Vale J, Manuel P, Oliveira E, Oliveira AR, Silva E, Melo V et al. (2015) Obstructive sleep apnea and diabetes mellitus. Revista Portuguesa de Pneumologia 21(2): 55-60.

Vasconcelos JP, Daniele TMC, Bruin PFC, Forti AC, Bruin VMS (2016) Daytime Sleepiness in patients with type 2 diabetes mellitus - a prospective cohort study. International Archives of Medicine Section: Endocrinology 9(228): 1-10.

Vgontzas A, Tan T, Bixler E, Martin L, Shubert D, Kales A (1994) Sleep apnea and sleep disruption in obese patients. Archives of Internal Medicine 154(15): 1705-1711.

Wesström J, Ulfberg J, Nilsson S (2005). Sleep apnea and hormone replacement therapy: a pilot study and a literature review. Acta Obstetricia et Gynecologica Scandinavica 84(1): 54-57.

West SD, Nicoll DJ, Stradling JR (2006) Prevalence of obstructive sleep apnoea in men with type 2 diabetes. Thorax 61(11): 945-950.

Young T, Palta M, Dempsey J, Skatrud J, Weber S, Badr S (1993) The occurrence of sleep-disordered breathing among middle-aged adults. The New England Journal of Medicine 328(17): 1230-1235.

Young T, Shahar E, Nieto FJ, Redline S, Newman AB, Gottlieb DJ et al. (2002) Predictors of sleep-disordered breathing in community-dwelling adults: the sleep heart health study. Archives of Internal Medicine 162(8): 893-900.

Young T, Peppard PE, Taheri S (2005) Excess weight and sleep-disordered breathing. Journal of Applied Physiology 99(4): 1592-1599. 


\title{
Prolonged Humanitarian Crises - Mental Health in a Refugee Setting at the Thai-Myanmar Border
}

\author{
By Peter Kaiser* , Marie T. Benner ${ }^{ \pm}$\& Kai Pohlmann
}

\begin{abstract}
Since 1945 there is systematic research on the psychological impact of traumata in the context of war and forced migration on the affected populations especially concerning post-traumatic stress disorder and related disorders. The so-called Hill tribes of Myanmar, living as long-term refugees at the Thai-Myanmar border are facing destroyed expectations for a better future. Non-governmental organizations as well as responsible stakeholders in the self-organizations of the camps should be alert about psychosocial problems and their manifestations like domestic violence, suicidal ideations/attempts, drug and alcohol abuse as well as social withdrawal. The mental health service should be encouraged to focus not only on sickening and the negative coping with stress and the feeling of uselessness, helplessness, hopelessness, but on salutogenetic aspects of mental health and psychosocial problems and the way people are coping with in a positive way. Resilience is a factor, easily overlooked by health care providers, especially in situations, which make people depending on help.
\end{abstract}

Keywords: Resilience, Long-term refugee settings, Mental health, Humanitarian aid

\section{Introduction}

The aim of this article is to describe the specific situation of a displaced ethnic group in a remote rural area in Southeast Asia, with focus on the mental health of those affected, the risk factors that arise due to the living situation and the existing resources and resistance factors acquired during the displacement. The article presents interventions that are supposed to improve the mental and general health of the affected population and would like to point out possible difficulties in working with them.

The structure of this article is as follows; in the first part, a brief overview of global perspective on mental health in humanitarian crises is given. The following is a description of the specific setting at the Thai-Myanmar border with an overview of the living conditions of the Karen ethnic group, to which this article is dedicated. The first part ends with a description of the procedure.

Then it is introduced the topic of mental health in general and in refugees, followed by a description of the mental health in the refugees in the camps at the Thai-Myanmar border. Furthermore, psychotherapeutic interventions in post-traumatic stress disorders (PTSD) and related disorders and the role of expectations and causal-attribution in mental health are discussed. The second part concludes with an analysis of the sustainability of Mental Health Psycho-

\footnotetext{
*Medical Director, Swiss Red Cross, Switzerland.

${ }^{ \pm}$Free Consultant in Nutrition and Public Health, Switzerland.

${ }^{*}$ Program Manager, Malteser International Cologne, Germany.
} 
social Support (MHPSS) services. The mentioned observations are discussed and the article closes with the conclusion.

\section{The Global Perspective on Mental Health in Humanitarian Crises}

Since 1945 there is systematic research on the psychological impact of traumata in the context of war and forced migration on the affected populations. Main disorders are anxiety disorders including phobias, and its special form of occurrence: PTSD; depressive disorders (withdrawal, apathy, guilty feelings); suicidal thoughts and attempts; anger, aggression and violent behavior (often towards spouse or children); drug and alcohol abuse; (jealous) delusions; mistrust; hysterical symptoms; somatization disorders and insomnia.

In the course of the Vietnam War, the interest in mental health grew - not only regarding the refugee populations but especially in the US health authorities, being confronted with returning traumatized combatants. Starting from 1975, around 3 million Vietnamese boatpeople found a home away from home in western countries, but the conditions for refugees have continued to worsen since then (Jablensky et al. 1994, Kinzie and Boehnlein 1989, Kinzie et al. 1990, Kinzie and Jaranson 1998, Krupinski et al. 1973).

Nowadays a refugee is waiting an average of 18 years in a refugee camp (Milner 2012) with the young generation does not know a different existence than being a refugee. Dadaab, a vast refugee camp in Kenya is the worst example of long-term detention, as it houses families that have been sequestrated in a remote and insecure location for more than three generations (Silove et al. 2017). It is estimated that half of the world's over 65 million people who are forcefully displaced from their homes as internally displaced persons (IDPs) within their countries or refugees who have crossed an international border, remain in "protracted situations," unstable and insecure locations, most commonly in dense urban areas, but also in refugee camps, increasing often for a long time.

The so-called Hill tribes of the northern and eastern regions of Myanmar, the former Burma, are only another not so well-known example of a prolonged humanitarian crisis. Other refugees from tribes such as the Shan, Karenni, and Karen are living as internally displaced persons in Myanmar for about 3 decades or have been forced to migrate across the green border into Thailand.

\section{The Setting at the Thai-Myanmar Border-The Displaced Population of the Karen}

Since 1976, the civil war between ethnic minorities and the military regime in Myanmar (Burma) has resulted in a mass influx of refugees and migrants into neighboring Thailand, Bangladesh and India. Flight to these countries continues for those forcibly expelled from the conflict zones. Approximately 100,000 refugees live in nine refugee camps (by the Thai government referred as temporary shelter (https://www.burmalink.org/background/thailand-burma-border/displaced- 
in-thailand/refugee-camps/) along the Thai-Myanmar border (TBC 2018), with the Karen People as the largest ethnic group, comprising $80.1 \%$ of the total population).

About $30 \%$ of the population is young people between 10-24 years who have grown up isolated in this closed setting and with little access to the outside world, information, education and a notable aid dependency as well as facing boredom, an unclear future and unhappiness. Formal education is limited to ten years of schooling, while job opportunities and access to universities as well as other forms of higher education are very limited. Traditional social norms and religion (Burmese Theravada Buddhists, Christian or Animists) do strongly influence the daily life and behavior of the refugee population (Benner et al. 2010).

The refugees are fully depending on Thai and international support for shelter, food, education, water/sanitation and health services, while income opportunities are limited (Benner et al. 2008). Malteser International (MI) has a long history of working in Asia and has been implementing a health project for Karen and Myanmar refugees along the Thai-Myanmar border already since 1993, funded by the European Union (Europe Aid and European Commission Humanitarian and Civil Protection Office).

A comprehensive Primary Health Care project was implemented with curative, preventive and promotional components. The aim was and is to limit the risk of epidemics, reduce mortality and morbidity and if needed and feasible strengthen further the capacity and capability of the camp community for selfreliance and sustainability, once the people return back to Myanmar. Since 2004 resettlement to different countries like US, Canada, Norway, Australia, is taking place, not only providing a chance for registered refugees to leave the camps, but also aiming at a reduction of the camps' population. Since several years, refugees are encouraged to repatriate, i.e., the (voluntary) returning to (former villages in) Myanmar. One of the greatest obstacles the refugees are facing when returning to their home country or being resettled is the fact that they have to be self-reliable and stand on their own feet. This special condition of "imposed helplessness" is the result of the increased humanitarian assistance started in the mid-nineties to support the increasing number of refugees to ensure sufficient services and to avoid disease outbreaks (Benner et al. 2008). However, there are different ways to cope with these uncertainties by considering the sociocultural and religious background of the Karen People as traditional social norms and religion strongly influence the daily life and behavior of the refugee population (Keenan 2010, Benner et al. 2010). The majority of Karen in Myanmar is Theravada Buddhists, who also practice animism, while approximately 35\% are Christian (Karen Buddhist Dhamma Dutta Foundation 2010).

MI is providing health services as well as the covering the water and sanitation needs (including waste management) for two camps: Ban Mae La-Oon (MLO) and Mae Ra Ma Luang (MRML). MLO camp is located in Sop Moei district about $80 \mathrm{~km}$ south of Mae Sariang (the base for Malteser International), about $5 \mathrm{~km}$ from MRML camp and about $4 \mathrm{~km}$ from the border to Myanmar. The camp is located in a degraded, hilly environment, with one access road. The population was up to 17,000 and is now at 11,700 (2018), mainly from Papun township. MRML camp is located in Sop Moei district as well, about $75 \mathrm{~km}$ south 
of Mae Sariang, located in a similar setting like MLO camp with equally difficult access during the rainy season. The camp is accessible via two roads. The camp is spread over an area of approximately $4 \mathrm{~km}$ along the Yuam River. The population was up to 17,000 in 2009 and is currently 13,000 people (2018).

The United Nations Refugee Convention (1951) and later Protocol (1967) proclaimed that host countries have a responsibility to provide "favourable" conditions for refugees, including, inter alia, the right to work, to freedom of association and movement, and to appropriate services.

The large exodus of Southeast Asian refugees in the 1970s and 1980s created a new challenge for the Convention (Ghosh 2016). The willingness of recipient countries to accept refugees was and is not only in Europe inversely related to the rate of influx and ethnic and religious difference of the incoming group (Joly 2016). This, and additionally due to experience with the preceding influx of the refugees of Vietnam, Cambodia and Laos, the difficulties of the Thai government to handle the situation along their Burmese border properly, is at least somewhat comprehensible. In consequence of the Thai as well as Burmese politics, refugees were made to the problem and not to a part of the solution.

The policies applied to refugees by host countries are crucial to the mental health of that population. It had never happened that the Karen refugees were integrated into the Thai national health system, although the refugees have been living on Thai soil since the 90s of the last century, a precondition for making the humanitarian system relevant for future public health responses (Spiegel 2017).

\section{Mental Health in Refugees}

Since 2000 approaches to a better integration of mental health services into the general health sectors had been named, like using the schools for promoting mental health, integration of mental health services within the Primary Health Care System, inventing urban based programmes like the Healthy City projects, the introduction of psychiatric wards in general hospitals or the replacement of large hospital for mental disorders with community mental health centres (Mohit 2001). Against the background of the importance of mental health for refugees, a wide adoption of influential policies and guidelines that assist the planning and implementation of programs, for example, the Inter-Agency Standing Committee (IASC) Guidelines for Mental Health and Psychosocial Support in Emergency Settings and the SPHERE handbook had taken place (Batniji et al. 2006, IASC 2007). A further major achievement has been the clinical guidelines produced by the WHO's mh-GAP, especially the module focusing on emergencies (WHO 2015, WHO 2013). Disregarding its efficiency in acute humanitarian crises, the mh-GAP always has to be contextually and culturally adapted to local needs.

This also applies to prolonged humanitarian crises. Here, under confined conditions, with a prospectively unclear ending, the coping mechanisms of the affected population become exhausted over the years, as it is known from to some extent comparable settings like the in Palestinian refugees (Afana et al. 2004). 
Traumatic events such as war, displacement, loss of loved ones (negative life events) or stress in daily life can trigger this predisposition (or "weak points") for mental disorders like psychosis (schizophrenia or major depression or mania) or can cause milder forms of mental disorder (without psychotic symptoms) like minor depression, anxiety, and others. But: "the depressive syndrome represents a small fraction of the entire field of depressive phenomena. It is a cultural category constructed by psychiatrists in the West to yield a homogeneous group of patients." (Kleinman 1977). Mental health has to be considered as being deeply interwoven with economic and political concerns, such as poverty, hunger and malnutrition, violence, social change and dislocation (Desjarlais et al. 1995). It is needless to mention that mental health mirrors to a large extend "healthy" social (and environmental) conditions.

Subject of mental health is behaviour of people. Ultimately the doctors/ medics task is to answer the question: "Is this behaviour normal?" This question lies at the heart of cross-cultural psychiatry, which must determine normality in its cultural context.

Compared to the common infectious diseases in the study area, which can mostly be cured by modern medicine, mental health disorders are often persistent and sometimes require lifelong treatment, particularly for high levels of symptoms of PTSD, major depression, schizophrenia etc. These disorders regularly require a combination of medical, psychological, social, and legal intervention. In order for mental health care to be effective, it is essential that primary health care serve as the main health service infrastructure. The challenge is to orientate and train primary health care workers in mental health skills and services, including diagnosis and therapy. Mental health services should be closely coordinated with general health services, psychosocial services, and other relevant rehabilitation, social, educational, occupational, cultural, and recreational activities. Mental health services should be community based, and, wherever possible, focus on early intervention at the primary and later at the secondary and tertiary levels of prevention (Patel 2002).

Too often, medical anthropologists and sociologists accuse psychiatrists of transforming social problems into medical conditions. Yet social scientists who place illness entirely in the social realm deny the personal dimension, the personal experience of suffering (Kleinman and Kleinman 1991). Confessing that there are improvements in these areas, still the problem of acceptance of all of these approaches by the refugee population is unsolved. Only a holistic approach in mental health, which encloses apart from the bio-psycho-social sides and other additional dimensions, like cultural and spiritual can increase the understanding on both sides of the table.

Refugees are particularly at risk of developing mental disorders due to traumatic pre-migration experiences and events while migrating, like the loss and separation from related people and the hardships while migrating and when finally arriving at a host country. The threat or loss of the security system, in terms of its own physical integrity or that of loved ones, makes it even more difficult to stay mentally healthy (Lipson 1993, Ekblad and Silove 1998). Further factors associated with poor mental health amongst refugees include beside socio- 
demographic characteristics and stressors in the post-displacement environment, the circumstances of prolonged detention, insecure residency status, challenging refugee determination procedures, restricted access to services, and lack of opportunities to work or study. All these straits are capable to compound the effects of past traumas in exacerbating symptoms of PTSD and depression (Silove et al. 2017). In refugee settings, the loss of human rights by threatening fundamental rights as there are arbitrary or unjust treatment, prohibition of expression or belief, persecution, use of force, torture is accompanied by the elimination of stable social framework. The meaningfulness of life is questioned, leading to existential crisis of meaning, as well as to endangerment of individual and social identity.

According the International Classification of Diseases (ICD-10), the PTSD (F43.1) has to be diagnosed when the onset of symptoms occurs within 6 months after the traumatizing event. A "probable" diagnosis can be made even if the interval is more than 6 months, provided the clinical features are typical and no other diagnosis can be made (anxiety, obsessive-compulsive disorder or depressive episode). In addition to the event of a trauma typical additional symptoms are repeated inescapable memory or re-enactment of the event in memory, daydreaming or dreams (flashback); significant emotional withdrawal, emotional numbing, avoidance of similar stimuli are common, but not essential for the diagnosis. In the case of persistence of complaints, the diagnosis of a persistent personality change after extreme stress ICD-10 F62.0 should applied, which is defined by new arising symptoms and persisting for at least 2 years in the person concerned. The severity of symptoms of PTSD patients correlates with the number of traumas suffered (Smith-Fawzi et al. 1997, Mollica et al. 1997).

The body of research conducted after disasters in the past three decades suggests that the burden of PTSD among persons exposed to disasters is substantial. Post-disaster PTSD is associated with a range of correlates including sociodemographic and background factors, event exposure characteristics, respective scenarios in crises, war and flight/forced migration, social support factors and personality traits. Relatively few studies have employed longitudinal assessments enabling documentation of the course of PTSD. There are no universal valid data on the prevalence of PTSD and other trauma-related mental health disorders. The frequencies of PTSD after following scenarios are 50-65\% after direct war experiences with personal danger; 50-55\% after rape and sexual abuse; $3-11 \%$ after traffic accidents; approx. 5\% after natural disasters, fire, and fire disasters; and 2-7\% in witnesses of accidents and violence (Neria et al. 2008). The prevalence of PTSD in refugee camps had been located between 4\% and 20\% (Silove 1999), in earlier studies up to 50\% (Kinzie and Boehnlein 1989, Mollica et al. 1993), while recent studies yielded a prevalence rate for PTSD to 15\%, correcting the tendency to regard all refugees as "traumatized" and in need of counselling (Priebe et al. 2016) Actually, it seems not possible to specify an empirical criterion by means of which traumatic and non-traumatic life events can be differentiated (Dobricki and Maercker 2010). Sack (2004) suggested the complex PTSD, which includes disturbances of affect-regulation, sexuality, selfperception, relationship formation, dissociative symptoms, somatization, changing 
personal beliefs and values, should be taken into consideration. The proposal of a complex PTSD category that comprises three clusters of intra- and interpersonal symptoms in addition to core PTSD symptoms by Karatzias et al. (2017) will be included into the ICD-11.

Failure to include indigenously derived measures that capture local expressions or idioms of distress also can lead to the under-enumeration of mental health problems (Kaiser and Benner 2003). To estimate the need for mental health services needs also to bear in mind that due to stigmata, there is an underreporting of mental and psychosocial problems, and help-seeking behavior. Mistrust in western mental health specialists and lack of knowledge of services may limit the extent to which refugees access mental health services, even if available. The sources of cultural and individual identity have to be taken into consideration (Groen et al. 2017), as these are typically endangered in prolonged crises. Particular men define themselves over income or the ability to feed and care for their families. In a refugee setting the role/position within the family, the social status in the community and the entire social context with changing of internal and external values of an ethnic group due to the close contact with members of foreign cultures and the dependence on them can be severely threatened.

Mental health services are lower in developing than in developed countries, as the proportion receiving services tended to correspond to countries' percentages of gross domestic product spent on health care (Wang et al. 2007). The main reason for this is the scarcity and inequitable distribution of services, but other factors contribute to the situation, including difficulties in coordinating national and international efforts, barriers to accessing care even when services are available, and persisting stigma associated with being both a refugee and mentally ill (Silove 2005). However, the evidence base for MHPSS interventions in stable settings is generally weaker than for the other topics like infectious diseases and so it is less possible to generalize findings to crisis-affected settings (Blanchet et al. 2017). Therefore, a substantially greater number of MHPSS intervention studies are required from these settings (Tol et al. 2011). Most studies focused predominantly on psychological interventions (for PTSD, in particular). Particular disorders that seem to be neglected include alcohol and other substance use disorders and there is also very little evidence on how interventions influence overall functioning (as opposed to specific mental disorders) (Porter and Haslam 2005). The same can be said about other stress-related behaviors like aggression (especially in the form of domestic violence) and social withdrawal. Only a small number of studies have followed up refugees for 10 years or longer, in all instances being limited to the measurement of general symptoms of anxiety and depression using screening instruments (Hauff and Vaglum 1995, Lie 2002, Beiser and Hou 2001).

\section{Mental Health in the Refugees in the Camps at the Thai-Myanmar Border}

The basic idea, the aim of the article is to point out the meaningfulness and necessity of MHPSS in settings like the one described. Especially in long-term refugee settings, after extensive control of communicable diseases, consideration 
of mental health is of great importance. Up to 2015, the psychological state of the presented population was paid less attention, apart from data on suicidality. For this reason, the data situation is scarce, so that the primary concern here is to point out the shortage and to induce a corresponding awareness among the organizations active in the health sector.

This section describes the way data on the mental health in the refugees in the camps were gained, and what procedures were implemented to improve the health conditions.

Health indicators should give reliable information about the conditions of the health sub-sector it covers. The indicators may be the result of quantitative and/or qualitative methods of evaluation and monitoring. The more quantitative data are available, the better the indicators can be compared to other data collections in other settings or of other cohorts.

Until recently (2015) no data were collected on mental health beside suicide rates in the both temporary shelters supported by MI. This neglect can be explained to some extent by lack of interest in donors, no trained health workers and doctors, preoccupation with others, more obvious health problems like infections, hygiene, mother and child health, and underreporting of mental health disorders due to stigmatization.

In this setting at the Thai-Myanmar border, from relevant mental health indicators like suicide rates, prevalence of psychosis and other mental disorders, drug and alcohol consumption (and related morbidity and lethality), domestic violence, prescription of psychotropic drugs etc., only data on suicide rates, recently implemented mental health services and the results of a KAP-B-Survey are available. There is probably an underreporting of domestic violence to the health services, and there was an underreporting of mental disorders, caused to the classification of these diseases under the category of "chronic disorders" before training took place in 2015.

The Health Information System (HIS, version revised January 2010) is designed to monitor primary health care services in a protracted refugee context in order to be able to detect epidemics and outbreaks early. Beside general reports on morbidity and mortality, several other, more specific HIS-data-reports like Injury Report, Nutrition Report, HIV/AIDS-Report etc., including a report on Mental Illness are generated with a special HIS toolkit. The data collection should get an overview on the psychosocial condition of the screened population. As mentioned, until 2015, mental health was not in the focus. Further reasons, why prevalence of moderate mental disorders (moderate depression and anxiety) can only be estimated, is underdiagnosing, as somatisation is quite regularly a way to cope with mental problems. In contrast, patients with acute episodes of psychosis like schizophrenia, are predominantly brought to Outpatient Department (OPD) and therefore detected. Contradictory to the former prevalent idea, that the prevalence of schizophrenia is worldwide more or less the same, schizophrenia and other psychotic disorders can be triggered by stressful life-events. It is known that these are more prevalent amongst refugees, resettled in high-income countries compared to other immigrants and host populations (Hollander et al. 2016). 
According to the data for quarterly reports to the Thai Ministry of Interior (Health Care Project for Uprooted People in Sob Moie District, Northern Thailand) and annual reports to ECHO (European Commission Directorate General for Humanitarian Aid: Health Project for Karen and Burmese Refugees along the Thai-Myanmar Border), between 2006 and 2009, the suicide rates varied in both camps between 0 and 4 per camp per year. Regarding the population of MLO with 11,700 refugees and MRML with 13,000 refugees respectively, the annual suicide rates between 2010 and 2016 fluctuated between 1 case per year (equivalent to 10 per 100,000) and up to 9 casualties per year, corresponding to 77 in 100,000), with an increase in the last 2 years. In comparison: the suicide rate worldwide in 2015 was 10.7 per 100,000. Thailand had a suicide rate of 6.8 in 2014 (7.8 in 2002), while Germany had a suicide rate of 12.5 (in 2013) (WHO 2018).

Due to the small total population in the camps and confounding influences (frequent drowning cannot be differentiated, whether it was an accident or suicide), the data on suicides should only be carefully interpreted as indicator of a deteriorating mental health situation - despite the MHPSS trainings which had taken place the last 3 years in the camp. Part of the staff estimates that there is even an underreporting of suicidal attempts due to shame. The problem of rising numbers of reported suicides in the 9 refugee camps along the Thai Myanmar border was even worth an article in the Bangkok Post 2017 quoting, that "family problems were a factor in nearly half of suicides. Alcohol and substance abuse played a role in more than a third." (Bangkok Post 2017).

As the data on suicide have to be interpreted very carefully, it cannot be stated, that these suicides are a sign of loss of hope, as the motivations are not always well known, and are frequently related to family-problems. Religions in general are promoting life (at least the life of their followers), therefore condemning suicide. It can only be speculated, that religious belief in the camps has a preventing impact on the decision of the individuals to end one's life. May be without the reported strong belief, even more people would commit suicide.

Beside the data on prevalence and incidence of mental disorders, further indicators are the quality and quantity of MHPSS provided by trained helpers including campaigns to raise awareness and tolerance as well as the knowledge on this subject in the population.

In 2015 and 2016 the first one week-trainings in mental health services and psychosocial support for the medical staff by the author, a psychiatrist and psychotherapist, took place, aiming to improve psychosocial wellbeing of refugees. MHPSS-counselors in the camps did receive a 3-months training in practical work and 15 days in theory. It was intended that the camp-based psychosocial counselors conduct counseling to clients with anxiety, minor depression and other minor psychosocial problems, when they got aware of the existence of the problems, i.e., the patients did show up at the service facilities. Before the training, health workers (medics with at least 6 months of training, and primary health workers with a 3 months medical education), had difficulties to apply a differential treatment scheme in epilepsy and psychosis patients and in general, the medical staff had no skills on diagnosis and management of non- 
psychotic mental illnesses such as anxiety, moderate depression, emotional disorder, mental retardation, developmental and behaviour disorder, problem with alcohol and drug use, posttraumatic stress disorder, self-harm/suicide and medically unexplained somatic complaints. For people with psychotic disorders and epilepsy, OPDs started to open once a week at MI hospitals, and since 2015 regular psychosocial counselling services for people with non-psychotic and psychosocial disorders are implemented (main reasons for counselling are epilepsy, depression, alcohol abuse). Thai residents from neighboring villages have free access to health care services inside the camps whenever needed, in 2009 e.g., $4.2 \%$, of all patients in the OPD have been non-refugees, in Inpatient Department (IPD) admissions of non-refugees amounted to $9.6 \%$ of all patients, consultations due to mental health problems are mainly patients with psychotic episodes.

Admittedly, the brain-drain of trained staff jeopardizes sustainable MHPSS, and the planned supervision of the counsellors was not performed on a regular base as scheduled until 2017.

Considering information of section leaders, camp committees, medical staff, it can be assumed that there are a lot of yet undiscovered cases with severe psychosocial problems in the camp, and that some of them are detected but due social reasons are not reported to the medical service. There exists an informationgap between the MHPSS-services offered by MI, and the knowledge, the refugee population has on these services. As there are still stigmata on mental disorders (psychosis) and other deviations in the community, no well-established official referral system for psychological patients between community and clinical services does exist. The different health seeking behaviour (people prefer to consult traditional healers in these kinds of disorders), has its impact too. Independent of this, caregivers seem to be in need of information how to deal with their sick ones.

To identify existing resources, a KAP-B-survey (knowledge, attitude, practice and behavior), was carried out in 2017 (Zwang 2017). It revealed, that current challenges reported regarding a potential return to Myanmar are livelihood/income opportunities, land ownership, security, and health access, making these concerns to major stressors for the refugees. Recently reduced food rations and the increase of expenditure for education by the Thai government and its applied pressure on the refugees seeking repatriation have an additional impact. Post-migration stressors which are typical in long time refugees such as lack of freedom, scarce job opportunity/no income, housing problems, lack of safe environment, and family separation have to be added to the problems (Porter and Haslam 2005, Carswell et al. 2011, Kaiser 2010). The conflicts in family are prominently stressful for all. All these influential factors have an impact on psychosocial wellbeing and demand for reaction. Consequently, leading to a combination of worries, anxiety, depression, suicidal ideas and possible but detrimental ways of coping like alcohol drinking and domestic violence, social withdrawal (Kaiser 2005).

As it is known that religion -or more precise- religious or spiritual belief can increase resilience and as religion plays a major role in coping with all kinds of 
stress in refugees (Kaiser and Benner 2003). The KAP-B-survey was also carried out to get a clearer idea about the influence of religious belief in the refugees living in the camps. The survey revealed, for the majority (53\%) of the respondents (statistical representative for the whole camp population), "my spirituality" was the strength to help them to cope with their situation, followed by "my family" (23\%). Migration (in contrast to the "forced" migration which had led the refugees to the camps years before) has become a major strategy to access sources of income that can no longer be generated at home. This strategy is especially prevalent among young people who traverse the borderlands in search of illegal jobs in factories and as maids in Bangkok and other towns of Thailand. Even for young migrants, religion is an important resource, spiritually as much as materially, and plays a key role in their itinerary. Migrants and refugees often depend on religious networks to support them in their new places of residence to procure jobs, lodgings and a community (Horstmann and Cole 2015).

\section{Psychotherapeutic Interventions in PTSD and Related Disorders}

Evidence-based traumatherapy procedures from the area of trauma-focused cognitive behavioral therapy (TF-CBT) (in contrast to non-trauma-focused) and Eye Movement Desensitization and Reprocessing (EMDR) are successfully used in numerous different settings (refugee camps, prisons, crisis intervention centers and inpatient and outpatient treatment facilities) and are the gold standard in the treatment of PTSD (Foa et al. 2009, Schauer et al. 2005, Bisson et al. 2007). Trauma-focused cognitive behavioral therapy is based on the principles of cognitive behavioral therapy and usually includes central trauma-focused techniques like imaginative exposure related to trauma memory, narrative exposure, in vivo exposure and/or cognitive restructuring related to trauma-related beliefs. The best investigated specific approaches within TF-CBT include prolonged exposure, cognitive processing therapy, cognitive therapy according to Ehlers \& Clark, narrative exposure therapy. Non-trauma-focused interventions: These are defined as therapeutic approaches, the main focus of which is not on processing the memory of the traumatic event and / or its meaning. Instead, the focus of these approaches is on teaching emotion regulation skills, dealing with post-traumatic stress symptoms or solving current problems (Schäfer et al. 2019). (EMDR) is a trauma-focused intervention that, after a structured focusing process, leads to an associative process. Both are accompanied by rhythmic hand movements performed by the therapist (Shapiro 2018).

Brief, structured, manualized psychotherapeutic procedures (mainly traumafocused cognitive behavioral therapies, often in combination with body and mindawareness exercises) - have been designed for use amongst refugee and postconflict populations (Hinton et al. 2013).

Nevertheless, one should be very careful when transferring Western diagnostic categories such as PTSD as well as associated trauma-focused therapies to the culturally distinct environments in which most refugees live (Summerfield 1999). 
Refugee research to date has predominantly focused on factors that make refugees more vulnerable for developing PTSD and/or psychological distress. Few papers have studied potential protective factors such as resilience. Especially against the background of insufficient psychosocial care, the importance of residence factors and sources of strength on the part of those affected must be emphasized. Not taking these into account and not promoting them would have an even more negative impact on the mental state of those affected. Therefore, more attention needs to be paid to this aspect of mental health.

Within the framework of war and trauma, resilience can be defined as personality traits that help protect against the psychological disorders resulting from exposure to terrifying incidents, such as mass violence or deportation under life-threatening circumstances; it encompasses bouncing back and positive adaptation in the face of safety-challenging experiences (Arnetz et al. 2013, Edward and Warelow 2005, Hoge et al. 2007, Charney 2004) and it explains how a victim of violence can deal positively with past traumatic experiences (Lee et al. 2008, Sossou et al. 2008).

Resilience is associated with less trauma-related psychological distress and should be considered in assessing risk and protective factors among victims of war-related violence. Studies could demonstrate that regardless of migrant status, pre-migration exposure to violence is a significant predictor of both psychological distress and PTSD symptoms. However, resilience is a significant inverse predictor of psychological distress, but not of PTSD symptoms (Arnetz et al. 2013). In this study, the effect of pre-migration trauma was not mitigated by the time elapsed since the event, confirming the findings by Marshall et al. (2005), who reported high levels of psychopathology among Cambodian refugees 2 decades after migration. However, they contradict other previous research (Ehlers and Clark 2003), suggesting that symptoms of PTSD would diminish with time. Items of the used resilience scale reflect the positive and non-passive responses to traumatic events and that participants' high resilience was associated with lower psychological distress. A different study (Holtz 1998) compared Tibetan refugees exposed to torture with a control group of Tibetans without a history of torture and found significantly higher anxiety scores among the torture-exposed. The author concluded that a number of factors such as commitment, spirituality and preparedness foster resilience against psychological distress.

A resilience-oriented rather than a symptom-oriented approach, putting more emphasis on studying the protective and recovery-fostering individual assets rather than focusing on illness-expectancy is what is needed with the large numbers of re-settlers and asylum-seekers arriving from conflict and unstable zones. Therefore, one could recommend studying resilience in prospective research of refugees and immigrant populations who are also likely to face large number of post-migration traumas.

According to the ADAPT (Adaption and Development After Persecution and Trauma model (Quosh 2013), 5 essential psychosocial pillars are disrupted by conflict and displacement, that is, systems of safety and security, interpersonal bonds and networks, justice, roles and identities, and existential meaning and coherence. Psychosocial interventions should therefore help to increase the 
capacity of refugees to restore their lost resources, especially their perception of self-efficacy, the therefore necessary supportive social environments are partly provided in the camps, but uncertain in the future settings back home in Myanmar.

Therefore, appropriate therapeutic interventions have to consider the comprehensive perceptions of the refugee experience and follow a multisystem approach, taking the ecosocial framework into account (Bronfenbrenner 1992, Hobfoll 1989, Miller and Rasmussen 2017). Sociotherapy seems to be one of the few well researched group-psychosocial interventions (Richters et al. 2008), the primary focus being the fostering of connections between people. Groups share and discuss daily problems ranging from interpersonal disputes, feelings of marginalization, and strategies to deal with gender-based violence and poverty at the community level.

In the Karen refugees as well, problems are discussed within their community, nevertheless respecting the multitude of taboos, subjects in eastern shame cultures, which emphasizes the blame of the social group rather than of the individual. Implemented group counselling sessions have been very well accepted by the community, the people did appreciate that they could talk about their problems even it was recommended to do the group counselling separated into female and male group.

A further approach of therapy has been applied to Karen refugees as a way of trauma healing and conflict transformation: Storytelling-workshops. The idea was that through mentalizing what is meant by peace, i.e. storytelling as a means to elicit the Karen refugee's ideas of peace. The participants should become aware not only of their confined situation, but of ways out. Another important point was the communication between the members of the storyteller-groups. It has to be questioned whether this approach did have a direct impact on coping but as means of collective conceptualizing what should be in the future the participants could profit (Fuertes 2016). It could be revealed that the overarching notion of peace for Karen refugees is that peace is encompassing. The massive effects of war and displacement on the Karen community made them describe peace as an allembracing reality that is both personal and social, with economic, political, and psycho-cultural components.

Like all other productions and consequences of culture, storytelling can be a means through which community is constructed. It also enables them to use these stories as bases as they articulate their vision of peace based on their current situation. Rough storytelling, groups and societies create, recreate, and alter social identities, knowledge, memory, and emotion. At least two theories informed the facilitation of storytelling work-shops. One is Freire's (2000) theory of literacy by which every human being (no matter what context he or she is from) is capable of being engaged in the world in an interactive encounter with others. Freire calls this a dialogical teaching/learning process, that is, a process of learning and knowing that invariably involves theorizing about people's experiences shared in the dialogue or in the interactive process. The other theory, person-centered theory, suggests that human development is an ongoing process. Individuals belonging to a community change and adapt to meet the demands of their environment. It means that people have the capacity to learn from experience, changing and 
growing through creativity and openness to experience (Fuertes 2004).

The KAP-B-Survey (Zwang 2017) could show a high degree of perceived dependency on help: $38 \%$ of the respondents did not have income and totally rely on temporary shelter services. However, $14 \%$ had a small shop, sell vegetables or other income through livelihood activities, $12 \%$ had a family member working, $15 \%$ of the respondents had another activity consisting in weaving, teaching or in a lesser extent raising pigs. Women were more engaged in positions with nongovernmental organizations (NGOs) generating an income (13\%) than male respondents $(4 \%)$, this frequently generating problems in the adult family members, realizing or assuming a damage to their role as the head of the household. Alcohol misuse, domestic violence and depression may be the consequences.

\section{The Role of Expectations and Causal-Attribution in Mental Health}

The individual worldview determines the way processes of illness and healing are explained - mental health practitioners should keep this in mind and should as well reflect their own view on pathogenesis.

Expectations are defined as cognitions which are future-directed and focused on the incidence or non-incidence of a specific event or experience (Rief and Glombiewski 2017, Rief et al. 2015). Expectations about treatment success are the most prominent predictor of outcome, both in psychopharmacological and psychological interventions, and they are considered to be a major determinant of placebo effects (Schedlowski et al. 2015). In the treatment of mental disorders, examining and modifying patients' expectations, is discussed as a central mechanism of change (Craske et al. 2014, Craske 2015). This focus on expectations does not disregard any past experiences, but considers them only of relevance if they determine predictions about future events. Neurobiology and psychological sub-disciplines such as developmental psychology and social psychology have focused on expectations for decades. Expectations lead to brain activities that sensitize for the expected experience (Koyama et al. 2005), and they are closely linked to affective reactions (Schwarz et al. 2016). Associative learning, influences via group norms and media, and the phenomenon of sticking to expectations despite expectation violations (cognitive "immunization") are psychologically relevant concepts to better understand why specific expectations are present. Some mental disorders are "expectation disorders" by definition. This is particularly so in the case of anxiety disorders, such as phobias. In these cases, patients expect adverse consequences when being exposed to specific stimuli, situations, or experiences (e.g., the phobic stimulus, the experience of palpitations).

The role of expectations in PTSD seems to be more complex. While most people feel secure and do not expect horrible events, this basic confidence in everyday life situations is violated if people suffer from trauma (Janoff-Bulman 1989). Some patients with PTSD do not want to talk about the trauma because they do not expect to be able to bear the emotions that will arise. In other mental disorders, expectations are not part of the diagnostic criteria, but are also of relevance. For example, individuals suffering from depression show more depression-specific negative expectations (Rief and Glombiewski 2016). If 
expectations are one of the most powerful predictors of outcome, interventions must maximally modify illness-specific expectations, and positive outcome expectations should be sufficiently established before treatment starts. One of the traditional psychological interventions that may be considered a powerful tool to change expectations is exposure therapy. However, traditional exposure therapy needs to be reformulated to better focus on the change of expectations (e.g., explicit comparison between pre-exposure expectations and post-exposure experiences) (Craske 2015) and is excluded in some sense in war traumata and PTSD.

Expectation-focused psychological interventions (EFPI) (Rief and Glombiewski 2016) places a strong focus on analyzing and summarizing disorderspecific expectations of the patient, and re-evaluates expectations by comparing pre-existing expectations with the experience during exposure.

\section{Discussion}

MHPSS in its well-defined sense as mental health service as well as psychosocial support for and with the concerned population are the only way to improve the mental health condition. What does that mean: In regions in which adequate psychiatric and psychotherapeutic care is not guaranteed by specialists, it is necessary to improve psychosocial support through psychoeducational measures and training of peer groups. This in the sense of a reference system, so that simple psychological problems can also be treated on site by laypersons and only the difficult cases are brought up to the few specialists available.

It should be pursued even when well educated and trained mental health workers and doctors are frequently leaving the refugee setting to other places (brain-drain) like third countries and new health workers have to be trained on a regular base. Beside this, the already started -but politically jeopardizedinstallation of (mobile and at present non-permanent) mental health services in Myanmar, in the region the refugees originated, is a way, which should be kept moving on.

Although brief, structured psychotherapies administered by lay counsellors, including the mentioned ones above, have been shown to be effective in the short term for a range of traumatic stress responses (Silove et al. 2017). One can therefore share the opinion of the British psychiatrist Vikram Patel, author of "Where There is no Psychiatrist," that non-specialist healthcare workers should become the front-line of mental health services, mainly in OPD-services, not only in poor countries and be incorporated into the core of mental health provision (Patel 2008).

It is mandatory for NGOs as well as the responsible stakeholders in the selforganizations of the camps to be alert about psychosocial problems and their manifestations like domestic violence, suicidal ideations/attempts, drug and alcohol abuse as well as social withdrawal in confinements of long-term refugees. NGOs should not only provide and promote mental health services, but educate and train health workers and laypeople to raise knowledge, reduce stigmatization and make mental health a public issue. 
The psychosocial program that was started in the camps at the Thai border during 2015 aiming to improve psychosocial wellbeing of refugees is functioning well in both camps. Shelter-based psychosocial counselors conduct counseling to clients with anxiety, minor depression and other minor psychosocial problems. Services for both refugees and hosting community are maintained at surrounding Thai villages. Under consideration of social justice and medical good practice, the needs of the local population must also be taken into account.

Regarding the social and cultural background of the Karen refugees one can ask why the suicides and psychosocial problems could not have been observed more often over the years in the camps. Before their forced migration from Myanmar to Thailand, the Karen were living in small villages with up to 30 or 40 families, performing small scale animal husbandry, practicing cultivation of several sorts of rice and different types of vegetables, beside hunting and fishing and slash and burn agriculture. After their flight to the refugee camps, life did change dramatically for the Karen refugees as the new location are comparable crowded places as each campsite sizes more than 10,000 inhabitants. The higher degree of anonymity forced people to more cooperation in their peer-groups, be it extended families or new neighborhoods. Organizational structures which in the past in this extend were not necessary had to be developed. The establishment of camp committees for various tasks evolved plus engagement with international NGOs.

Family problems in the camps were now not so easy to be hidden; domestic violence became probably more a subject of public discussion as in the past.

Negative coping with stress and the feeling of uselessness (because of not having any work to do), helplessness (because of being dependent on the support of third parties and not being able to support oneself and one's family on one's own), hopelessness (concerning the individual future and that of one's relatives, the situation in the camps and the development in Myanmar in general) (Benner et al. 2010) probably increased the danger of domestic violence and the abuse of alcohol. Even when NGOs tried to establish some educational and health standards in the camps, although the camps are located in remote areas with no access to internet, television, telephone and other kinds of media and systems of communication, it has been very difficult to provide some meaningful support.

Being dependent on the support of the international community and the support by the Thai and Myanmar governments for more than three decades, the refugees are likely facing increased difficulties to cope with the now changing situation and the urge to be repatriated back to Myanmar.

Data on the suicide rate between 2010 and 2016, as well as estimation of the numbers of suicides during 2006 to 2009 , suggest that the suicide rate ranks to the highest in the world and could be a serious public health. Even there was no special defined mental health and psychosocial support service in the beginning of the NGO engagement in the camps around twenty years ago, there was additional a cultural barrier to show up with health workers or with close relatives and friends. Like in many other Asian ethnic groups, psychosocial problems, stress and suicidal ideation are taboos, an underreporting of mental health and psychosocial condition-associated problems, casualties and fatalities cannot be excluded. 
Nevertheless, one could show that humans are very adaptable to a changing environment of living, this is especially true for the youth. Closed to all of them have been born in the camps and therefor do not know how the life will be in the land of their ancestors, being responsible for one's own.

As in other comparable refugee settings, the focus of the engagement of medical NGOs in the last two to three decades lay in providing first medical aid, improving the general health and hygienic conditions including performing vaccinations and Mother and Child Health-Programs, giving health education et cetera. Unfortunately, only after infectious diseases were under control and the general health condition was more or less stable (not until 2015), mental health as an important topic became a subject in the camps, what reduces the power of meaning of this article.

\section{Conclusion}

The mental health service should be encouraged to focus not only on sickening but on salutogenetic aspects of mental health and psychosocial problems and the way people are coping with: In areas of scarce resources, it is important not only to provide a minimum level of mental health services, but to encourage those affected to consider and use their own resources as a form of help for selfhelp, such as peer support and discussion groups for women, men or on specific topics such as grief, pregnancy etc., or use of indigenous natural products, for example for sleep disorders. Resilience is a factor, easily overseen by health care providers, especially in situations, which make people depending on help. Mental health care should consider the role of expectations and causal-attribution and being able to have a positive impact on it, i.e., in training health workers. It may be necessary to take up and, if possible, modify ideas that are harmful to health and social interaction with regard to the development and maintenance of mental disorders ' often ideas regarding the development of infertility, schizophrenia or also regarding the use of violence against women, the elderly or children.

In people like the Karen, the consideration of their heritage and the ways deriving from it, should be respected and valued. In their struggle for daily life, they apply more than one single specific religious belief; the people are reality oriented and rather pragmatic than dogmatic.

\section{Acknowledgements}

Our thanks to all the people from the two camps who participated and supported the study; Malteser International who supported with logistics and with manpower; the Karen Refugee Committee, the Karen Youth Organization, as well as the European Union and Malteser International, who generously funded this study. 


\section{References}

Afana AH, Qouta S, Sarraj EE (2004) Humanitarian practice network: mental health needs in Palestine. Gaza Community Mental Health Program, November 2004.

Arnetz J, Rofa Y, Arnetz B, Ventimiglia M, Jamil H (2013) Resilience as a protective factor against the development of psychopathology among refugees. The Journal of Nervous and Mental Disease 201(3): 167-172.

Bangkok Post (19.06.2017) Retrieved from: http://travelwirenews.com/suicide-ratealarming-at-myanmar-refugee-camp-161822/. [Accessed 18 January 2018].

Batniji R, van Ommeren M, Saraceno B (2006) Mental and social health in disasters: relating qualitative social science research and the Sphere standard. Social Science \& Medicine 62(8): 1853-1864.

Beiser M, Hou F (2001) Language acquisition, unemployment and depressive disorder among Southeast Asian refugees: a 10-year study. Social Science \& Medicine 53(10): $1321-1334$.

Benner MT, Muangsookjarean A, Sondorp E, Townsend L (2008) Neglect of refugee participation. FMR 30. Retrieved from https://bit.ly/3aHBIUP.

Benner MT, Townsend J, Kaloi W, Htwe K, Naranichakul N, Hunnangkul S et al. (2010) Reproductive health and quality of life of young Burmese refugees in Thailand. Conflict and Health 4(1): 5.

Bisson JL, Ehlers A, Matthews R, Pilling S, Richards D, Turner S (2007) Psychological treatment for chronic post-traumatic stress disorder: systematic review and metaanalysis. The British Journal of Psychiatry 190(2): 97-104.

Blanchet K, Ramesh A, Frison S (2017) Evidence on public health interventions in humanitarian crises. Lancet 8.

Bronfenbrenner U (1992) Ecological systems theory. London: Jessica Kingsley.

Carswell K, Blackburn P, Barker C (2011) The relationship between trauma, postmigration problems and the psychological well-being of refugees and asylum seekers. The International Journal of Social Psychiatry 57(2): 107-119.

Charney DS (2004) Psychobiological mechanisms of resilience and vulnerability: implications for successful adaptation to extreme stress. American Journal of Psychiatry 161(2): 195-216.

Craske MG (2015) Zur Rolle der Exposition bei der Therapie von Angststörungen (The role of exposure in the treatment of anxiety disorders). Verhaltenstherapie 25(Feb): 134-144.

Craske MG, Treanor M, Conway CC (2014) Maximizing exposure therapy: an inhibitory learning approach. Behaviour Research and Therapy 58C(1): 10-23.

Desjarlais R, Eisenberg I, Good B, Kleinman A (1995) World mental health: problems and priorities in low-income countries. New York: Oxford University Press.

Dobricki M, Maercker A (2010) (Post-traumatic) embitterment disorder: Critical evaluation of its stressor criterion and a proposed revised classification. Nordic Journal of Psychiatry 64(3): 147-152.

Edward KL, Warelow P (2005) Resilience: when coping is emotionally intelligent. Journal of the American Psychiatric Nurses Association 11(2): 101-102.

Ehlers A, Clark D (2003) Early psychological interventions for adult survivors of trauma: a review. Biological Psychiatry 53(9): 817-826.

Ekblad S, Silove D (1998) Proposals for the development of mental health and psychosocial services in refugee camps. Geneva: Consultant Mission Report to UNHCR.

Foa EB, Keane TM, Friedman MJ, Cohen JA (Eds.) (2009) Effective treatments for PTSD. Practice guidelines from the International Society for Traumatic Stress Studies. $2^{\text {nd }}$ Edition. New York, NY: Guilford Press. 
Freire P (2000) Pedagogy of the oppressed. New York: Continuum International.

Fuertes A (2004) In their own words: contextualizing the discourse of (war) trauma and healing. Conflict Resolution Quarterly 21(4): 491-501.

Fuertes A (2016) Karen refugees describe peace within the context of displacement. Conflict Resolution Quarterly 33(3): 297-312.

Ghosh PS (2016) Migrants, refugees and the stateless in South Asia. New Delhi: SAGE Publications India.

Groen SPN, Richters JM, Laban CJ, Devillé WL (2017) Cultural identity among Afghan and Iraqi traumatized refugees: towards a conceptual framework for mental health care professionals. Culture, Medicine and Psychiatry 42(1): 69-91.

Hauff E, Vaglum P (1995) Organised violence and the stress of exile. Predictors of mental health in a community cohort of Vietnamese refugees three years after resettlement. The British Journal of Psychiatry 166(3): 360-367.

Hinton DE, Pich V, Hofmann SG (2013) Acceptance and mindfulness techniques as applied to refugee and ethnic minority populations with PTSD: examples from culturally adapted CBT. Cognitive and Behavioral Practice 20(1): 33-46.

Hobfoll SE (1989) Conservation of resources. A new attempt at conceptualizing stress. The American Psychologist 44(3): 513-524.

Hoge EA, Austin ED, Pollack MH (2007) Resilience: research evidence and conceptual considerations for posttraumatic stress disorder. Depress Anxiety 24(2): 139-152.

Hollander AC, Dal H, Lewis G (2016) Refugee migration and risk of schizophrenia and other non-affective psychoses: cohort study of 1.3 million people in Sweden. British Medical Journal 352: i1030

Holtz T (1998) Refugee trauma versus torture trauma. Journal of Nervous and Mental Disease 186(1): 24-34.

Horstmann A, Cole T (2015) The Focus. State violence, state building. The Newsletter 71. Retrieved from https://bit.ly/3aGpnA0.

IASC-Inter-Agency Standing Committee (2007) Guidelines on mental health and psychosocial support in emergency settings. Geneva: Inter-Agency Standing Committee.

Jablensky A, Marsella AJ, Ekblad S, Jansson B, Levi L, Bornemann T (1994) Refugee mental health and well-being: conclusions and recommendations. In AJ Marsella, T Bornemann, S Ekblad, J Orley (Eds.), 327-339. Amidst Peril and Pain. The Mental Health and Well-Being of the World's Refugees. Washington, DC: American Psychological Association.

Janoff-Bulman R (1989) Assumptive worlds and the stress of traumatic events: applications of the schema construct. Social Cognition 7(2): 113-136.

Joly D (2016) Heaven or hell?: asylum policies and refugees in Europe. London: Springer.

Kaiser P (2005) Coping with stress, mental health and psychotherapy in long term refugees. Viennese Ethnomedicine Newsletter 8(1): 8-15.

Kaiser P (2010) Considering local resources. Curare 33(3-4): 188-193.

Kaiser P, Benner MT (2003) Religion als Ressource: die Karen in Flüchtlingslagern an der Thailändisch-burmesischen Grenze (Religion as a resource: the Karen in refugee camps on the Thai-Burmese border). Curare 26(1-2): 37-52.

Karatzias T, Cloitre M, Maercker A, Kazlauskas E, Sheylin M, Hyland P, Bisson JI, Roberts NP, Brewin CR (2017) PTSD and complex PTSD: ICD-11 updates on concept and measurement in the UK, USA, Germany and Lithuania. European Journal of Psychotraumatology 8(sup7): 1418103.

Karen Buddhist Dhamma Dutta Foundation (2010) The Karen people: culture, faith and history 6: 24-28. 
Keenan P (2010) Faith at a crossroads: religions and beliefs of the Karen people of Burma. Karen Heritage 1(1).

Kinzie JD, Boehnlein JJ (1989) Post-traumatic psychosis among Cambodian refugees. Journal of Traumatic Stress 2(2): 185-198.

Kinzie JD, Jaranson J (1998) Refugees and asylum seekers. In T Keane, E Gerrity, F Tuma (Eds.), Mental Health Consequences of Torture and Related Violence and Trauma. Rockville, MD: The Truth and Reconciliation Commission (of South Africa) by a Working Group Sponsored by the National Institute of Mental Health.

Kinzie, JD, Boehnlein JK, Leung P, Moore L, Riley C, Smith D (1990) The high prevalence rate of PTSD and its clinical significance among Southeast Asian refugees. American Journal of Psychiatry 147(7): 913-917.

Kleinman A (1977) Depression, somatization and the "new cross-cultural psychiatry." Social Science and Medicine 11(1): 3-9.

Kleinman A, Kleinman J (1991) Suffering and its professional transformation: towards an ethnography of interpersonal experience. Culture, Medicine and Psychiatry 15(3): 275-301.

Koyama T, McHaffie JG, Laurienti PJ (2005) The subjective experience of pain: where expectations become reality. PNAS 102(36): 12950-12955.

Krupinski J, Stoller A, Wallace L (1973) Psychiatric disorders in East European refugees now in now in Australia. Social Science Medicine 7: 331-349.

Lee HS, Brown SL, Mitchell MM, Schiraldi GR (2008) Correlates of resilience in the face of adversity for Korean women immigrating to the US. Journal of Immigrant and Minority Health 10(5): 415-422.

Lie B (2002) A 3-year follow-up study of psychosocial functioning and general symptoms in settled refugees. Acta Psychiatrica Scandinavica 106(6): 415-425.

Lipson JG (1993) Afghan refugees in California: mental health issues. Issues in Mental Health Nursing 14(4): 411-423.

Marshall GN, Schell TL, Elliott MN, Berthold SM, Chun CA (2005) Mental health of Cambodian refugees 2 decades after resettlement in the United States. Journal of American Medical Association 294(5): 571-579.

Miller K, Rasmussen A (2017) The mental health of civilians displaced by armed conflict: an ecological model of refugee distress. Epidemiology and Psychiatric Sciences 26(2): 129-138.

Milner J (2012) TED-talk integrative approach. Retrieved from https://bit.ly/2JEJZg8. [Accessed 18 January 2018].

Mohit A (2001) Psychiatry and mental health for developing countries, challenges for the $21^{\text {st }}$ century. $13^{\text {th }}$ Congress of Pakistan Psychiatric Society, World Health Organization.

Mollica RF, Poole C, Son L, Murray CC, Tor S (1997) Effects of war trauma on Cambodian refugee adolescents' functional health and mental health status. Journal of the American Academy of Child and Adolescent Psychiatry 36(8): 1098-1106.

Mollica RF, Donelan K, Tor S, Lavelle J, Elias C, Frankel M et al. (1993) The effect of trauma and confinement on functional health and mental health status of Cambodians living in Thailand-Cambodia border camps. Journal of American Medical Association 270(5): 581-586.

Neria Y, Nandi A, Galea S (2008) Post-traumatic stress disorder following disasters: a systematic review. Psychological Medicine 3(4): 467-480.

Patel V (2002) Where there is no psychiatrist. A mental health care manual. Glasgow: The Royal College of Psychiatrists.

Patel V (2008) Mental health in the developing world: time for innovative thinking. SciDev.Net. 
Porter M, Haslam N (2005) Predisplacement and postdisplacement factors associated with mental health of refugees and internally displaced persons: a meta-analysis. Journal of American Medical Association 294(5): 602-612.

Priebe S, Giacco D, El-Nagib R (2016) Public health aspects of mental health among migrants and refugees: a review of the evidence on mental health care for refugees, asylum seekers and irregular migrants in the WHO European region. Copenhagen: WHO Regional Office for Europe.

Quosh C (2013) Mental health, forced displacement and recovery: integrated mental health and psychosocial support for urban refugees in Syria. Intervention 11: 295320.

Richters A, Dekker C, Scholte WC (2008) Community based sociotherapy in Byumba, Rwanda. Intervention 6(2): 100-116.

Rief W, Glombiewski JA (2016) Warum psychologische Interventionen "erwartungsfokussiert" sein sollten. (Why psychological interventions should be "expectationfocused"). Verhaltenstherapie 26(1): 47-54.

Rief W, Glombiewski JA (2017) The role of expectations in mental disorders and their treatment. World Psychiatry 16(2): 210-211.

Rief W, Glombiewski JA, Gollwitzer M (2015) Expectancies as core features of mental disorders. Current Opinion in Psychiatry 28(5): 378-385.

Sack M (2004) Diagnostic and clinical aspects of complex post-traumatic stress disorder. Nervenarzt 75(5): 451-459.

Schäfer I, Gast U, Hofmann A, Knaevelsrud C, Lampe A, Liebermann P, Lotzin A et al. (2019) S3-Leitlinie Posttraumatische Belastungsstörung. (S3 guideline posttraumatic stress disorder). Berlin: Springer.

Schauer M, Neuner F, Elbert T (2005) Narrative exposure therapy. Cambridge, MA: Hogrefe und Huber.

Schedlowski M, Enck P, Rief W (2015) Neuro-bio-behavioral mechanisms of placebo and nocebo responses: implications for clinical trials and clinical practice. Pharmacological Reviews 67(3): 697-730.

Schwarz KA, Pfister R, Büchel C (2016) Rethinking explicit expectations: connecting placebos, social cognition, and contextual perception. Trends in Cognitive Sciences 20(6): 469-480.

Shapiro $\mathrm{F}$ (2018) Eye movement desensitization and reprocessing (EDMR) therapy: basic principles, protocols, and procedures. $3^{\text {rd }}$ Edition. New York: The Guilford Press.

Silove D (1999) The psychosocial effects of torture, mass human rights violations, and refugee trauma: toward an integrated conceptual framework. The Journal of Nervous and Mental Disease 187(4): 200-207.

Silove D (2005) The best immediate therapy for acute stress is social. Bulletin of the World Health Organization 83(1): 75-76.

Silove D, Ventevogel P, Rees S (2017) The contemporary refugee crisis: an overview of mental health challenges. World Psychiatry 16(1): 130-139.

Smith-Fawzi MC, Pham T, Lin L, Nguyen TV, Murphy E, Mollica RF (1997) The validity of Post-traumatic Stress Disorder among Vietnamese refugees. Journal of Traumatic Stress 10(1): 101-108.

Sossou MA, Craig CD, Ogren H, Schnak M (2008) A qualitative study of resilience factors of Bosnian refugee women resettled in the Southern United States. Journal of Ethnic \& Cultural Diversity in Social Work 17(4): 365-385.

Spiegel PB (2017) The humanitarian system is not just broke, but broken: recommendations for future humanitarian action. The Lancet (Published June 08, 2017. Online Series). Retrieved from: https://bit.ly/3dVCuiT. 
Summerfield DA (1999) Critique of seven assumptions behind psychological trauma programs in war-affected areas. Social Science \& Medicine 48(10): 1449-1462.

TBC (2018) The border consortium refugee camp populations: May 2018. Retrieved from www.theborderconsortium.org.

Tol WA, Barbui C, Galappatti A (2011) Mental health and psychosocial support in humanitarian settings: linking practice and research. The Lancet 378: 1581-1591.

Wang PS, Aguilar-Gaxiola S, Alonso J, Levinson D (2007) Use of mental health services for anxiety, mood, and substance disorders in 17 countries in the WHO world mental health surveys. The Lancet 370: 841-850.

WHO-World Health Organization, United Nations High Commissioner for Refugees (2013) Assessment and management of conditions specifically related to stress. MhGAP Intervention Guide Module. Geneva: World Health Organization.

WHO-World Health Organization, United Nations High Commissioner for Refugees (2015) mh-GAP Humanitarian Intervention Guide (mh-GAP-HIG). Clinical management of mental, neurological and substance use conditions in humanitarian emergencies. Geneva: World Health Organization.

WHO-World Health Organization (2018) Suicide rates. Retrieved from: https://bit.ly/ 3bnPWtB.

Zwang J (2017) KAP-B Survey 2017 report. Internal report to Malteser International. Cologne: Malteser International. 